\title{
In silico analysis of phytohormone metabolism and communication pathways in citrus transcriptome
}

\author{
Vera Quecini ${ }^{1}$, Gisele A.M. Torres ${ }^{2}$, Vicente E. de Rosa $\mathrm{Jr}^{1}$, Marcos A. Gimenes ${ }^{3}$, \\ Jeanne B. de M. Machado ${ }^{4}$, Antonio V. de O. Figueira ${ }^{4}$, Vagner Benedito ${ }^{5}$, Maria Luisa P.N. Targon ${ }^{6}$ \\ and Mariângela Cristofani-Yaly ${ }^{6}$ \\ ${ }^{1}$ Centro de Pesquisa e Desenvolvimento de Recursos Genéticos, Instituto Agronômico de Campinas, \\ Campinas, SP, Brazil. \\ ${ }^{2}$ Empresa Brasileira de Pesquisa Agropecuária - Trigo, Passo Fundo, RS, Brazil. \\ ${ }^{3}$ Empresa Brasileira de Pesquisa Agropecuária, Recursos Genéticos e Biotecnologia, Brasília, DF, Brazil. \\ ${ }^{4}$ Laboratório de Melhoramento de Plantas, Centro de Energia Nuclear na Agricultura, \\ Universidade de São Paulo, Piracicaba, SP, Brazil. \\ ${ }^{5}$ Samuel Roberts Noble Foundation, Ardmore, OK, USA. \\ ${ }^{6}$ Centro APTA de Citricultura Sylvio Moreira, Instituto Agronômico de Campinas, Cordeirópolis, SP, Brazil.
}

\begin{abstract}
Plant hormones play a crucial role in integrating endogenous and exogenous signals and in determining developmental responses to form the plant body throughout its life cycle. In citrus species, several economically important processes are controlled by phytohormones, including seed germination, secondary growth, fruit abscission and ripening. Integrative genomics is a powerful tool for linking newly researched organisms, such as tropical woody species, to functional studies already carried out on established model organisms. Based on gene orthology analyses and expression patterns, we searched the Citrus Genome Sequencing Consortium (CitEST) database for Expressed Sequence Tags (EST) consensus sequences sharing similarity to known components of hormone metabolism and signaling pathways in model species. More than 600 homologs of functionally characterized hormone metabolism and signal transduction members from model species were identified in citrus, allowing us to propose a framework for phytohormone signaling mechanisms in citrus. A number of components from hormone-related metabolic pathways were absent in citrus, suggesting the presence of distinct metabolic pathways. Our results demonstrated the power of comparative genomics between model systems and economically important crop species to elucidate several aspects of plant physiology and metabolism.
\end{abstract}

Key words: defense responses, development, plant growth regulators.

Received: July 21, 2006; Accepted: March 6, 2007.

\section{Introduction}

Plant growth and development are controlled by the integration of several endogenous and environmental signals. Plant hormones play a crucial role in integrating endogenous and exogenous signals and in determining the final developmental responses to form the plant body. Hormones are molecules that are produced by one specific organ and conveyed to target tissues, where they elicit a physiological response at low concentration (Davies, 1995). This definition does not hold true for most of the

Send correspondence to Vera Quecini. Centro de Pesquisa e Desenvolvimento de Recursos Genéticos, Instituto Agronômico de Campinas, Av. Theodureto de Almeida Camargo 1500, 13075-30 Campinas, SP, Brazil. E-mail: vquecini@iac.sp.gov.br. plant hormones, which are synthesized by several different tissues or cell types, but can act locally, as well as at a distance. Moreover, the majority of the plant hormones are small, relatively simple molecules (Gray, 2004). Traditionally, plant hormones have been considered to be small lipophilic compounds, such as abscisic acid (ABA), auxin (IAA), brassinosteroids (BR), cytokinins (CK), ethylene (ET), gibberellin (GA), jasmonates (JA) and salicylic acid (SA) (Davies, 1995). Recent evidence from genetic and biochemical studies show the involvement of many secretory and non-secretory peptide signals in many aspects of plant growth regulation, including defense responses, callus growth, meristem organization, self-incompatibility, root growth, leaf-shape regulation, nodule development, 
and organ abscission, and comprise a newly-found class of peptide hormones in plants (Matsubayashi and Sakagami, 2006).

Virtually every aspect of plant growth and development is under hormonal control to some extent. A diverse array of cellular and developmental processes may be controlled by single or multiple hormones that may function in concert to control a single process. The application of exogenous hormone has been largely employed to study the function of its endogenous counterparts in plants. This leads to the attribution of general roles for each phytohormone such as the well-characterized function of ethylene in fruit ripening, the regulation of the cell cycle by auxin and CK, the induction of seed germination and stem elongation by GA, and the maintenance of seed dormancy by ABA. Forward genetic approaches have allowed the isolation of hormone biosynthetic and response mutants (Gazzarrini and McCourt, 2003). More recently, biochemical and in silico genome studies have demonstrated the hormonal role of previously unsuspected molecules (Matsubayashi and Sakagami, 2006). An increasing number of genomic tools are being used to probe hormone biosynthesis, transport and response; this integrated approach has contributed to a clearer picture of the mechanisms involved in plant developmental control by hormones.

Plant hormone biosynthesis is closely associated to primary and secondary metabolism. Auxins are tryptophan conjugates and distinct genetic pathways control their biosynthesis (Cohen et al., 2003). CKs are adenine-related purines (Sakakibara, 2006); GAs are tetracyclic diterpenoids synthesized in a complex pathway involving plastids, endoplasmic reticulum and the cytosol (Fleet and Sun, 2005). ABA is synthesized either from MVA (mevalonic acid) or MEP (methylerythritol-phosphate) (Nambara and Marion-Poll, 2005), especially in vascular bundles and guard cells (Koiwai et al., 2004). Ethylene is synthesized from methionine by the intermediate S-adenosyl-L-methionine (AdoMet) and 1 aminocyclopropane-1-carboxylate (ACC) (Chae and Kieber, 2005). BR biosynthesis is highly networked and consists of two parallel routes: an early and a late C-6 oxidation pathway, connected at multiple steps, and also linked to an early C-22 oxidation pathway (Fujioka and Yokota, 2003). JA is an oxylipin, consisting in a group of structurally diverse biologically active compounds, generated by the coordinated action of lipases, lipoxygenases, and a group of cytochrome P450 specialized in the metabolism of hydroperoxy fatty acids (Schilmiller and Howe, 2005). Peptide hormones are produced by the proteolytic processing of the C-terminus of a polypeptide precursor that may be or may be not synthesized through a secretory pathway as in the case of the RAPID ALKALINIZAITON FACTORS (RALF) and RALF like (RALFL) or systemin and phytosulfokine, respectively (Matsubayashi and Sakagami, 2006).
The extensive effects of even diminute concentrations of plant hormones have led to a tight control of function, not only by biosynthesis rate, but also by a plethora of factors, such as availability of receptors, catabolic rate, conversion into inert forms, translocation, and several interconnected steps of signal transduction. Surprisingly, hormone-mediated signal transduction appears to have evolved common themes for distinct phytohormones in plants, such as protein phosphorylation, G-protein and Calcium/calmodulin-mediated signal transduction, and bacterial two-component signaling system-like and regulated proteolysis (Serino and Deng, 2003; Assmann, 2004; Gray, 2004; Mizuno, 2005).

Ethylene and CK are both perceived by plasma membrane-associated receptors, similar to bacterial two-component regulators that contain an intracellular histidine kinase (HK) domain (Stepanova and Alonso, 2005; Sakakibara, 2006). The kinase activity is activated by ligand binding, resulting in self-phosphorylation and initiating a series of phospho-transfer reactions, which culminate in activation of a response regulator protein that functions as the effector component of the pathway (Guo and Ecker, 2004; Ferreira and Kieber, 2005). Ethylene is perceived by a family of five receptors: ETHYLENE RECEPTOR1 (ETR1) and ETHYLENE RESPONSIVE SENSOR1 (ERS1), containing a consensus HK domain, functioning as negative regulators of the pathway. The Raf-like Mitogen-Activated Protein (MAP) Kinase Kinase Kinase, CONSTITUTIVE TRIPLE RESPONSE1 (CTR1) interacts with the receptors and also functions as a negative regulator. The integral membrane protein, ETHYLENE INSENSITIVE2 (EIN2), and the transcription factors EIN3 and EIN-LIKE1 (EIL1) are positive regulators of ethylene signaling, downstream of CTR1. The binding of ethylene to receptors inactivates them and results in down-regulation of CTR1 activity. In the absence of ethylene, transcription factors EIN3 and EIL1 are targeted for degradation by an SKP1/Cullin/F-box protein (SCF) complex (Chae and Kieber, 2005).

Similarly, BR is perceived by a receptor complex of two leucine-rich-repeat receptor-like kinases (LRR-RLKs) that interact with each other (Vert et al., 2005). Activation of the receptor kinases by BR binding leads to the de-phosphorylation and accumulation of two nuclear proteins due to the inhibition of a negative regulator (Vert et al., 2005). In the absence of BR, the negative regulator phosphorylates the nuclear proteins and targets them for degradation by the ubiquitin-dependent proteasome pathway. In the case of auxin, a large family of transcriptional repressors Aux/IAA dimerizes with members of the AUXIN RESPONSE FACTOR (ARF) family of transcription factors, preventing ARFs from activating auxin-responsive genes, reviewed in Woodward and Bartel (2005). Upon auxin stimuli, the receptor TRANSPORT INHIBITOR RESPONSE1 (TIR1), an SCF ubiquitin E3 ligase F-box protein, ubiquitinates Aux/IAA proteins marking them for degradation by the 
$26 \mathrm{~S}$ proteasome, thereby de-repressing the response pathway (Parry and Estelle, 2006). In a similar manner, perception of active GAs leads to degradation of various transcriptional repressor proteins containing the DELLA-domain, via an SCF-E3 ubiquitin ligase-SLEEPY1 (SLY1) complex (McGinnis et al., 2003). Interestingly, DELLA protein levels are also regulated by auxin and ethylene, indicating a function as a general regulator of plant growth mediated by several plant hormones (Fleet and Sun, 2005).

Perception and signal transduction mechanisms of plant hormones primarily involved in stress responses also share common themes, which are also shared with development regulatory hormones. The SCF complex mediates JA signaling; the F box protein COI1 (CORONATINE INSENSITIVE1) is part of an SCF complex that includes ARABIDOPSIS SKP1-LIKE1 (ASK1) or ASK2 and CULLIN1 (CUL1). However, the transcriptional regulator(s) affected by hormone interaction with SCF complexes remain unknown (Schilmiller and Howe, 2005). ABA transduction pathways are characterized by a plethora of intracellular messengers, reflecting its function in integrating several stress responses and antagonizing pathways via cross-talk (Himmelbach et al., 2003). Accumulation of ABA is controlled by upstream signaling events, and plays a quantitative role in signal transduction (Verslues and Zhu, 2005). However, ABA accumulation can be controlled by several metabolic processes, such as ABA synthesis, catabolism or conjugation, and within each of these metabolic processes there are several genes that may act as rate-limiting factors. These genes may be subjected to feedback regulation by ABA (Verslues and Zhu, 2005). NCED (9-cis-epoxycarotenoid dioxygenase) catalyses the cleavage of the $\mathrm{C} 25$ carotenoids, 9-cis-neoxanthin or 9-cis-violaxanthin, to the C15 ABA-precursor xanthoxin; a reaction proposed to be rate limiting in ABA synthesis. NCED3 is the most strongly induced by dehydration, among the nine genes of NCED family in Arabidopsis; and thus, is a good candidate for direct regulation by upstream signaling (Verslues and Zhu, 2005). There are several possible candidates for modulators of ABA response. Recent evidence points to sugar sensing and reactive oxygen production as potential links between the metabolic status and ABA responses.

The precise signaling mechanism of peptide hormones in plants remains elusive, but biochemical evidence suggested that they translocate by vascular bundles, where they bind to the BR membrane receptor in a non-competitive manner. Subsequently, the peptide-receptor association triggers various events: the modulation of ion fluxes, increase in cytoplasmic calcium, up-regulation of calmodulin gene expression, inactivation of plasma membrane $\mathrm{H}^{+}$-ATPase activity (via calcium-dependent phosphorylation), and activation of a MAPK leading to activation of phospholipase A and allene oxide cyclase which mediate the release of linolenic acid from membrane lipids and the formation of jasmonic acid-intermediate 12-oxo-phytodie- noic acid (OPDA), respectively (Matsubayashi and Sakagami, 2006). Activating these signaling pathways in vascular bundles leads to increased production of jasmonic acid which further upregulates expression of the polypeptide precursor genes. This results in a further increase in the level of jasmonic acid in the bundles via a positive feedback loop. Finally, jasmonic acid or a related compound moves through the phloem and ultimately induces production of defensive proteins in the target leaves (Matsubayashi and Sakagami, 2006).

In this study, we have investigated the Citrus Genome Sequencing Project Consortitum (CitEST) database, employing bioinformatics tools and in silico expression analysis to dissect hormone metabolism and signal transduction pathways which regulate development and cellular communication. Expressed Sequence Tags (EST) contigs corresponding to genes involved in hormone biosynthesis, translocation, transport, and signaling were identified and the main components of phytohormone pathways which regulate citrus development were presented. We propose a framework for hormone-mediated signal transduction in citrus species based on comparative genomics analyses.

\section{Material and Methods}

\section{Database searches and alignments}

Homologs of functionally characterized genes involved in phytohormone metabolism and signaling were identified by BLAST (Altschul et al., 1997) and keyword searches against citrus EST database (CitEST), consisting of approximately 176,200 EST sequences obtained from 53 libraries. Data validation was performed by local tBLASTx and tBLASTn searches of the retrieved sequences against the GenBank database. The resulting alignments were filtered by a threshold $e$-value of $10^{-15}$ and further analyzed according to functional domain description. Validated sequences were translated and the deduced protein alignments were performed using ClustalX (Thompson et al., 1997). Whenever necessary, alignments were manually adjusted using Lasergene MegAlign (DNASTAR, Madison, WI, USA).

\section{Motif analysis and in silico characterization}

The identified citrus homologs were further investigated for recognizable functional domains described in several protein and gene function analysis databases built inside CitEST (European Bioinformatics Institute-European Molecular Biology Laboratory, EMBL-EBI, ExPaSy, Swiss Institute of Bioinformatics, SIB, Protein Families database and Pfam).

\section{Phylogenetic analysis}

The putative functionality of the deduced amino acid sequence of citrus transcripts, in comparison to their Arabidopsis and other model species homologs, was as- 
sessed by genetic distance and phylogenetic studies. Phylogenetic analyses were performed using distance and parsimony methods with PAUP* 4.0b10, using default parameters. Re-sampling bootstrap trees containing 1,000 random samples were constructed using PSIGNFIT. Modular functional domains were employed for genetic distance studies with genes previously characterized as having divergent regions and conserved blocks.

\section{In silico gene expression analysis}

In silico qualitative gene expression profiling was performed using virtual northern blot (VNB) analyses of the citrus EST database. Frequency of reads of each EST contig for a given library was calculated and normalized to the total number of reads from the investigated library and the total number of reads in all libraries. A correlation matrix between EST contigs and libraries was then generated, and gene expression patterns among ESTs and libraries were obtained by hierarchical clustering based on Spearman Rank correlation matrix using Cluster v.2.11 (Eisen et al., 1998), by substituting clusters by their average expression pattern. Graphic outputs were generated using Tree View v.1.6 software.

\section{Results and Discussion}

\section{CitEST database survey}

We have performed extensive BLAST and keyword searches of the citrus transcriptome to identify homologs of the genes involved in hormone biosynthesis and signal transduction in citrus. We have searched for genes related to auxin, cytokinin, ethylene, abscisic acid, gibberellic acid, jasmonic acid and peptide hormone biosynthesis, transport and translocation, catabolism and signal transduction pathways. In CitEST databases, 601 assembled sequences and EST singlets sharing significant sequence identity with functionally characterized proteins were identified and analyzed (Table 1, Figure 1). The functional characterization of citrus sequences is virtually equivalent to Arabidopsis in cellular component and molecular function (Figure 1, Figure S1 and Figure S2). However, transcripts with enzyme activity are more abundant in citrus whereas those showing transcription factor activity are more abundant in Arabidopsis proteome (Figure 1). The significance of these findings remains to be investigated in further functional studies.
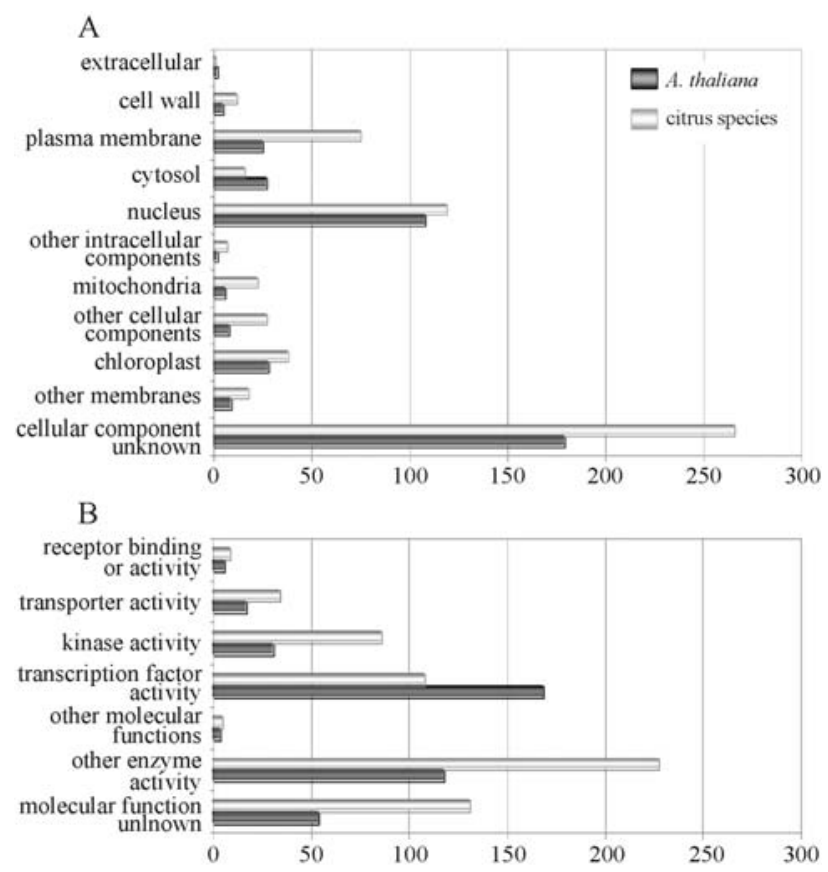

Figure 1 - Comparison between the functional classification of citrus transcripts and Arabidopsis proteome associated to phytohormone metabolism and signaling pathways using gene ontology. A. cellular component; B. molecular function. The normalized number of genes is represented on the x-axis. Assignments are based on the data available at the TIGR Arabidopsis thaliana Gene Index version 13.0.

Table 1 - Number of citrus transcripts identified by tBLASTn searches of CitEST databases showing sequence similarity to hormone metabolism and signaling components in model species.

\begin{tabular}{lccc}
\hline \multicolumn{4}{c}{ CitEST transcripts $\left(\%^{\mathrm{a}}\right.$ - absent gene(s)) } \\
\hline Phytohormone & Biosynthesis, metabolism and transport & Signal transduction & Total \\
\hline Abscisic acid & $5(100 \%)$ & $24-(92.3 \%-$ ABI1, ABI2) & 29 \\
Auxin & $17(94.1 \%-$ CYP707A) & $36(100 \%)$ & 53 \\
Brassinosteroids & $33(100 \%)$ & $63(96.8 \%-$ TTL, TRIP1) & 96 \\
Cytokinin & $13(100 \%)$ & $31(96.8 \%-$ CPC $)$ & 44 \\
Ethylene & $18(100 \%)$ & $35(97.1 \%-$ EIN2) & 53 \\
Gibberellic acid & $18(100 \%)$ & $14(87.5 \%-$ PHOR1, miR159) & 32 \\
Jasmonic acid & $87(95.6 \%-$ AtEXT family) & $112(100 \%)$ & 199 \\
Peptide hormones & 0 & SCRL, IDA, IDL, PLS, CLV3, CLE) & 15 \\
Salicylic acid & $33(100 \%)$ & $47(97.9 \%-$ ACD6) & 80 \\
\hline Total & 224 & 377 & 601 \\
\hline
\end{tabular}

${ }^{a}$ Percentage of identified sequences in comparison to the number of bait sequences searched. 


\section{Abscisic acid}

Although leaf abscission is not primarily induced by ABA, but by ethylene, it has been shown that in 'Cleopatra' mandarin (Citrus reshni) water-stressed seedlings required ABA accumulation in roots to induce ethylene synthesis (Gómez-Cadenas et al., 1996). Similarly, fruitlet abscission in 'Satsuma' mandarin (Citrus unshiu) has also been correlated to sugar shortage, leading to increased levels of ABA, which, in turn, triggered ethylene synthesis (Gómez-Cadenas et al., 2000).

In plants, ABA plays major roles in environmental stress responses. ABA biosynthetic pathway has already been completely elucidated in plants, and shown to be highly conserved in angiosperms (Xiong and Zhu, 2003). ABA signaling and action are, however, much less understood and, so far, only fragmentary information is available. ABA is synthesized from a $\mathrm{C}_{40}$ carotenoid precursor. In fact, many ABA-deficient mutants showed impaired carotenoid biosynthesis, as exemplified by Pinalate, a sweet orange mutant which is defective in zetacarotene desaturase activity that leads to reduced ABA contents (Rodrigo et al., 2003). The first step of the pathway is the conversion of zeaxanthin into violaxanthin catalyzed by zeaxanthin epoxidase (ZEP), followed by conversion to neoxanthin, a 9-cis-epoxycarotenoid, in plastids. Then, 9cis-neoxanthin undergoes an oxidative cleavage by 9-cisepoxycarotenoid dioxygenase (NCED) resulting in xanthoxin, a $\mathrm{C}_{15}$ intermediate that is exported to the cytosol. NCED is the first committed enzyme to an ABA pathway and a major regulatory point. Xanthoxin is then attacked by a short-chain alcohol dehydrogenase/reductase (SDR), producing ABA-aldehyde. The last step in the pathway is the ABA-aldehyde oxidation to abscisic acid (ABA) by ABAaldehyde Oxidase (AAO). AAO requires molybdenum as cofactor (MoCo), which is sulfurylated by MoCo sulfurase (Seo et al., 2000; Xiong et al., 2001; Xiong et al., 2002; Porch et al., 2006).

Several CitEST reads were strongly related to genes involved in ABA biosynthesis: zeaxanthin epoxidase (ZEP/ ABA1/LOS6); 9-cis-epoxicarotenoid dioxygenase (NCED/NOT/VP14); abscisic aldehyde oxidase (AAO/ SIT/TAO3); and molybdenum cofactor sulfurase (ABA3/ LOS5/FLC) (Table S1). Recently, two NCED genes from Citrus sinensis have been cloned and characterized as presenting differential expression patterns and distinct enzymatic properties concerning substrate recognition: $C S N C E D 1$ was expressed in ripening fruits, whereas CsNCED2 transcripts were found only in chromoplastcontaining tissues, such as flavedo (Rodrigo et al., 2006). ABA is catabolized by oxidation, reduction or conjugation (Cutler and Krochko, 1999). Phaseic acid (PA), dihydrophaseic acid (DPA), and glucose conjugates are the usual forms of inactivating ABA in plants. Recently, neophaseic acid (neoPA) was described as a novel ABA metabolite and detected in sweet orange fruits (Zhou et al., 2004). No reads from CitEST database matched Arabidopsis ABA-8'-hydroxylase CYP707A, the main enzyme involved in ABA inactivation (Saito et al., 2004).

ABA perception and signaling are still poorly understood. ROP10 is a small GTPase that participates in ABA signaling pathway as a negative regulator of ABA responses. It functions by modulating the expression of genes that respond to different ABA levels in Arabidopsis (Xin et al., 2005). We were able to identify two contig transcripts showing sequence similarity to ROP10 in the CitEST database.

ABA-responsive elements (ABRE) are present in promoters of ABA-regulated genes. ABRE-binding factors $(\mathrm{ABF})$ activate transcription through the aforementioned cis elements by phosphorylation. TRAB1 from rice is a bZIP-domain transcription factor responsible for ABA regulation at ABRE (Kagaya et al., 2002; Kobayashi et al., 2005). CitEST database contained a single read sharing extensive sequence similarity to TRAB1. The role of TRAB1 in citrus remains unknown; however, the high level of sequence identity surpassed taxonomic classes (from a monocot to a dicot species), suggesting a conserved function.

OST1 (OPEN STOMATA1) is an ABA-activated serine-threonine protein kinase (AAPK) specifically implicated in the signaling pathway. Its expression is upregulated by ABA and osmotic stress. OST1 acts upstream to the production of reactive oxygen species (ROS), a key second messenger that induces cytosolic $\mathrm{Ca}^{2+}$ influx by activating plasma membrane $\mathrm{Ca}^{2+}$-channels (Zhang et al., 2001; Mustilli et al., 2002). ABI1 and ABI2 are PP2C-type phosphatases that negatively regulate $\mathrm{ABA}$ activity in OST1-ROS cascade (Yoshida et al., 2006). Citrus transcriptome analysis identified OST1-related cDNAs, but none was highly similar to ABI1 or ABI2, suggesting that the OST1-ROS pathway may be present in citrus and ABI negative regulators may be absent from the database due to their low transcriptional activity in comparison to OST1. Alternatively, ABI activities may have been replaced by other proteins.

RCN1 (ROOTS CURL IN NPA1) is a serine-threonine phosphatase type 2 regulatory subunit that functions as a general positive regulator during early stages of ABA signaling, upstream of the cytosolic $\mathrm{Ca}^{2+}$ sensing (Kwak et al., 2002). Several transcripts sharing high sequence identity to RCN1 were identified in citrus. Seventeen reads were grouped into two EST contigs, demonstrating the extensive sequence conservation among citrus genomes.

Inactivation of RAC1 by ABA is critical for stomatal closure in Arabidopsis. RAC1/ROP6 is a small GTPase belonging to the Rho gene family, and associated to cytoskeleton regulation in yeast and animals (Lemichez et al., 2001). Transcripts showing sequence similarity to RAC1 were the most abundant of ABA metabolism and signaling-related genes identified in citrus transcriptome: 31 reads assembled in five contigs. As a central element in 
plant adaptation to osmotic stress given its involvement in stomatal closure, it is reasonable to assume that RAC1 may play a strategic role in drought tolerance in citrus. GPA1 is a canonical $\mathrm{G} \alpha$ subunit of a heterotrimeric $\mathrm{G}$ protein implicated in downstream ABA signaling events (Wang et al., 2001). GCR1 is a G protein-coupled receptor, which physically interacts with GPA1, functioning as a negative regulator of GPA1-mediated ABA responses (Pandey and Assmann, 2004). In citrus transcriptome, we identified homologs of Arabidopsis GPA1 and GCR1, indicating a possible conserved mechanism in ABA signaling cascade involving these proteins. Since most investigations on ABA signaling have been carried out on model species, it is important to broaden these findings to other taxonomic groups to validate bona fide universal mechanisms of hormone action.

\section{Auxin}

We have identified 53 EST contigs showing similarity to proteins involved in auxin biosynthesis, metabolism, transport and signal transduction in the CitEST database. Results from comparisons against NCBI database can be found in Table S2. The longest contig consisted of 47 reads and showed similarity to a cullin-like protein. The contigs were assembled from sequences of almost all libraries but the most abundant were from leaf and fruit libraries (Table S2). The enzymes responsible for the biosynthesis of auxin are most active in young tissues: such as shoot apical meristems and in growing leaves and fruits. The same tissues are the locations where the highest concentrations of indole-3-acetic acid (IAA) are found. In fact, we have observed that the vast majority of sequences assembled in the contigs with similarity to proteins involved in IAA biosynthesis were from leaf $(58.44 \%)$ and fruit (31.8\%) libraries.

Auxins exert control over many important developmental processes in plants, including cell division and cell expansion, vascular tissue differentiation, root initiation, apical dominance, gravitropic and phototropic responses, flowering, fruit ripening, leaf senescence and abscission of leaves and fruit (Eckardt, 2001). Due to the importance of IAA in plant growth and development, extensive studies of the biosynthesis of this compound have been performed since its discovery as a plant hormone. The pathway for the biosynthesis of IAA in plants remains, however, to be elucidated, probably due to the existence of multiple pathways and possible functional redundancy among various participating enzymes. Indole-3-acetic acid is the most abundant naturally occurring auxin. Plants produce active IAA both by de novo synthesis and by releasing IAA from conjugates. This work emphasizes the analysis of the pathways involved in de novo IAA synthesis in citrus.

Genetic and biochemical experiments have demonstrated that two routes are responsible for IAA biosynthesis: a tryptophan-dependent and a tryptophan-inde- pendent one (Bartel, 1997). The starting point for IAA synthesis is in the tryptophan (Trp) biosynthetic pathway (Eckardt, 2001). Two routes from Trp to IAA are generally accepted as occurring in plants: one from Trp through indole-3-acetaldoxime (IAOx) and indole-3-acetonitrile (IAN) to IAA. Two Arabidopsis cytochrome P450 proteins, CYP79B2 and CYP79B3, can catalyse the conversion of Trp to IAOx in vitro (Hull et al., 2000). In addition to cytochrome P450s, several Arabidopsis proteins with similarity to flavin monoxygenases (FMOs) have been found to increase IAA production via a probable IAOx intermediate in superexpression mutants. The FMO encoded by YUCCA gene converts tryptamine to N-hydroxyl tryptamine (Zhao et al., 2001). Once YUCCA has converted tryptamine to N-hydroxyl tryptamine, another hydroxylation step is necessary to synthesize IAOx. This is presumably carried out by another FMO-like protein or a cythochrome P450. We have found five FMO contigs, from the largest number of reads (75). Six contigs of CYP83B1 were found and, according to Eckardt (2001), it is evidence that P450 CYP83B1 converts IAOx to its corresponding acinitro compound: the first step in indole-glucosinole biosynthesis. This represents a metabolic branch point between IAA and indole-glucosinolaste biosynthesis in Arabidopsis and CYP83B1 is found to play a role in regulating auxin homeostasis. One contig of CYP79B2 was found. In model systems, it catalyzes the formation of IAOx from Trp (Hull et al., 2000).

As mentioned earlier, it is often assumed that the conversion of IAOx to IAA proceeds through IAN. IAN can be converted to IAA through the action of nitrilases. The distribution appears to be limited to three families (Cruciferae, Graminae and Musaceae), although it is possible that similar enzymes catalyze this reaction in other plants. Three nitrilases from Arabidopsis (NIT1 to NIT3) are capable of converting IAN to IAA (Eckardt, 2001). In the present work, we have found two contigs of NIT4 that probably do not play a role in IAA biosynthesis, according to Piotrowski et al. (2000). We have also found one contig with 12 reads showing sequence similarity to NITRILASE1-like protein of Arabidopsis. In maize, two nitrilases ZmNIT1 and $Z m$ NIT2 are expressed in seeds. ZmNIT2 efficiently hydrolyzes indole-3-acetonitrile to IAA and could thus be involved in auxin biosynthesis. However, some studies using nit1-1 mutants suggested that IAOx may be converted to IAA via a distinct route (Eckardt, 2001).

The alternative route proceeds from Trp via indole acetaldehyde (IAAld) to IAA. IAAld may be a good candidate for an intermediate between TAOx and IAA: instead of conversion to IAN, IAOx could be reduced to an imine followed by $\mathrm{pH}$-dependent hydrolysis to IAAld, which can be converted to IAA via aldehyde oxidase (AO) (Normanly and Bartel, 1999). In fact, some investigations have shown that an AO, tentatively called IAAld oxidase, may be involved in IAA synthesis. In the present survey, we have 
found two contigs with similarity to AO. According to our data, it seems that in citrus the same two vias are involved in the Trp-dependent IAA biosynthesis.

The versatility of auxins as signaling molecules is illustrated by the fact that a number of messages can be communicated simultaneously to different target cells. Precisely regulated auxin transport and redistribution have been implicated in some of these responses. Auxins are the only class of polarly transported phytohormones and their polar flow has been linked to many aspects of development, including establishment of the embryonic axis, continuous differentiation of vascular tissues and tropic growth responses, such as photo- and gravitropism. In higher plants, IAA is synthesized in shoot apices and transported towards the root tip, where it probably enters an opposite flow in the epidermis. The basipetal transport of IAA appears to be essential for the formation of continuous vascular strands and other aspects of cell polarity, while the opposite movement in the root epidermis is required for root gravitropism. Polar auxin transport proceeds in a cell-to-cell fashion involving influx and efflux through cell membranes. The directionality of the transport is thought to result from the polar distribution of specialized carrier molecules in the plasma membrane (Leyser and Berleth, 1999). Members of the Arabidopsis PIN-FORMED1 (PIN1) and AUXINRESISTANT1 (AUXI) gene families are suspected to constitute components of the auxin efflux and influx machinery, respectively. The PIN1 protein has been implicated in general auxin transport along the apical-basal axis, evidenced by the impaired auxin transport in pin 1 mutant stem segments. The recent identification of PIN1 gene product as a basically membrane-localized protein with structural similarities to bacterial membrane transporters strongly suggests a role in auxin efflux (Leyser and Berleth, 1999). In citrus, we have identified three contigs corresponding to PIN family members.

Auxin causes rapid changes in gene expression, and two families of proteins have been identified in this response: auxin response factors (ARFs) and Aux/IAA proteins (Callis, 2005). Auxin regulates a broad spectrum of developmental processes, mediating transcriptional regulation via protein degradation (Weijers and Jürgens, 2004). Regulation by proteolysis has emerged as a resounding theme in plant hormone signaling. The ubiquitin-mediated degradation of key regulatory proteins has been demonstrated, or is at least likely, for all of the phytohormone response pathways (Smalle and Vierstra, 2004). In the case of auxin, the response pathway is normally subject to repression by a large family of transcriptional regulators called Aux/IAA proteins (Gray, 2004). These proteins dimerize with members of the AUXIN RESPONSE FACTOR (ARF) family of transcription factors, thus, preventing ARFs from activating auxin-responsive genes (Tiwari et al., 2004). Upon an auxin stimulus, an SCF ubiquitin ligase containing the TIR1 F-box protein ubiquitinates the
Aux/IAA proteins, marking them for degradation by the $26 \mathrm{~S}$ proteasome, thereby de-repressing the response pathway (Gray et al., 2001). Auxin de-represses the pathway by promoting AUX/IAA binding to $\mathrm{SCF}^{\mathrm{TIR} 1}$ and leading to their degradation. $\mathrm{SCF}^{\mathrm{TIR} 1}$ function requires AXR1dependent RUB1 modification of an AtCUL1 subunit of the SCF. In citrus, we have identified three contigs corresponding to a putative CULLIN1 from $A$. thaliana. One is similar to a putative CULLIN3 from Oryza sativa (japonica cultivar-group), four contigs have similarity to TRANSPORT INHIBITOR RESPONSE1 (TIR1) from A. thaliana (Table S3). Seven ARF7, one ARF2 and one ARF1-like transcripts were also identified (Table S3). Eight Aux/IAA transcriptional regulators, four with similarity with auxin responsive family in Arabidopsis and four closer to Populus tremula, were identified in citrus transcriptome.

One transcript corresponding to ABP1 (AUXIN BINDING PROTEIN1) was identified in citrus species. The identification of a plant auxin-binding protein 20 years ago marked a major advance in understanding auxin perception in plants. Developing plants lacking ABP1 show defective cell elongation, fail to organize the basic plant body plan, and subsequently degenerate (Callis, 2005). But, it was demonstrated that the auxin-dependent SCF ${ }^{\text {TIR1 }}$ Aux/IAA interaction requires neither integral membrane proteins nor the candidate auxin receptor, auxin binding protein 1 (ABP1) (Weijers and Jürgens, 2004). Recently, TIR1 has been demonstrated to function as the auxin receptor in plants (Dharmasiri et al., 2005).

\section{Brassinosteroids}

We have identified 96 transcripts from citrus species that share sequence similarity to BR metabolism and signal transduction components from model species (Table S4, Table S5). Thirty-three are related to several steps of BR biosynthesis and processing, and the vast majority of them (20) are similar to BR oxidation P450 cytochrome proteins (Table S4). In citrus species, 63 ESTs are similar to BR signal perception and transduction: including 30 sequences homologous to receptor and receptor-like proteins, 25 similar to phosphorelay cascade and cross-talk intermediates and 7 whose deduced amino acid sequence is homologous to BR-induced transcriptional regulators (Table S5).

Brassinosteroids are $\mathrm{C}_{27}, \mathrm{C}_{28}$, and $\mathrm{C}_{29}$ steroids depending on their C-24 alkyl substituents, reviewed in Fujioka and Yokota (2003). In plants, they are present in a wide array of free, naturally occurring BRs. Brassinolide (BL) is the most biologically active $\mathrm{C}_{28} \mathrm{BR}$ and, together with its $\mathrm{C}_{28}$ congeners, is widely distributed in the plant kingdom. BR biosynthetic pathway is highly networked and consists of several paralleled BL pathways that branch and interact with each other (Noguchi et al., 1999). Initially, campesterol is converted to campestanol in an early C-22 oxidation pathway. Campestanol, in turn, is converted to castasterone (CS) through either early C-6 oxidation or late 
C-6 oxidation, after which $\mathrm{CS}$ is further converted into BL. In citrus, we have identified homologs of the enzymes involved in the early C-22 oxidation pathway, such as DET2 and DWF4 and in both parallel C-6 oxidation pathways, including several CDP family members and BR6OX (Table S4). Thus, as demonstrated for rice, Catharanthus roseus, tobacco and Arabidopsis (Suzuki et al., 1995; Choi et al., 1996), BR biosynthetic pathways appear to be highly conserved in citrus species.

In plants, BRs are perceived by the transmembrane leucine-rich repeat (LRR) serine/threonine kinase protein BRI1 (BRASSINOSTEROID INSENSITIVE 1) that interacts with another LRR receptor kinase, BAK1 (BRI-ASSOCIATED RECEPTOR KINASE 1) (Li et al., 2002; Nam and Li, 2002). Thus, BAK1 serves as a co-receptor for BRI1 to perceive the BR signal at the cell surface. The immediate targets for signal transmission from the receptor complex remain elusive, but several candidate signaling substrates have been identified for BRI1, including a transthyretin-like protein (TTL) and a TGF- $\beta$-receptorinteracting protein (TRIP1) (Nam and Li, 2004; Ehsan et al., 2005). TTL has been demonstrated to function as a negative regulator of BR-induced plant growth, although it fails to affect BR-induced transcriptional changes (Sablowski and Harberd, 2005). Alternatively, it is likely to function by locally regulating BR-induced responses, such as cell expansion (Nam and Li, 2004). The receptor kinase TRIP1 has been hypothesized to function as a general transcriptional regulator, although it remains to be demonstrated (Ehsan et al., 2005). The family of receptor kinase BRI1 and BRI-like (BRL) is represented by 30 transcripts identified in $C$. sinensis, $C$. reticulata and $P$. trifoliata transcriptomes (Table S5). Similarly, 9 cDNAs correspond to the co-receptor BAK1 in citrus species (Table S5). We were unable to identify TTL and TRIP1 homologs in citrus using bioinformatic tools.

Cytoplasmic protein kinase BIN2 (BRASSINOSTEROID INSENSITIVE 2) functions downstream of the receptor complex to negatively regulate BR-initiated signal transduction and shares sequence homology to Drosophila SHAGGY kinase and mammalian glycogen synthase kinase 3 (GSK3) (He et al., 2002; Li and Nam, 2002). Three BIN2 homologs are present in citrus transcriptome and the deduced amino acid sequence of two of them is more than $50 \%$ identical to the sequence of Arabidopsis BIN2 (Table S5). BR-induced changes in gene expression have been demonstrated to involve BZR1 and BES1; there are two closely related nuclear proteins that function as positive transcriptional regulators (review in Li and Deng, 2005). In the absence of BR signaling, BZR1 and BES1 are present in phosphorylated forms, resultant from BIN2 kinase activity (Wang et al., 2002; Yin et al., 2005). Phosphorylated BZR1 has been hypothesized to be degraded by the $26 \mathrm{~S}$ proteasome (Wang et al., 2002). BZR1 and BZL are members of a novel sub-family of bHLH transcription factors (He et al.,
2005; Yin et al., 2005). The BZR1 binding site, CGTG(T/C)G, is found in four BR biosynthetic genes that are feedback regulated, including $C P D$ and DWF4 (He et al., 2005). In citrus, BZR family is represented by 2 cDNAs containing the characteristic domain of unknown function found in the Arabidopsis family (Table S5). The phosphorylation status of BES1 is modulated by the nuclear serine/threonine protein phosphatase BSU1, which is also likely to be involved in the proteolytic degradation of BES1 via the Kelch-repeat domain at the N-terminus of the phosphatase (Mora-Garcia et al., 2004). C. sinensis and P. trifoliata BSU1 homologs show high sequence conservation at the kinase domain, although the identity at the Kelch repeats is less significant (data not shown). Citrus species have two BES-like proteins, sharing up to $40 \%$ of sequence identity between each other. The conserved domain of unknown function at the N-terminus of Arabidopsis BES1 is present in all identified citrus homologs. Thus, BRregulated gene expression in citrus is hypothesized to be functionally equivalent to the Arabidopsis pathway.

\section{Cytokinin}

We have identified 44 ESTs corresponding to CKrelated metabolism in citrus. From the total, 13 correspond to genes involved in the hormone biosynthesis, transport and catabolism (Table S6) and the remaining 31 are involved in CK-mediated signal transduction (Table S7).

The enzymes responsible for the first step in CK biosynthesis, the modification of the adenine moiety, are represented by one $C$. reticulata transcript highly similar to IPT3, IPT4, IPT7 and IPT8 from A. thaliana and several other species, and two C. sinensis cDNAs: one similar to IPT1 and one closer to IPT5 (Table S6). In general, IPT coding sequences are conserved throughout evolution, especially at the ATP/GTP binding motif (Kakimoto, 2001), thus the biological meaning of the family divergence in citrus species is likely to reflect functional redundancy. The enzymes modifying the adenine side-chain, the second step of CK biosynthesis, share extensive sequence similarity to several UDP-glycosyl transferases and corresponded to one EST singlet and one contig in citrus (Table S6). The purine permease family consists of several small hydrophobic polytopic membrane proteins involved in translocation of adenine-related compounds; however only two members, AtPUP1 and AtPUP2, have been demonstrated to translocate CK (Burkle et al., 2003). The family is represented in C. sinensis by two EST contigs that share sequence homology to both AtPUP1 and AtPUP2. In Arabidopsis, CK degradation is mediated by a five-gene family of cytokinin oxydases $(C K X)$. Similarly in citrus, $C K X$-related transcripts were identified (Table S6).

Genetic and biochemical evidence has demonstrated that cytokinin signal transduction is primarily dependent on the bacterial and yeast two-component signal transduction pathways where stimuli-binding specifically leads to histi- 
dine-asparagine multi-step phosphorelays, which in turn induce changes in gene expression (Grefen and Harter, 2004). Two-component signaling systems consist of sensor kinases, histidine phosphotransfer proteins and response regulators (Mizuno, 2005). The Arabidopsis cytokinin receptor kinases (Arabidopsis HISTIDINE $\underline{\text { KINASE2 }}$ (AHK2), AHK3, AHK4/CYTOKININ RESPONSE 1 (CRE1)/WOODENLEG (WOL)) contain a conserved extra-cellular cytokinin-binding domain called CHASE (cyclases/histidine kinases associated sensory extracellular), a histidine kinase and a receiver domain (Ferreira and Kieber, 2005; Riefler et al., 2006). In citrus, we have identified 5 EST contigs sharing extensive sequence conservation with Arabidopsis AHKs, including at the functional receiver domain (Table S7, Figure 2). Five Arabidopsis histidine-phosphotransfer proteins (AHPs) encode small proteins (of about 150 amino acids) mediating the phosphotransfer from the receptor kinases to the response regulators (Ferreira and Kieber, 2005).

The Arabidopsis genome has another 23 genes that are similar in sequence and domain structure to bacterial response regulators, and these encode both positive and negative elements in cytokinin signaling. In citrus, we have identified 3 transcripts corresponding to AHP genes from A. thaliana and from the woody model species Populus tremuloides (Table S7). Highest sequence homology is ob- served at the His-Asp phosphotransfer region, suggesting that these transcripts correspond to functionally active proteins in phosphorelay-mediated signal transduction (Figure 2). Arabidopsis RR genes belong to two main groups based on their sequence similarities: domain structure and transcriptional response to cytokinin (Mizuno, 2005). The type-A ARRs consist of a receiver domain and a short carboxyl terminus and their transcription is rapidly elevated in response to exogenous cytokinin; these are considered to be primary response genes (Liebfried et al., 2005; Kim et al., 2006). The type-B ARRs have a carboxy-terminal output domain that has a DNA-binding glutamic acid-rich protein (GARP) domain and a transcriptional activation domain in addition to the receiver domain, and in contrast, its transcription is not altered by cytokinin (Ferreira and Kieber, 2005; Mason et al., 2006). In citrus, we have identified 13 ARR genes: 7 corresponding to B-type and 6 to A-type response regulators.

\section{Ethylene}

The structural simplicity of the plant hormone ethylene contrasts with its dramatic effects on various developmental processes. These range from seed germination to senescence and organ abscission, and in the cellular processes that ethylene initiates in response to a diversity of environmental signals (Stepanova and Alonso, 2005).

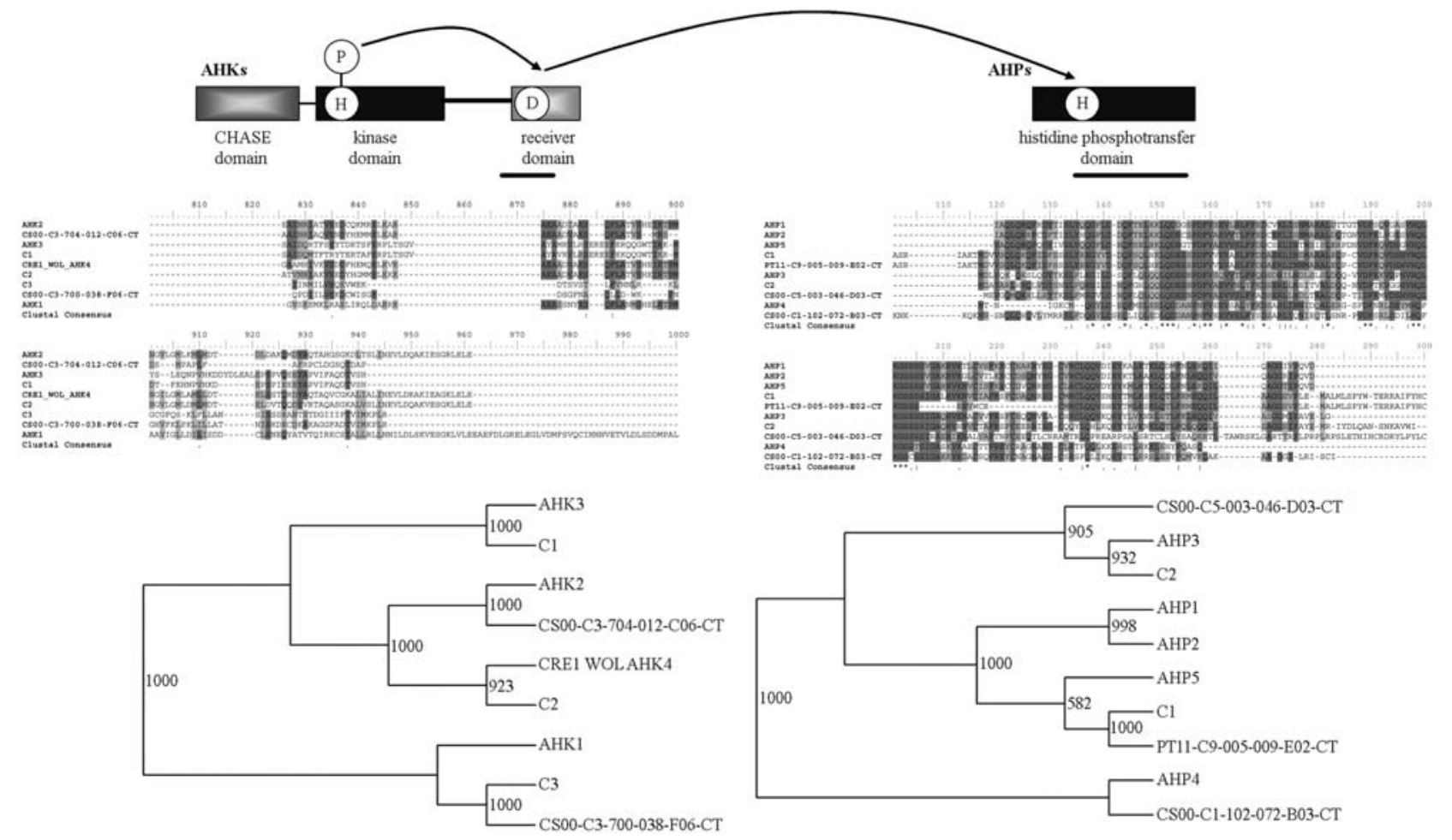

Figure 2 - Cytokinin-mediated signal transduction in citrus. Schematic representation of AHK to AHP phosphorelay. Alignment of the receiver domain from A. thaliana and citrus AHK proteins and phylogenetic analysis of citrus AHKs. Alignment of the conserved histidine phosphotransfer domain from A. thaliana and citrus AHP proteins and phylogenetic analysis of the deduced amino acid sequence of citrus and Arabidopsis full-length proteins. Phylogenetic analysis was performed using full-length Arabidopsis proteins and the deduced amino acid sequence of citrus transcripts as described. Black and gray shading of amino acid residues represents sequence identity and similarity, respectively. 
Ethylene is synthesized from the amino acid methionine via the intermediates S-adenosyl-L-methionine (AdoMet) and 1-aminocyclopropane-1-carboxylate (ACC). The conversion of AdoMet to ACC is the first committed, and generally, rate-limiting step in ethylene biosynthesis and is catalyzed by the enzyme ACC synthase (ACS). Ethylene is then made from ACC by the enzyme ACC oxidase (ACO). Both ACS and ACO are encoded by multigene families in most plant species and these genes are regulated differently at the transcriptional level (Chae and Kieber, 2005). The Arabidopsis genome contains nine ACS genes that encode eight functional and one non-functional ACS protein. In $C$. sinensis transcriptome, we have identified three transcripts showing sequence similarity to Arabidopsis ACS enzymes (Table S8). Similarly, in P. trifoliata, the ACS family is represented by three transcripts (Table S8). Molecular genetic studies in Arabidopsis have provided evidence that ACS protein stability is regulated by the ubiquitin-26S proteasome, reviewed in Chae and Kieber (2005). In this species, the gene ETO1 encodes a BTB (Broad-complex, Tramtrack, Bric-à-brac) domaincontaining protein, a class that has been shown to link CUL3-based ubiquitin ligase to substrate proteins (Pintard et al., 2004). ETO1 also contains six predicted tetratricopeptide repeat motifs, which are involved in diverse protein - protein interactions and can serve as a scaffold for the assembly of multiprotein complexes. In citrus, we have identified four ETO1 homologs (Table S8), including a transcript sharing more than $70 \%$ of sequence identity to the Arabidopsis protein.

Ethylene is sensed by a family of endoplasmic reticulum (ER)-localized membrane-bound receptors (Chen et al., 2002) that share sequence similarity with bacterial two-component histidine kinases (Stepanova and Alonso, 2005). The functional role of the kinase activity of ET receptors is not clear (Chen et al., 2005). The citrus ETR family consists of six transcripts, whose deduced amino acid sequence is highly similar to ETR proteins from model species, especially at the kinase domain (Table S9). The receptors function as negative regulators of the signaling partner CTR1 (Hua and Meyerowitz, 1998). CTR1 is a Raf-like protein kinase (Kieber et al., 1993) that has a role as a second negative regulator of the pathway that co-localizes and directly interacts with the receptors (Gao et al., 2003). We have identified several citrus cDNAs showing sequence similarity to CTR1 (Table S9). However, the sequence identity is mostly localized at the conserved Raf kinase domain. Thus, at this point, we cannot rule out a role for citrus CTR1-like transcripts in ET-independent signaling pathways.

EIN2, a novel plant-specific protein, is the downstream signaling partner of CTR1. EIN2 has two welldefined domains: (i) an $\mathrm{N}$ terminus with similarity to the NRAMP family of metal ion transporters and (ii) a unique hydrophilic C terminus (Alonso et al., 1999). Interestingly, we were unable to find EIN2 homologs in citrus transcriptome databases. In contrast, nine homologs of EIN3/EIN3-like proteins, a family of plant-specific transcription factors that are structurally and functionally conserved among several plant species (Stepanova and Alonso, 2005), were identified (Table S9). The activation of this family by ET is, at least in part, mediated by the regulation of their protein abundance through an ubiquitin-mediated proteasomal pathway. Two F-box proteins (EBF1 and EBF2) that form part of an SCF complex are involved in the regulation of EIN3 levels by ET in Arabidopsis (Guo and Ecker, 2003; Potuschak et al., 2003). Functional studies of EIN3 have demonstrated that it binds to the promoter sequences of an ethylene-inducible transcription factor gene $E R F 1$, a member of the ethylene response element binding protein (EREBP) family of genes, reviewed in Chen et al. (2005). ET-triggered signal transduction controls the expression levels of a large number of target genes through what seems to be a transcriptional cascade (Alonso et al., 2003).

\section{Gibberellin}

The biosynthesis of the diterpene carboxylate hormone gibberellin (GA) has been well-characterized (Hedden and Phillips, 2000). We searched for genes involved in biosynthesis and signaling of GA in Citrus sinensis, and we were able to identify homologs to all biosynthesis components, and several transcripts shared sequence identity to genes involved in signaling (Table S10). At the first stage of GA biosynthesis, geranyl-geranyl diphosphate is cyclized to ent-kaurene by copalyl diphosphate synthase (CPS) and/or ent-kaurene synthase in the chloroplasts. Genes coding for these two enzymes share a high level of similarity, hindering identification. In the CitEST database, one homologous sequence to the genes coding for these enzymes was present as a singlet. In Arabidopsis, extremely low amounts of CPS mRNA were detected during plant development, with cell-specific expression (Olszewski et al., 2002). In the second step, ent-kaurene is oxidized by entkaurene oxidase $(\mathrm{KO})$ to ent-kaurenoic acid, which is then oxidized by ent-kaurenoic acid oxidase (KAO) to $\mathrm{GA}_{12}$-aldehyde by cytochrome P450 monooxygenases in the endoplasmic reticulum (Helliwell et al., 1998, Helliwell et al., 2001). Three EST-contigs similar to KO were identified, whereas three contigs and two singlets resembling KAO were identified. The conversion of $\mathrm{GA}_{12}$-aldehyde to $\mathrm{C} 19$ GA proceeds via the 13-hydroxylation pathway, resulting in $\mathrm{GA}_{20}$ and $\mathrm{GA}_{1}$, or alternatively by the non-13 hydroxylation pathway, which produces $\mathrm{GA}_{9}$ and $\mathrm{GA}_{4}$. These enzymes are encoded by a small multigene family in Arabidopsis (Olszewski et al., 2002). Transcripts for both enzymes were present in the citrus transcriptome: one contig showed low similarity to $\mathrm{GA}_{3}$ hydroxilase, and another to $\mathrm{GA}_{20}$ oxidase. 
Gibberellins are synthesized in apical meristematic tissues and immature seeds, and have been detected in phloem translocation streams and in root exudates (Huntley et al., 2002; Lough and Lucas, 2006). Little is known about the regulation of GA catabolism, but the first step of GA degradation involves $\mathrm{GA}_{2}$-oxidases (GAOX) that hydroxylate C-2 of active GAs (Martin et al., 1999; Thomas et al., 1999; Sakamoto et al., 2001). Three contigs (two from C. sinensis) and one singlet showing homology to genes encoding for the GAOX group of enzymes were identified. $\mathrm{GA}_{2}$ oxidase, the enzyme involved in the first step of GA degradation, displayed high expression levels in all analyzed libraries (data not shown). $\mathrm{GA}_{2}$-oxidase genes have been cloned from several species, and in Arabidopsis they are encoded by a five-gene family, two genes associated with C19-GAs hydroxylation, and the remaining three coding for enzymes capable of hydroxylating C20 (Schomburg et al., 2003). The identified reads (26) were grouped into three distinct expression clusters with one containing 21 reads.

Regulation of GA biosynthesis is complex and it is likely to be feedback-regulated. Several important positive and negative regulators of GA signaling have been identified in model plants. GA is believed to bind a receptor, activating G-proteins, which in turn, enhance GA signaling pathways. GID1 was identified and characterized as a soluble receptor of GA in rice (Ueguchi-Tanaka et al., 2005). In citrus, two contigs with high similarity to GID1 were identified. The gene PHORl was described in Solanum tuberosum (Amador et al., 2001), and it has been shown that, upon GA binding, PHOR1 was translocated into the nucleus, where it acts as a positive regulator. No PHOR1 homologous sequences were found in the CitEST database.

The GA signal also activates protein kinase and GID2/SLY1-(F-box)-mediated degradation of DELLA proteins (Nambara et al., 1998). DELLA proteins function as negative regulators of GA signaling, and their degradation through the ubiquitin/proteasome pathway is considered a key event in the regulation of GA-initiated processes (Peng et al., 1997; Richards et al., 2001). One contig with high similarity to SLEEPY (SLY) protein was found in our analysis (Table S10). The expression pattern of the putative DELLA contigs in citrus displayed one read expressed in flowers, and all the others present in juvenile leaves. The observed profile of DELLA transcripts suggested that the genes present a tissue- and treatment-specific expression pattern. The limited number of reads prevented us from performing expression analysis in other citrus species. DELLA is a sub-family within the GRAS family of plant regulatory proteins involved in several aspects of plant development (Bolle, 2004). In rice, wheat, barley and maize, there is one homolog of Arabidopsis RGA/GAI coding for a DELLA protein repressor. However, in the dicot A. thaliana, five DELLA proteins were identified: RGA
(REPRESSOR OF gal-3) and GAI (GA INSENSITIVE) and three RGA-LIKE proteins: RGL1, RGL2, and RGL3. Recent evidence suggests that RGA, RGL1, and RGL2 are involved in modulating floral development in a tissuespecific manner (Lee et al., 2002; Wen and Chang, 2002; Tyler et al., 2004). In contrast, Lycopersicum esculentum genome appears to contain a single DELLA protein, named LeGAI (Bassel et al.; 2004). Six DELLA-related contigs were identified in citrus. Four contigs were identified containing domains that allow the identification of GRAS sequences from the DELLA subfamily (Tian et al., 2004), suggesting that Citrus sinensis contains at least four DELLA genes. Incomplete consensus sequence in the majority of the contigs carrying the DELLA domain prevented us from performing a comprehensive phylogenetic analysis of the citrus DELLA family. Interestingly, three contigs presented $C$. sinensis reads matching contigs with reads from other species or genera (data not shown). Furthermore, the C. sinensis genome contains genes highly similar to other Citrus and Poncirus species.

The expression of Arabidopsis GAI in rice caused a dwarf phenotype, suggesting that GAI is sufficiently conserved to allow it to function in the context of a heterologous genome (Peng et al., 1999). Recent evidence demonstrates that GAI mRNA is translocated through the phloem (Haywood et al., 2005). A specific population of RNA molecules was identified in the phloem translocation stream (Yoo et al., 2004). Haywood et al. (2005) proposed that GAI mRNA delivery via phloem allows flexibility in fine-tuning developmental programs, allowing transcripts access to petal primordia and ground tissues.

DELLA proteins are targeted to $o$-GlcNAc modifications (Thornton et al., 1999). In Arabidopsis, SPINDLY (SPY) is a negative regulator of GA signal transduction. Sequence analysis of SPY suggests that it encodes an $o$-glucosyl-N-acetyltransferase, which can activate DELLA proteins (Jacobsen et al., 1996). In the citrus transcriptome, one contig and three singlets with high similarity to SPY were identified (Table S10). After degradation of DELLA proteins, positive transcription factors that were once blocked by DELLA, such as GAMYB, are free to activate the transcription of several genes (Gubler et al., 2002). A single sequence sharing similarity with GAMYB was found in Citrus reticulata. Achard et al.(2004) suggested that microRNA (miR159) modulates GA-mediated development via its effects on GAMYB activity, thus acting as a homeostatic regulator. We were unable to identify miR159 homologs in the CitEST database.

GA-mediated signal transduction is likely to encompass other genes, but the involvement of GAR2, SHI, GAST and several SCARECROW-regulators awaits further functional evidence. We have identified CitEST sequences homologous to those GA-signaling candidates; however, they were not referred to in this study due to space constraints. 


\section{Jasmonate}

The jasmonate family of molecules includes jasmonic acid (JA) and its methyl ester, methyl jasmonate (MeJA) and is derived from oxylipins, a group of biologically active compounds synthesized from the oxidative metabolism of polyunsaturated fatty acids (Schilmiller and Howe, 2005). These compounds are involved in regulating stress-induced gene expression, mechanical responses such as tendril coiling, and reproductive development (Browse, 2005).

In a survey of citrus transcriptome, we have identified 199 homologs of model plant genes involved in the metabolism and functioning as signaling partners of the jasmonate family of plant hormones (Table S11, Table S12). From the total, 87 citrus transcripts share sequence homology to JA biosynthesis components (Table S11), whereas the remaining 112 are similar to JA-triggered signal transduction pathway members (Table S12). Interestingly, the family of extensins, a group of homologous hydroxyproline-rich glycoproteins responsible for plant cell wall self-assembly and cell extension (Ringli et al., 2001) and JA-induced wounding and pathogen infection defense mechanisms (Shanmugam, 2005), is absent from citrus transcriptome databases. The crucial role of extensins in negative and positive regulation of cell expansion and elongation constitutes a major morphogenetic mechanism operating at all levels of plant growth and development, thus it is unlikely that this class of protein is absent from citrus species.

Most plant oxylipins are synthesized in a pathway initiated by lipoxygenase (LOX), a non-heme iron dioxygenase that adds molecular oxygen to either the 9 or the 13 position of the $\mathrm{C}_{18}$ chain of linoleic acid. Plants express numerous LOX isoforms with distinguishable expression pattern, subcellular location, and substrate utilization (Schilmiller and Howe, 2005). In citrus, we have identified 15 transcripts whose deduced amino acid sequences show the conserved lipoxygenase LH2 domain (Table S11). The conservation at the functional domain indicates that they are likely to represent functional LOX proteins. The hydroxyperoxy products of LOX are metabolized to an array of oxylipins by several enzymes, including closely related members of a cytochrome P450 family: allene oxide synthase (AOS), epoxy alcohol synthase, peroxygenase, alkyl hydroperoxide reductase, and LOX itself (Schilmiller and Howe, 2005).

The family of AOS enzymes transforms 13-hydroperoxy linolenic acid (13-HPOT) to the jasmonate family of compounds that includes JA/MeJA and their metabolic precursor, 12-oxo-phytodienoic acid (12-OPDA) (Schilmiller and Howe, 2005). Metabolism of 9-hydroperoxy fatty acids generates a group of oxylipins that are structurally related but distinct to the oxylipins generated by the 13-LOX pathway, the 9-hydroperoxy linolenic acid (9HPOT). The 13- and 9-hydroxyperoxydes are metabolized by allene oxide cyclase (AOC) isoforms (Schilmiller and Howe, 2005). AOC and AOS family homologs were identi- fied in citrus species (Table S11). The $\alpha, \beta$-unsaturated carbonyl moiety that distinguishes cyclopentenone oxylipins (e.g. 12-OPDA) from cyclopentanone oxylipins (e.g. JA) functions as a negative regulator of novel signaling activity (Seo et al., 2001).

The discovery of a gene encoding a JA carboxyl methyltransferase (JMT) indicates that MeJA is an important component of the mix of oxylipin signals that mediates defense responses (Seo et al., 2001; Zubieta et al., 2003). The deduced amino acid sequences of citrus JMT are moderately similar to the Arabidopsis protein with the highest similarity at the methyltransferase domain (Table S11). However, at this point a methyltransferase activity dissociated from JA metabolism cannot be ruled out. $D A D 1$ is a member of $D A D 1$-like gene family in Arabidopsis and this family is hypothesized to regulate jasmonate production in response to other cues or to be involved in the biosynthesis of other classes of oxylipins (Matsui et al., 2004). In citrus, the family is represented by five transcripts including three C. reticulata-specific mRNAs (Table S11).

Jasmonates function as cellular regulators in diverse developmental processes, such as seed germination, root growth, fertility, fruit ripening, and senescence. In addition, JA activate plant defense mechanisms in response to insect wounding, various pathogens, and environmental stresses such as drought, low temperature and salinity and are also involved in the regulation of some stages of secondary metabolism (Cheong and Choi, 2003). The leucine-rich repeats and F-box motif protein COI1 is required to degrade a repressor of the jasmonate signaling pathway (Liechti et al., 2006). Signaling in the jasmonate pathway depends on at least two massive signaling machines that interact in vivo to form a complex of at least $0.7 \mathrm{mDa}$ (Feng et al., 2003). The first of these complexes is the $\mathrm{SCF}^{\mathrm{COI} 1}$ complex, which is an E3-ubiquitin ligase (Devoto et al., 2002). In this complex, the F-box protein COI1 (Ren et al., 2005) physically associates with Skp-like proteins cullin and AtRbx1 to form active $\mathrm{SCF}^{\mathrm{COI} 1}$. The second multimolecular complex involved in JA signaling is the COP9 signalosome (CSN), which interacts in vivo with $\mathrm{SCF}^{\mathrm{CO} I 1}$ (Feng et al., 2003). We have identified citrus transcripts sharing extensive sequence conservation with COI1 (Table S12, Figure 3). The sequence identity is higher at the F-box domain (Figure 3). Interestingly, COI1-like transcripts are highly frequent in C. latifolia libraries.

Reversible protein phosphorylation has been demonstrated to be involved in JA signal transduction pathways leading to jasmonate-induced gene transcription (Jensen et al., 2002). A transposon-inactivation study revealed that mitogen-activated protein kinase 4 (MPK4) is required for jasmonate-responsive gene expression in Arabidopsis (Petersen et al., 2000). Interestingly, the deduced amino acid sequence of six citrus transcripts is more than $50 \%$ identical to AtMPK4 (Table S12), suggesting a functional conservation between the proteins from citrus species and their 


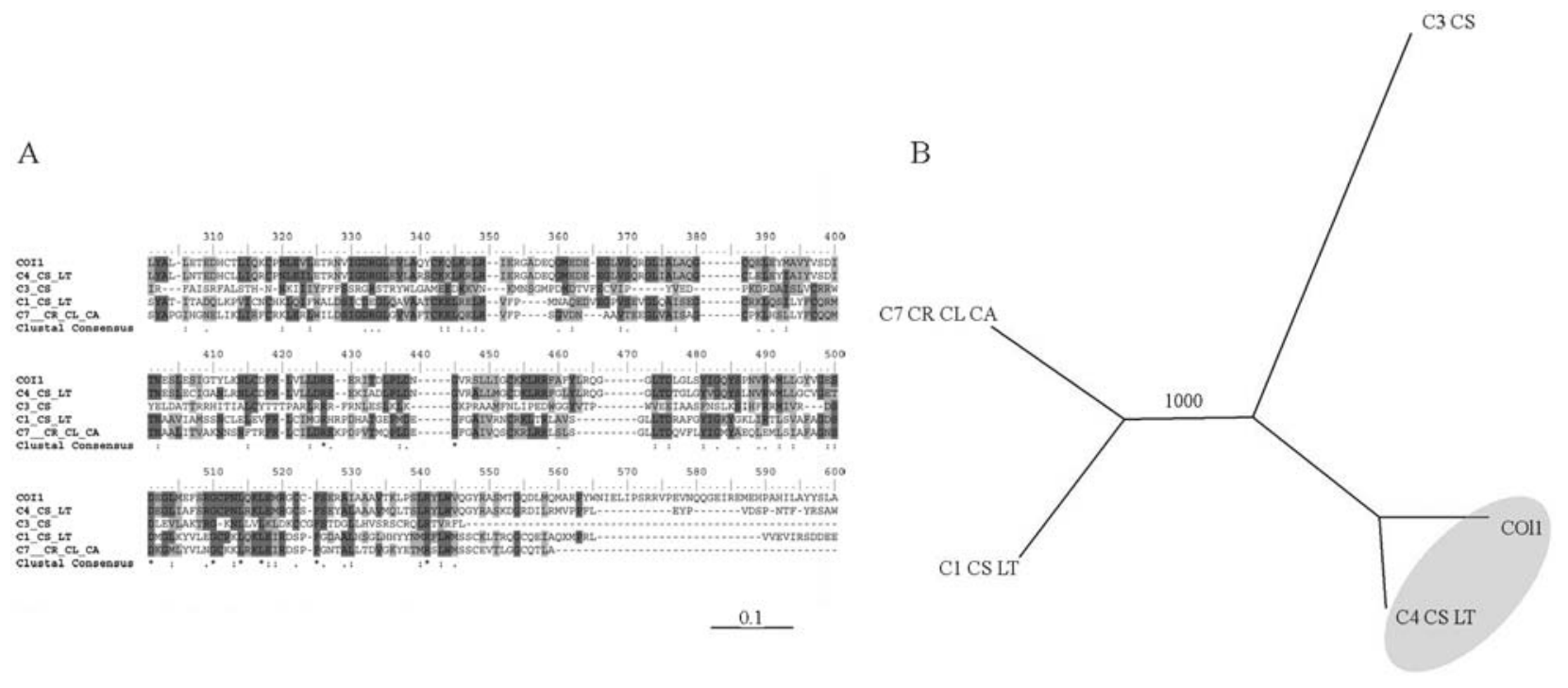

Figure 3 - Jasmonates-mediated signal transduction in citrus. Alignment of the degenerated F-box domain from A. thaliana and citrus COI1 proteins. Phylogenetic analyses of the deduced amion acid sequence of citrus COI1 homologs and full length $A$. thaliana counterpart. Phylogenetic analysis was performed as described. Shaded circle represents the AtCOI1 branch.

Arabidopsis counterpart. The other seven cDNAS from citrus present intermediate (from 44 to $28 \%$ ) deduced amino acid identity to AtMPK4 (Table S12).

The expression of some JA-responsive genes is controlled in part by AP2/ERF-domain transcription factors (Yanhui et al., 2006). These proteins bind to "jasmonateand elicitor-responsive elements" (JEREs) (van der Fits and Memelink, 2001). In citrus, several homologs of JAinduced transcriptional regulators were identified: including the development regulators AS1, ATAF2 and CPC (He and Gan, 2001; Delessert et al., 2005; Kwak et al., 2005); the basic-loop-helix JIN1 (Boter et al., 2004); the homeobox OCP3 (Coego et al., 2005); and the MYB telomere repeat-binding family of TRF1 and TRFL proteins (Yanhui et al., 2006) (Table S12). In citrus, JA-induced transcriptional regulators are highly frequent in biotic stress- and senescence-associated libraries, although distinct classes of factors show non-overlapping expression patterns (Figure 4).

\section{Peptide hormones}

Recently, a novel class of non-lipophilic peptide hormones was identified in several plant species, including $A$. thaliana, Solanum tuberosum and S. lycopersicum. Several secretory and non-secretory peptide signals have been demonstrated to be involved in plant growth regulation: including defense responses, callus growth, meristem organization, self-incompatibility (SI), root growth, leaf-shape regulation, nodule development, and organ abscission (Matsubayashi and Sakagami, 2006). These peptides have been identified by biochemical purification, genetic studies and in silico genome analysis. In general, they consist of a great number of highly-homologous genes that encode short open reading frames that are transcribed and translated at very low levels but severely affect plant develop-

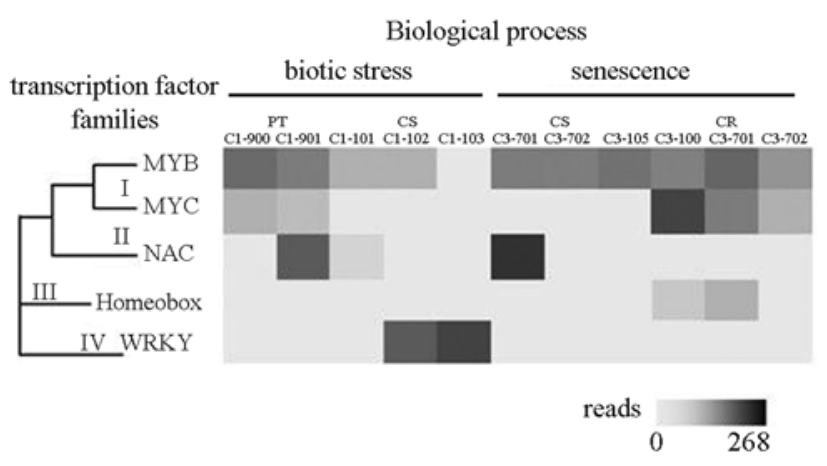

Figure 4 - Differential expression of JA-induced transcription factors in citrus. The normalized number of transcription factor homologous reads in each library is represented as grayscale. Citrus species libraries are represented by two-word abbreviations (CS, C. sinensis; CR, C. reticulata; CL, C. limonia; CG, C. aurantifolia; CA, Citrus aurantium; LT, C. latifólia; PT, Poncirus trifoliata). Hierarchical clustering of the expression patterns is represented by Roman numerals.

ment (Wen et al., 2004). In the CitEST database, we have identified 15 ESTs showing strong sequence similarity to previously characterized plant peptide hormones (Table S13). Interestingly, a large group of peptide hormones was absent from the screened citrus databases: including Solanum lycopersicum systemins (TomSys), S. lycopersicum and $A$. thaliana small, secreted, cysteine rich proteins (SCR/SP11, SCRL), A. thaliana inflorescence deficient in abscission (IDA) and IDA-like (IDL), A thaliana POLARIS (PLS), A. thaliana CLAVATA3 and CLV3-like (CLV3, CLE and approximately another 100 similar sequences). Although this absence is unexpected, it might be attributed to the undetectable levels of expression of peptide hormone genes in wild type plants (Wen et al., 2004). In addition, the expression pattern of PSK1 and BRI1 
homologs was distinct from the profile obtained for RALFL homologs: the normalized frequency of RALFLlike reads was higher in all species, including in C. limoni, C. aurantifolia, C. aurantium and C. latifolia that presented no PSK1 and BRI1 homolog (Figure 5).

\section{Salicylic acid}

SA belongs to a group of plant phenolics that possesses an aromatic ring bearing a hydroxyl group or its functional derivative. It was called a plant hormone by Raskin (Raskin, 1992a; Raskin, 1992b). Recently, SA has been demonstrated to be involved in various physiological processes like stomatal closure, flowering induction, and heat production, besides playing a central role in defense responses against biotic and abiotic stresses (Raskin, 1992a; Lee et al., 1995). In planta SA levels are probably the result of de novo synthesis (Yalpani et al., 1993); thus biosynthesis and metabolism knowledge functions as control steps for manipulating disease resistance.

In plants, the biosynthesis of SA consists of two parallel routes (Wildermuth et al., 2001). In citrus transcriptome analyses, we have found 33 sequences with high similarity to Arabidopsis components of SA metabolism: 26 for biosynthesis and seven for its catabolism. The first SA biosynthetic pathway is derived from shikimic acid. Firstly, chorismate is converted to prephenate, and prephe-

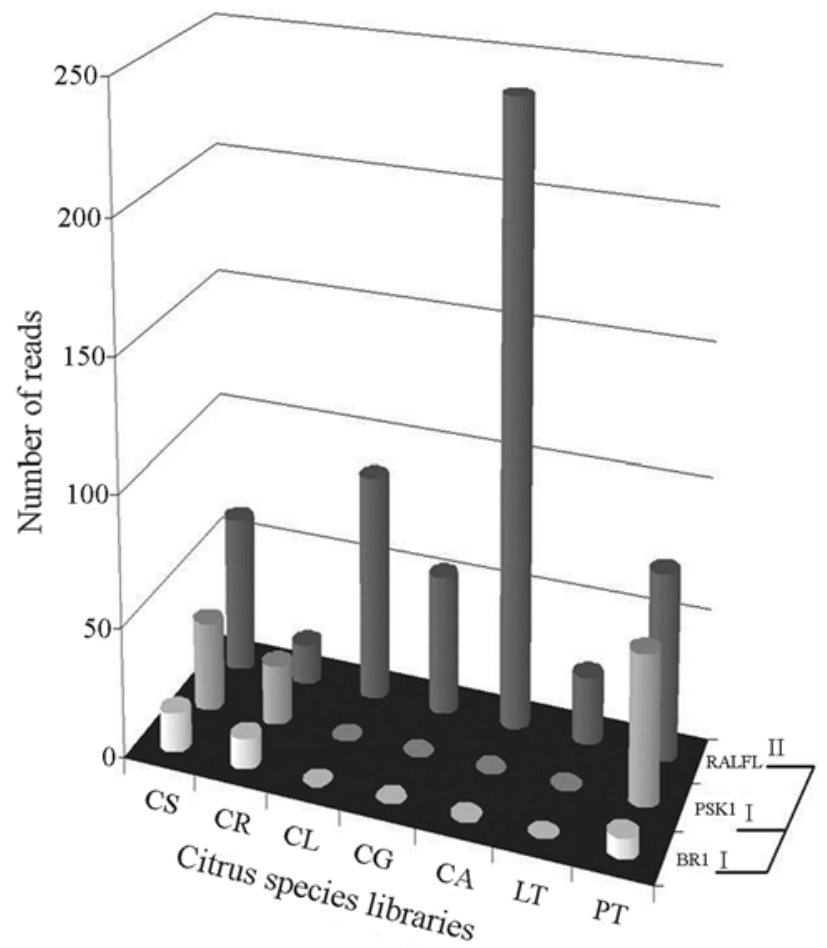

Figure 5 - Differential expression of peptide hormones in citrus species. The normalized number of reads for the transcripts in each library is represented in the y-axis. Citrus species libraries are represented by two-word abbreviations (CS, C. sinensis; CR, C. reticulata; CL, C. limonia; $\mathrm{CG}, C$. aurantifolia; CA, Citrus aurantium; LT, C. latifolia; PT, Poncirus trifoli$a t a)$. Hierarchical clustering of the expression patterns is represented by Roman numerals. nate to phenylpyruvate that is subsequently converted to phenylalanine by the action of the enzymes chorismate mutase $(\mathrm{CM})$, prephenate dehydratase (PD) and phenylpyruvate amino transferase, respectively (Warpeha et al., 2006). Trans-cinnamic acid (CA) is synthesized from Phe by the action of Phe ammonia lyase (PAL). The production of benzoic acid (BA) from CA is not well understood and it could be step-limiting in SA biosynthesis. BA2H, the monooxygenase responsible for the conversion of BA to SA conjugates, is constitutively expressed in tobacco and is highly induced by the TMV inoculation in this species, just before the onset of HR-cell death, as well as under UV irradiation, or exposure to $\mathrm{O}_{3}$ (Leon et al., 1995, Chong et al., 2001). This step is also responsible for stress-induced flowering of Pharbitis nil (Hatayama and Takeno, 2003). BA2H is the first soluble cytochrome P450 identified in plants and animals, but no coding sequence is yet known in plants.

A second pathway for the synthesis of SA has been recently shown in plants (Wildermuth et al., 2001). Chorismate is converted to isochorismate by isochorismate-synthase (ICS) and then to SA and pyruvate, probably due to the action of pyruvate lyase (IPL). In citrus transcriptome survey, we have identified one transcript homologous to Arabidopsis ICS1 gene covering the chorismate-binding region (Table S14). In model species, SAR responses require SA synthesized through ICS1. Interestingly, three of the four C. sinensis ESTs forming the contig C1-CR/CS originated from libraries of infected leaves.

In plants, $\mathrm{SA}$ is present as a free acid and as conjugated metabolites: SA 2-O- $\beta$-D-glucoside (SAG), glucosyl salicylate (GS) and methylsalicylate (MeSA) (Lee and Raskin, 1999). GS formation is transiently induced under pathogen attack and serves as a protective mechanism from the phytotoxic effects of high concentrations of SA (Lee and Raskin, 1999). In citrus transcriptome, four ESTs presented relatively high similarity to tobacco SA GTase. The methylation of SA into methyl-salicylate (MeSA) is mediated by a carboxyl methyl transferase that has salicylic acid (SAMT) as specificity of substrate. This enzyme belongs to a recently described family named 'SABATH' with reference to model proteins (D'Auria et al., 2003). In citrus, we have identified four homologs to benzoic acid/salicylic acid:carboxyl methyl transferases (Table S14). The deduced amino acid sequences of these transcripts are highly conserved at the SA-binding critical residues in comparison to their tobacco counterparts (Zubieta et al., 2003).

We have found 70 homologs of genes involved in SA signaling pathway (Table S15). Plant-pathogen interactions trigger a complex network of regulatory processes among phytohormone-controlled pathways, including the antagonism between SA and JA signaling. In Arabidopsis, AtMPK4, WRKY70 and SSI2 have been demonstrated to have cross-talk intermediates and are discussed in JA subsection. Interestingly, $A C D 6$ homologs were absent from citrus transciptome. They encode a novel ankyrin repeat- 
containing protein that participates in cell death control and probably has overlapping and/or redundant functions with other proteins. NDR1, a protein of unknown function, hypothesized to be a transducer of pathogen signals and/or to interact directly with pathogens, is represented by two homologous sequences in citrus EST databases.

Transcripts corresponding to the proteins forming the EDS1-PAD4-SAG101 complex were identified in citrus. These proteins present sequence similarity to acyl hydrolases, reinforcing the role of lipid signals in defense responses and indicating another probable cross-talk point in SA and JA/ET signaling (Wiermer et al., 2005). NPR1 and its homologous NPR4 are represented by two and seven homologs in citrus species, respectively. NPR1 plays a central regulator role in SA signaling and plant defense responses and NPR4 is required for the basal defense against pathogens.

Remarkably, we have found four sequences with high sequence similarity to SABP2 in citrus transcriptome. In Arabidopsis, it displays SA-stimulated lipase activity essential for basal resistance (Kumar and Klessig, 2003; Wiermer et al., 2005). It has been thought to be the longsought-after SA receptor; however, recent evidence has implicated it in the hydrolysis of inactive MeSA to SA (Forouhar et al., 2005). More interestingly, citrus SABP2 displays higher levels of sequence conservation to a $C$. sinensis transcript coding for an ethylene-induced esterase (Zhong et al., 2001). This suggests the existence of a direct link between SA- and ET-mediated signaling pathways.
The SA-responsive genes are mainly regulated by a set of transcription factors that includes TGA, WRKY70 and WHIRLY1, which are present in citrus transcription databases. TGA constitutes a conserved plant subfamily of NPR1-regulated basic domain/Leu zipper (bZIP) transcription factors associated with detoxification and defense (Klinedinst et al., 2000; Pontier et al., 2001). The most important NPR1-interacting TGA factors are TGA2 and TGA3 that are represented by several transcripts in citrus. In Arabidopsis, WHY1 is dependent on SA but it functions in an NPR1-independent manner to induce plant defense gene expression and to mediate SAR (Desveaux et al., 2004). This type of regulator response confirms that SA signaling has an NPR1-independent branch. The great similarity observed between the citrus and Arabidopsis transcripts probably reflects functional conservation between the species. Another interesting finding is the high sequence conservation observed between VAD1 and two citrus transcripts. VAD1 is hypothesized to represent a new function in cell-death control associated to cells in the vicinity of vascular bundles. It contains a GRAM domain that functions in membrane-associated processes to protein or lipid binding (Lorrain et al., 2004).

\section{Concluding Remarks}

This preliminary survey of citrus components of hormone-associated pathway has provided useful information for further studies of developmental control in these spe-

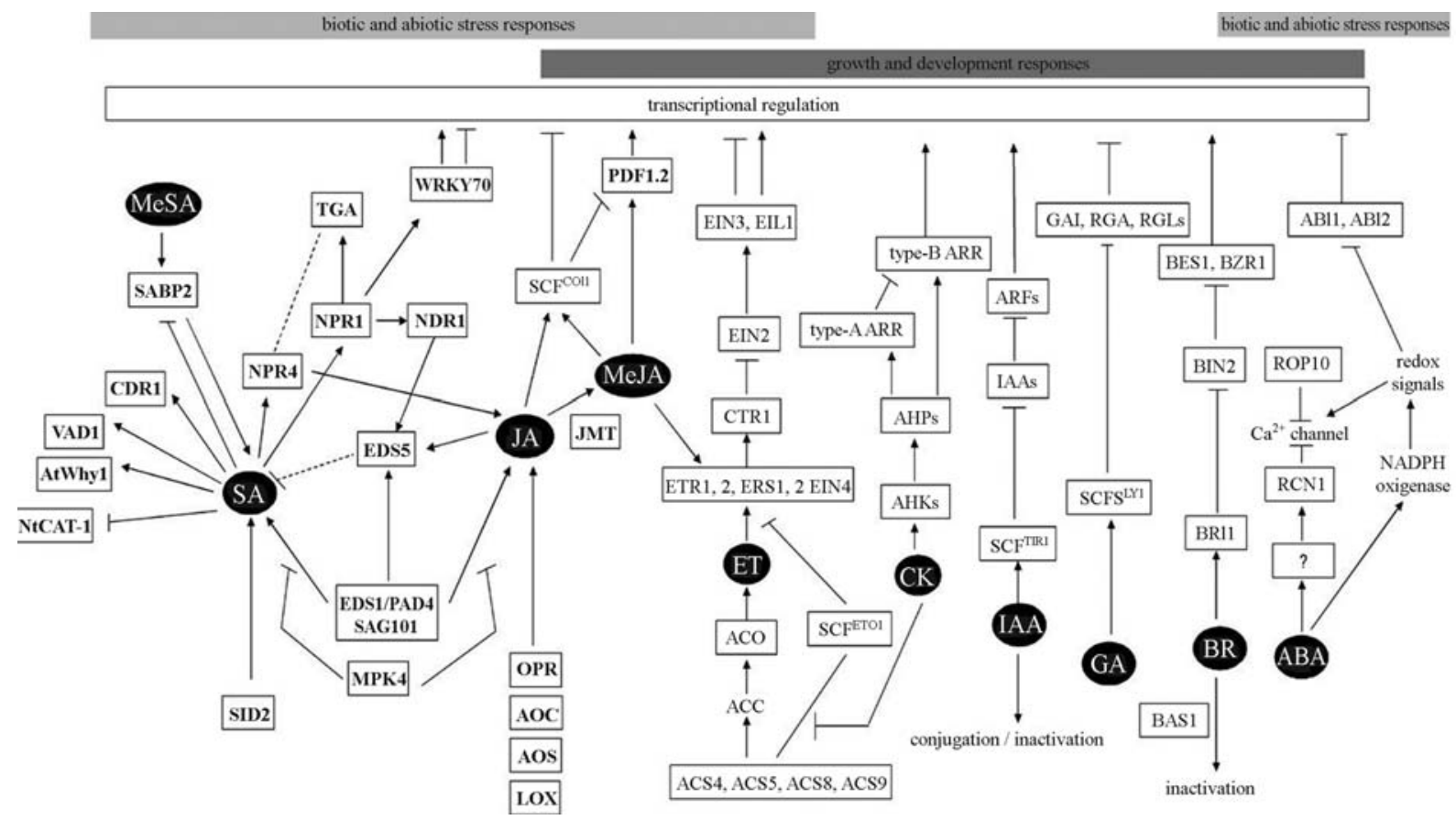

Figure 6 - Schematic representation of citrus hormone signaling pathways controlling stress and developmental responses. Phytohormones are represented by black circles and pathway components are shown in white boxes. Full lines represent genetic and direct interactions and dashed lines show hypothesized interactions. Arrowheads demonstrate positive interactions; lines without arrowheads are for interactions where directionality is unknown and blocked lines represent negative interactions. For clarity reasons, not all relevant genes or interactions have been shown. 
cies. It has allowed the identification of conserved members of signaling pathways in a non-model species and the elaboration of a framework for future studies (Figure 6). The results obtained here indicate high conservation in hormone biosynthetic pathways between model species and citrus. Signaling pathways are generally less conserved, although the vast majority of investigated processes were identified in citrus species (Figure 6). These studies will help to elucidate the molecular basis of developmental control and to understand how environmental factors modulate plant development and the expression of phenotypic characters. The results obtained give a new perspective on several aspects of hormonal regulation of physiological processes in citrus.

\section{Acknowledgments}

The work in the authors' laboratories is supported by CNPq and FAPESP. J.B.M.M.is a recipient of a CAPESPRODOC fellowship. The CITEST project was sponsored by grants from $\mathrm{CNPq} /$ Institutos do Milênio/Citrus 620054/01-8 to Marcos A. Machado.

\section{References}

Achard P, Herr A, Baulcombe DC and Harberd NP (2004) Modulation of floral development by a gibberellin-regulated microRNA. Development 131:3357-3365.

Alonso JM, Hirayama T, Roman G, Nourizadeh S and Ecker JR (1999) EIN2, a bifunctional transducer of ethylene and stress responses in Arabidopsis. Science 284:2148-2152.

Alonso JM, Stepanova AN, Solano R, Wisman E, Ferrari S, Ausubel FM and Ecker JR (2003) Five components of the ethylene-response pathway identified in a screen for weak ethylene-insensitive mutants in Arabidopsis. Proc Natl Acad Sci USA 100:2992-2997.

Altschul SF, Madden TL, Schäffer AA, Zhang J, Zhang Z, Miller W and Lipman DJ (1997) Gapped BLAST and PSI-BLAST: A new generation of protein database search programs. Nucleic Acids Res 25:3389-3402.

Amador V, Monte E, García-Martínez J-L and Prat S (2001) Gibberellins signal nuclear import of PHOR1, a photoperiodresponsive protein with homology to Drosophila ARMADILLO. Cell 106:343-354.

Assmann SM (2004) Plant G proteins, phytohormones, and plasticity: Three questions and a speculation. Sci STKE re20, www.stke.org/cgi/content/full/sigtrans;2004/264/re20.

Bartel B (1997) Auxin biosynthesis. Annu Rev Plant Physiol Plant Mol Biol 48:51-66.

Bassel GW, Zielinska E, Mullen RT and Bewley JD (2004) Down-regulation of DELLA genes is not essential for germination of tomato, soybean, and Arabidopsis seeds. Plant Physiol 136:2782-2789.

Bolle C (2004) The role of GRAS proteins in plant signal transduction and development. Planta 218:683-692.

Boter M, Ruiz-Rivero O, Abdeen A and Prat S (2004) Conserved MYC transcription factors play a key role in jasmonate signaling both in tomato and Arabidopsis. Genes Dev 18:1577-1591.
Browse J (2005) Jasmonate: An oxylipin signal with many roles in plants. Vitam Horm 72:431-456.

Burkle L, Cedzich A, Dopke C, Stransky H, Okumoto S, Gillissen B, Kuhn C and Frommer WB (2003) Transport of cytokinins mediated by purine transporters of the PUP family expressed in phloem, hydathodes, and pollen of Arabidopsis. Plant J 34:13-26.

Callis J (2005) Auxin action. Nature 435:436-437.

Chae HS and Kieber JJ (2005) Eto Brute? Role of ACS turnover in regulating ethylene biosynthesis. Trends Plant Sci 10:291296.

Chen YF, Randlett MD, Findell JL and Schaller GE (2002) Localization of the ethylene receptor ETR1 to the endoplasmic reticulum of Arabidopsis. J Biol Chem 277:19861-19866.

Chen YF, Etheridge N and Schaller GE (2005) Ethylene signal transduction. Ann Bot 95:901-915.

Cheong JJ and Choi YD (2003) Methyl jasmonate as a vital substance in plants. Trends Genet 19:409-413.

Choi YH, Fujioka S, Harada A, Yokota T, Takatsuto S, Noguchi $\mathrm{T}$, Watanabe $\mathrm{T}$, Kuriyama $\mathrm{H}$, Yokota $\mathrm{T}$, Chory $\mathrm{J}$, et al. (1996) A brassinolide biosynthetic pathway via 6-deoxocastasterone. Phytochemistry 43:593-596.

Chong J, Pierrel MA, Atanassova R, Werck-Reichhart D, Fritig B and Saindrenan P (2001) Free and conjugated benzoic acid in tobacco plants and cell cultures. Induced accumulation upon elicitation of defense responses and role as salicylic acid precursors. Plant Physiol 125:318-28.

Coego A, Ramirez V, Gil MJ, Flors V, Mauch-Mani B and Vera P (2005) An Arabidopsis homeodomain transcription factor, OVEREXPRESSOR OF CATIONIC PEROXIDASE 3, mediates resistance to infection by necrotrophic pathogens. Plant Cell 17:2123-2137.

Cohen JD, Slovin JP and Hendrickson AM (2003) Two genetically discrete pathways convert tryptophan to auxin: More redundancy in auxin biosynthesis. Trends Plant Sci 8:197199.

Cutler AJ and Krochko JE (1999) Formation and breakdown of ABA. Trends Plant Sci 4:472-478.

D'Auria JC, Chen F and Pichersky E (2003) The SABATH family of methyltransferases in Arabidopsis thaliana and other plant species. Rec Adv Phytochem 37:95-125.

Davies PJ (1995) Plant Hormones: Physiology, Biochemistry and Molecular Biology. Kluwer Academic Press, Dordrecht, $833 \mathrm{pp}$.

Delessert C, Kazan K, Wilson IW, Van Der Straeten D, Manners J, Dennis ES and Dolferus R (2005) The transcription factor $A T A F 2$ represses the expression of pathogenesis-related genes in Arabidopsis. Plant J 43:745-757.

Desveaux D, Subramaniam R, Despres C, Mess JN, Levesque C, Fobert PR, Dangl JL and Brisson N (2004) A "Whirly" transcription factor is required for salicylic acid-dependent disease resistance in Arabidopsis. Dev Cell 6:229-40.

Devoto A, Nieto-Rostro M, Xie D, Ellis C, Harmston R, Patrick E, Davis J, Sherratt L, Coleman M and Turner JG (2002) COI1 links jasmonate signalling and fertility to the SCF ubiquitin-ligase complex in Arabidopsis. Plant J 32:457-466.

Dharmasiri N, Dharmasiri S and Estelle M (2005) The F-box protein TIR1 is an auxin receptor. Nature 435:441-445.

Eckardt NA (2001) New insights into auxin biosynthesis. Plant Cell 13:1-3. 
Ehsan H, Ray WK, Phinney B, Wang X, Huber SC and Clouse SD (2005) Interaction of Arabidopsis BRASSINOSTEROIDINSENSITIVE 1 receptor kinase with a homolog of mammalian TGF-beta receptor interacting protein. Plant $\mathrm{J}$ 43:251-261.

Eisen MB, Spellman PT, Brown PO and Botstein D (1998) Cluster analysis and display of genome-wide expression patterns. Proc Natl Acad Sci USA 5:14863-14868.

Feng S, Ma L, Wang X, Xie D, Dinesh-Kumar SP, Wei N and Deng XW (2003) The COP9 signalosome interacts physically with SCF COI1 and modulates jasmonate responses. Plant Cell 15:1083-1094.

Ferreira FJ and Kieber JJ (2005) Cytokinin signaling. Curr Opin Plant Biol 8:518-525.

Fleet CM and Sun T-P (2005) A DELLAcate balance: The role of gibberellin in plant morphogenesis. Curr Opin Plant Biol 8:77-85.

Forouhar F, Yang Y, Kumar D, Chen Y, Fridman E, Park SW, Chiang Y, Acton TB, Montelione GT, Pichersky E, et al. (2005) Structural and biochemical studies identify tobacco SABP2 as a methyl salicylate esterase and implicate it in plant innate immunity. Proc Natl Acad Sci USA 102:17731778.

Fujioka S and Yokota T (2003) Biosynthesis and metabolism of brassinosteroids. Annu Rev Plant Biol 54:137-164.

Gao Z, Chen YF, Randlett MD, Zhao XC, Findell JL, Kieber JJ and Schaller GE (2003) Localization of the Raf-like kinase CTR1 to the endoplasmic reticulum of Arabidopsis through participation in ethylene receptor signaling complexes. J Biol Chem 278:34725-34732.

Gazzarrini S and McCourt P (2003) Cross-talk in plant hormone signalling: What Arabidopsis mutants are telling us. Ann Bot 91:605-612.

Gómez-Cadenas A, Mehouachi J, Tadeo FR, Primo-Millo E and Talon M (2000) Hormonal regulation of fruitlet abscission induced by carbohydrate shortage in citrus. Planta 210:636643.

Gómez-Cadenas A, Tadeo FR, Talon M and Primo-Millo E (1996) Leaf abscission induced by ethylene in waterstressed intact seedlings of Cleopatra mandarin requires previous abscisic acid accumulation in roots. Plant Physiol 112 :401-408.

Gray WM (2004) Hormonal regulation of plant growth and development. PLoS Biol 2:1270-1273, www.plosbiology.org.

Gray WM, Kepinski S, Rouse D, Leyser O and Estelle M (2001) Auxin regulates $\mathrm{SCF}^{\mathrm{TIR} 1}$-dependent degradation of AUX/IAA proteins. Nature 414:271-276.

Grefen C and Harter K (2004) Plant two-component systems: Principles, functions, complexity and cross talk. Planta 219:733-742.

Gubler F, Chandler PM, White RG, Llewellyn DJ and Jacobsen JV (2002) Gibberellin signaling in barley aleurone cells: Control of SLN1 and GAMYB expression. Plant Physiol 129:191-200

Guo H and Ecker JR (2003) Plant responses to ethylene gas are mediated by $\mathrm{SCF}(\mathrm{EBF} 1 / \mathrm{EBF} 2)$-dependent proteolysis of EIN3 transcription factor. Cell 115:667-677.

Guo H and Ecker JR (2004) The ethylene signaling pathway: New insights. Curr Opin Plant Biol 7:40-49.

Hatayama T and Takeno K (2003) The metabolic pathway of salicylic acid rather than of chlorogenic acid is involved in the stress-induced flowering of Pharbitis nil. J Plant Physiol 160:461-7.

Haywood V, Yu TS, Huang NC and Lucas WJ (2005) Phloem long-distance trafficking of GIBBERELLIC ACIDINSENSITIVE RNA regulates leaf development. Plant J 42:49-68.

He JX, Gendron JM, Sun Y, Gampala SS, Gendron N, Sun CQ and Wang ZY (2005) BZR1 is a transcriptional repressor with dual roles in brassinosteroid homeostasis and growth response. Science 307:1634-1638.

$\mathrm{He} \mathrm{Y}$ and Gan S (2001) Identical promoter elements are involved in regulation of the OPR1 gene by senescence and jasmonic acid in Arabidopsis. Plant Mol Biol 47:595-605.

He Y, Fukushige H, Hildebrand DF and Gan S (2002) Evidence supporting a role of jasmonic acid in Arabidopsis leaf senescence. Plant Physiol 128:876-884.

Hedden P and Phillips AL (2000) Gibberellin metabolism: New insights revealed by the genes. Trends Plant Sci 5:523-230.

Helliwell CA, Sheldon CC, Olive MR, Walker AR, Zeevaart JA, Peacock WJ and Dennis ES (1998) Cloning of the Arabidopsis ent-kaurene oxidase gene GA3. Proc Natl Acad Sci USA 95:9019-9024.

Helliwell CA, Sullivan JA, Mould RM, Gray JC, Peacock WJ and Dennis ES (2001) A plastid envelope location of Arabidopsis ent-kaurene oxidase links the plastid and endoplasmic reticulum steps of the gibberellin biosynthesis pathway. Plant J 28:201-208.

Himmelbach A, Yang Y and Grill E (2003) Relay and control of abscisic acid signaling. Curr Opin Plant Biol 6:470-479.

Hua J and Meyerowitz EM (1998) Ethylene responses are negatively regulated by a receptor gene family in Arabidopsis thaliana. Cell 94:261-271.

Hull AK, Vij R and Celenza JL (2000) Arabidopsis cytochrome P450s that catalyze the first step of tryptophan-dependent indole-3-acetic acid biosynthesis. Proc Natl Acad Sci USA 97:2379-2384.

Huntley RP, Jones LH and Hanke DE (2002) Cytokinins and gibberellins in sap exudate of the oil palm. Phytochemistry 60:117-127.

Jacobsen SE, Binkowski KA and Olszewski NE (1996) SPINDLY, a tetratricopeptide repeat protein involved in gibberellin signal transduction in Arabidopsis. Proc Natl Acad Sci USA 93:9292-9296.

Jensen AB, Raventos D and Mundy J (2002) Fusion genetic analysis of jasmonate-signalling mutants in Arabidopsis. Plant J 29:595-606.

Kagaya Y, Hobo T, Murata M, Ban A and Hattori T (2002) Abscisic acid-induced transcription is mediated by phosphorylation of an abscisic acid response element binding factor, TRAB1. Plant Cell 14:3177-3189.

Kakimoto T (2001) Identification of plant cytokinin biosynthetic enzymes as dimethylallyl diphosphate: ATP/ADP isopentenyltransferases. Plant Cell Physiol 42:677-685.

Kieber JJ, Rothenberg M, Roman G, Feldmann KA and Ecker JR (1993) CTR1, a negative regulator of the ethylene response pathway in Arabidopsis, encodes a member of the raf family of protein kinases. Cell 72:427-441.

Kim HJ, Ryu H, Hong SH, Woo HR, Lim PO, Lee IC, Sheen J, Nam HG and Hwang I (2006) Cytokinin-mediated control of leaf longevity by AHK3 through phosphorylation of 
ARR2 in Arabidopsis. Proc Natl Acad Sci USA 103:814819.

Klinedinst S, Pascuzzi P, Redman J, Desai M and Arias J (2000) A xenobiotic-stress activated transcription factor and its cognate target genes are preferentially expressed in root tip meristem. Plant Mol Biol 42:679-688.

Kobayashi Y, Murata M, Minami H, Yamamoto S, Kagaya Y, Hobo T, Yamamoto A and Hattori T (2005) Abscisic acidactivated SNRK2 protein kinases function in the gene-regulation pathway of ABA signal transduction by phosphorylating ABA response-binding factors. Plant J 44:939-949.

Koiwai H, Nakaminami K, Seo M, Mitsuhashi W, Toyomasu T and Koshiba T (2004) Tissue-specific localization of an abscisic acid biosynthetic enzyme, AAO3, in Arabidopsis. Plant Physiol 134:1697-1707.

Kumar D and Klessig DF (2003) High-affinity salicylic acidbinding protein 2 is required for plant innate immunity and has salicylic acid-stimulated lipase activity. Proc Natl Acad Sci USA 100:16101-6.

Kwak JM, Moon J-H, Murata Y, Kuchitsu K, Leonhard N, DeLong A and Schroeder JI (2002) Disruption of a guard cell-expressed protein phosphatases $2 \mathrm{~A}$ regulatory subunit, RCN1, confers abscisic acid insensitivity in Arabidopsis. Plant Cell 14:2849-2861.

Kwak SH, Shen R and Schiefelbein J (2005) Positional signaling mediated by a receptor-like kinase in Arabidopsis. Science 307:1111-1113.

Lee HI and Raskin I (1999) Purification, cloning, and expression of a pathogen inducible UDP-glucose:salicylic acid glucosyltransferase from tobacco. J Biol Chem 274:36637-36642.

Lee HI, Leon J and Raskin I (1995) Biosynthesis and metabolism of salicylic acid. Proc Natl Acad Sci USA 92:4076-9.

Lee S, Cheng H, King KE, Wang W, He Y, Hussain A, Lo J, Harberd NP and Peng J (2002) Gibberellin regulates Arabidopsis seed germination via $R G L 2$, a $G A I / R G A$-like gene whose expression is up-regulated following imbibition. Genes Dev 16:646-658.

Lemichez E, Wu Y, Sanchez J-P, Mettouchi A, Mathur J and Chua $\mathrm{N}-\mathrm{H}$ (2001) Inactivation of AtRacl by abscisic acid is essential for stomatal closure. Gene Dev 15:1808-1816.

Leon J, Lawton MA and Raskin I (1995) Hydrogen peroxide stimulates salicylic acid biosynthesis in tobacco. Plant Physiol 108:1673-1678.

Leyser O and Berleth T (1999) A molecular basis for auxin action. Cell Dev Biol 10:131-137.

Li J and Nam KH (2002) Regulation of brassinosteroid signaling by a GSK3/SHAGGY-like kinase. Science 295:1299-1301.

Li J, Wen J, Lease KA, Doke JT, Tax FE and Walker JC (2002) BAK1, an Arabidopsis LRR receptor-like protein kinase, interacts with BRI1 and modulates brassinosteroid signaling. Cell 110:213-222.

Li L and Deng XW (2005) It runs in the family: Regulation of brassinosteroid signaling by the BZR1-BES1 class of transcription factors. Trends Plant Sci 10:266-268.

Liebfried A, To JP, Busch W, Stehling S, Kehle A, Demar M, Kieber JJ and Lohmann JU (2005) WUSCHEL controls meristem function by direct regulation of cytokinin-inducible response regulators. Nature 438:1172-1175.

Liechti R, Gfeller A and Farmer EE (2006) Jasmonate signaling pathway. Sci STKE 322:cm2. [DOI: $10.1126 /$ stke. $3222006 \mathrm{~cm} 3]$
Lorrain S, Lin B, Auriac MC, Kroj T, Saindrenan P, Nicole M, Balague C and Roby D (2004) VASCULAR ASSOCIATED DEATH1, a novel GRAM domain-containing protein, is a regulator of cell death and defense responses in vascular tissues. Plant Cell 16:2217-32.

Lough TJ and Lucas WJ (2006) Integrative plant biology: Role of phloem long-distance macromolecular trafficking. Annu Rev Plant Biol 57:203-232.

Martin DN, Proebsting WM and Hedden P (1999) The SLENDER gene of pea encodes a gibberellin 2-oxidase. Plant Physiol 121:775-781.

Mason MG, Mathews DE, Argyros AD, Maxwell BB, Kieber JJ, Alonso JM, Ecker JR and Schaller GE (2006) Multiple type-B response regulators mediate cytokinin signal transduction in Arabidopsis. Plant Cell 17:3007-3018.

Matsubayashi Y and Sakagami Y (2006) Peptide hormones in plants. Annu Rev Plant Biol 57:649-674.

Matsui K, Fukutomi S, Ishii M and Kajiwara T (2004) A tomato lipase homologous to DAD1 (LeLID1) is induced in postgerminative growing stage and encodes a triacylglycerol lipase. FEBS Lett 569:195-200.

McGinnis KM, Thomas SG, Soule JD, Strader LC, Zale JM, Sun TP and Steber CM (2003) The Arabidopsis SLEEPY1 gene encodes a putative F-box subunit of an SCF E3 ubiquitin ligase. Plant Cell 15:1120-1130.

Mizuno T (2005) Two component phosphorelay signal transduction systems in plants: From hormone responses to circadian rhythms. Biosci Biotech Biochem 69:2263-2276.

Mora-Garcia S, Vert G, Yin Y, Cano-Delgado A, Cheong H and Chory J (2004) Nuclear protein phosphatases with Kelchrepeat domains modulate the response to brassinosteroids in Arabidopsis. Genes Dev 18:448-460.

Mustilli A-C, Merlot S, Vavasseur A, Fenzi F and Giraudat J (2002) Arabidopsis OST1 protein kinase mediates the regulation of stomatal aperture by abscisic acid and acts upstream of reactive oxygen species production. Plant Cell 14:3089-3099.

Nam KH and Li J (2002) BRI1/BAK1, a receptor kinase pair mediating brassinosteroid signaling. Cell 110:203-212.

Nam KH and Li J (2004) The Arabidopsis transthyretin-like protein is a potential substrate of BRASSINOSTEROIDINSENSITIVE 1. Plant Cell 16:2406-2417.

Nambara E and Marion-Poll A (2005) Abscisic acid biosynthesis and catabolism. Annu Rev Plant Biol 56:165-185.

Nambara E, Kawaide H, Kamiya Y and Naito S (1998) Characterization of an Arabidopsis thaliana mutant that has a defect in ABA accumulation: ABA-dependent and ABA-independent accumulation of free amino acids during dehydration. Plant Cell Physiol 39:853-858.

Noguchi T, Fujioka S, Choe S, Takatsuto S, Yoshida S, Yuan H, Feldmann KA and Tax FE (1999) Brassinosteroidinsensitive dwarf mutants of Arabidopsis accumulate brassinosteroids. Plant Physiol 121:743-752.

Normanly J and Bartel B (1999) Redundancy as a way of life: IAA metabolism. Curr Opin Plant Biol 2:207-213.

Olszewski N, Sun TP and Gubler F (2002) Gibberellin signaling: Biosynthesis, catabolism, and response pathways. Plant Cell 14:S61-S80.

Pandey S and Assmann SM (2004) The Arabidopsis putative G protein-coupled receptor GCR1 interacts with the g protein 
$\alpha$ subunit GPA1 and regulates abscisic acid signaling. Plant Cell 16:1616-1632.

Parry G and Estelle M (2006) Auxin receptors: A new role for F-box proteins. Curr Opin Cell Biol 18:152-156.

Peng J, Carol P, Richards DE, King KE, Cowling RJ, Murphy GP and Harberd NP (1997) The Arabidopsis GAI gene defines a signaling pathway that negatively regulates gibberellin responses. Genes Dev 11:3194-3205.

Peng J, Richards DE, Moritz T, Cano-Delgado A and Harberd NP (1999) Extragenic suppressors of the Arabidopsis gai mutation alter the dose-response relationship of diverse gibberellin responses. Plant Physiol 119:1199-1208.

Petersen M, Brodersen P, Naested H, Andreasson E, Lindhart U, Johansen B, Nielsen HB, Lacy M, Austin MJ and Parker JE (2000) Arabidopsis MAP KINASE 4 negatively regulates systemic acquired resistance. Cell 103:1111-1120.

Pintard L, Willems A and Peter M (2004) Cullin-based ubiquitin ligases: Cul3-BTB complexes join the family. EMBO J 23:1681-1687.

Piotrowski M, Schönfelder S and Weiler EW (2000) The Arabidopsis thaliana isogene NIT4 and its orthologs in tobacco encode $\beta$-cyoano-L-alanine hydratase/nitrilase. J Biol Chem 278:1708-1712.

Pontier D, Miao Z-H and Lam E (2001) Trans-dominant suppression of plant TGA factors reveals their negative and positive roles in plant defense responses. Plant J 27:529-538.

Porch TG, Tseung C-W, Schmelz EA and Settles AM (2006) The maize Viviparous10/Viviparous 13 locus encodes the Cnx 1 gene required for molybdenum cofactor biosynthesis. Plant J 45:250-263.

Potuschak T, Lechner E, Parmentier Y, Yanagisawa S, Grava S, Koncz C and Genschik P (2003) EIN3-dependent regulation of plant ethylene hormone signaling by two Arabidopsis $\mathrm{F}$ box proteins: EBF1 and EBF2. Cell 115:679-689.

Raskin I (1992a) Salicylate, a new plant hormone. Plant Physiol 99:799-803.

Raskin I (1992b) Role of salicylic acid in plants. Annu Rev Plant Physiol Plant Mol Biol 43:439-463.

Ren C, Pan J, Peng W, Genschik P, Hobbie L, Hellmann H, Estelle M, Gao B, Peng J and Sun C (2005) Point mutations in Arabidopsis CULLIN1 reveal its essential role in jasmonate response. Plant J 42:514-524.

Richards DE, King KE, Ait-Ali T and Harberd NP (2001) How gibberellin regulates plant growth and development: A molecular genetic analysis of gibberellin signaling. Annu Rev Plant Physiol Plant Mol Biol 52:67-88.

Riefler M, Novak O, Strnad M and Schmülling T (2006) Arabidopsis cytokinin receptor mutants reveal functions in shoot growth, leaf senescence, seed size, germination, root development, and cytokinin metabolism. Plant Cell 18:4054.

Ringli C, Hauf G and Keller B (2001) Hydrophobic interactions of the structural protein GRP1.8 in the cell wall of protoxylem elements. Plant Physiol 125:673-682.

Rodrigo M-J, Alquezar B and Zacarías L (2006) Cloning and characterization of two 9-cis-epoxycarotenoid dioxygenase genes, differentially regulated during fruit maturation and under stress conditions, from orange (Citrus sinensis L. Osbeck). J Exp Bot 57:633-643.

Rodrigo M-J, Marcos JF, Alférez F, Mallent MD and Zacarías L (2003) Characterization of Pinalate, a novel Citrus sinensis mutant with a fruit-specific alteration that results in yellow pigmentation and decreased ABA content. J Exp Bot 54:727-738.

Sablowski R and Harberd NP (2005) Plant genes on steroids. Science 307:1569-1570.

Saito S, Hirai N, Matsumoto C, Ohigashi H, Ohta D, Sakata K and Mizutani M (2004) Arabidopsis CYP707As encode (+)-abscisic acid 8'-hydroxylase, a key enzyme in the oxidative catabolism of abscisic acid. Plant Physiol 134:14391449.

Sakakibara H (2006) Cytokinins: Activity, biosynthesis, and translocation. Annu Rev Plant Biol 57:431-449.

Sakamoto T, Kobayashi M, Itoh H, Tagiri A, Kayano T, Tanaka $\mathrm{H}$, Iwahori S and Matsuoka M (2001) Expression of a gibberellin 2-oxidase gene around the shoot apex is related to phase transition in rice. Plant Physiol 125:1508-1516.

Schilmiller AL and Howe GA (2005) Systemic signaling in the wound response. Curr Opin Plant Biol 8:369-377.

Schomburg FM, Bizzell CM, Lee DJ, Zeevaart JA and Amasino RM (2003) Overexpression of a novel class of gibberellin 2-oxidases decreases gibberellin levels and creates dwarf plants. Plant Cell 15:151-163.

Seo HS, Song JT, Cheong JJ, Lee YH, Lee YW, Hwang I, Lee JS and Choi YD (2001) Jasmonic acid carboxyl methyltransferase: A key enzyme for jasmonate-regulated plant responses. Proc Natl Acad Sci USA 98:4788-4793.

Seo M, Peeters AJM, Koiwai H, Oritani T, Marion-Poll A, Zeevaart JAD, Koornneef M, Kamiya Y and Koshiba T (2000) The Arabidopsis aldehyde oxidase 3 (AAO3) gene product catalyses the final step in abscisic acid biosynthesis in leaves. Proc Natl Acad Sci USA 97:12908-12913.

Serino G and Deng XW (2003) The COP9 signalosome: Regulating plant development through the control of proteolysis. Annu Rev Plant Biol 54:165-182.

Shanmugam V (2005) Role of extracytoplasmic leucine rich repeat proteins in plant defence mechanisms. Microbiol Res 160:83-94.

Smalle J and Vierstra RD (2004) The ubiquitin 26s proteasome proteolytic pathway. Annu Rev Plant Physiol Plant Mol Biol 55:555-590.

Stepanova AN and Alonso JM (2005) Arabidopsis ethylene signaling pathway. Sci STKE cm4, www.stke.org/cgi/content/ full/sigtrans;2005/276/cm4.

Suzuki H, Fujioka S, Takatsuto S, Yokota T, Murofushi N and Sakurai A (1995) Biosynthesis of brassinosteroids in seedlings of Catharanthus roseus, Nicotiana tabacum, and Oryza sativa. Biosci Biotech Biochem 59:168-172.

Thomas SG, Phillips AL and Hedden P (1999) Molecular cloning and functional expression of gibberellin 2-oxidases, multifunctional enzymes involved in gibberellin deactivation. Proc Natl Acad Sci USA 96:4698-4703.

Thompson JD, Gibson TJ, Plewniak F, Jeanmougin F and Higgins DG (1997) The CLUSTALX windows interface: Flexible strategies for multiple sequence alignment aided by quality analysis tools. Nucleic Acids Res 25:4876-4882.

Thornton TM, Swain SM and Olszewski NE (1999) Gibberellin signal transduction presents ellipsis the SPY who O-GlcNAc'd me. Trends Plant Sci 4:424-428.

Tian AG, Luo GZ, Wang YJ, Zhang JS, Gai JY and Chen SY (2004) Isolation and characterization of a Ptil homologue from soybean. J Exp Bot 55:535-537. 
Tiwari SB, Hagen G and Guilfoyle TJ (2004) Aux/ IAA proteins contain a potent transcriptional repression domain. Plant Cell 16:533-543.

Tyler L, Thomas SG, Hu J, Dill A, Alonso JM, Ecker JR and Sun TP (2004) DELLA proteins and gibberellin-regulated seed germination and floral development in Arabidopsis. Plant Physiol 135:1008-1019.

Ueguchi-Tanaka M, Ashikari M, Nakajima M, Itoh H, Katoh E, Kobayashi M, Chow TY, Hsing YI, Kitano H, Yamaguchi I, et al. (2005) GIBBERELLIN INSENSITIVE DWARF1 encodes a soluble receptor for gibberellin. Nature 437:627628 .

van der Fits L and Memelink J (2001) The jasmonate-inducible AP2/ERF-domain transcription factor ORCA3 activates gene expression via interaction with a jasmonate-responsive promoter element. Plant J 25:43-53.

Verslues PE and Zhu J-K (2005) Before and beyond ABA: Upstream sensing and internal signals that determine ABA accumulation and response under abiotic stress. Biochem Soc Trans 33:375-379.

Vert G, Nemhauser JL, Geldner N, Hong F and Joanne Chory (2005) Molecular mechanisms of steroid hormone signaling in plants. Annu Rev Cell Dev Biol 21:177-201.

Wang XQ, Ullah H, Jones AM and Assmann SM (2001) G protein regulation of ion channels and abscisic acid signaling in Arabidopsis guard cells. Science 292:2070-2072.

Wang ZY, Nakano T, Gendron J, He J, Chen M, Vafeados D, Yang Y, Fujioka S, Yoshida S, Asami T, et al. (2002) Nuclear-localized BZR1 mediates brassinosteroid-induced growth and feedback suppression of brassinosteroid biosynthesis. Dev Cell 2:505-513.

Warpeha KM, Lateef SS, Lapik Y, Anderson M, Lee BS and Kaufman LS (2006) G-protein-coupled receptor 1, G-protein Galpha-subunit 1, and prephenate dehydratase 1 are required for blue light-induced production of phenylalanine in etiolated Arabidopsis. Plant Physiol 140:844-55.

Weijers D and Jürgens G (2004) Funneling auxin action: Specificity in signal transduction. Curr Opin Plant Biol 7:687-693.

Wen CK and Chang C (2002) Arabidopsis RGL1 encodes a negative regulator of gibberellin responses. Plant Cell 14:87-100.

Wen J, Lease KA and Walker JC (2004) DVL, a novel class of small polypeptides: Overexpression alters Arabidopsis development. Plant J 37:668-677.

Wiermer M, Feys BJ and Parker JE (2005) Plant immunity: The EDS1 regulatory node. Curr Opin Plant Biol 8:383-9.

Wildermuth MC, Dewdney J, Wu G and Ausubel FM (2001) Isochorismate synthase is required to synthesize salicylic acid for plant defence. Nature 414:562-5.

Woodward AW and Bartel B (2005) Auxin: Regulation, action and integration. Ann Bot 95:707-735.

Xin Z, Zhao Y and Zheng Z-L (2005) Transcriptome analysis reveals specific modulation of abscisic acid signaling by ROP10 small GTPase in Arabidopsis. Plant Physiol 139:1350-1365.

Xiong L and Zhu JK (2003) Regulation of abscisic acid biosynthesis. Plant Physiol 133:29-36.

Xiong L, Ishitani M, Lee H and Zhu JK (2001) The Arabidopsis $L O S 5 / A B A 3$ locus encodes a molybdenum cofactor sulfurase and modulates cold stress- and osmotic stress-responsive gene expression. Plant Cell 13:2063-2083.
Xiong L, Lee H, Ishitani M and Zhu JK (2002) Regulation of osmotic stress-responsive gene expression by the LOS6/ABA1 locus in Arabidopsis. J Biol Chem 277:8588-8596.

Yalpani N, Leon J, Lawton MA and Raskin I (1993) Pathway of salicylic acid biosynthesis in healthy and virus-inoculated tobacco. Plant Physiol 103:315-321.

Yanhui C, Xiaoyuan Y, Kun H, Meihua L, Jigang L, Zhaofeng G, Zhiqiang L, Yunfei Z, Xiaoxiao W, Xiaoming Q, et al. (2006) The MYB transcription factor superfamily of Arabidopsis: Expression analysis and phylogenetic comparison with the rice MYB family. Plant Mol Biol 60:107-124.

Yin Y, Vafeados D, Tao Y, Yoshida S, Asami T and Chory J (2005) A new class of transcription factors mediates brassinosteroid-regulated gene expression in Arabidopsis. Cell 120:249-259.

Yoo BC, Kragler F, Varkonyi-Gasic E, Haywood V, ArcherEvans S, Lee YM, Lough TJ and Lucas WJ (2004) A systemic small RNA signaling system in plants. Plant Cell 16:1979-2000.

Yoshida R, Umezawa T, Mizoguchi T, Takahashi S, Takahashi F and Shinozaki K (2006) The regulatory domain of SRK2E/OST1/SnRK2.6 interacts with ABI1 and integrates abscisic acid (ABA) and osmotic stress signals controlling stomatal closure in Arabidopsis. J Biol Chem 281:53105318.

Zhang X, Zhang L, Dong F, Gao J, Galbraith DW and Song CP (2001) Hydrogen peroxide is involved in abscisic acid-induced stomatal closure in Vicia faba. Plant Physiol 126:1438-1448.

Zhao Y, Christensen SK, Fankhauser C, Cashman JR, Cohen JD, Weigel D and Chory J (2001) A role for flavin monooxygenase-like enzymes in auxin biosynthesis. Science 291:306-309.

Zhong GY, Goren R, Riov J, Sisler EC and Holland D (2001) Characterization of an ethylene-induced esterase gene isolated from Citrus sinensis by competitive hybridization. Physiol Plant 113 :267-274.

Zhou R, Cutler AJ, Ambrose SJ, Galka MM, Nelson KM, Squires TM, Loewen MK, Jadhav AS, Ross ARS, Taylor DC, et al. (2004) A new abscisic acid catabolic pathway. Plant Physiol 134:361-369.

Zubieta C, Ross JR, Koscheski P, Yang Y, Pichersky E and Noel JP (2003) Structural basis for substrate recognition in the salicylic acid carboxyl methyltransferase family. Plant Cell 15:1704-1716.

\section{Internet Resources}

Citrus Biotechnology Laboratory, http://citest.centrodecitricultu ra.br (September 13, 2006).

Cluster v.2.11 Software, http://rana.lbl.gov/EisenSoftware.htm.

DNASTAR Lasergene Software, http://www.dnastar.com/web/ index.php.

European Bioinformatics Institute-European Molecular Biology Laboratory (EMBL-EBI), www.ebi.ac.uk/interpro/ (September 4, 2006).

Expert Protein Analysis System (ExPaSy), http://www.expasy. org/prosite/ and http://www.us.expasy.org/sprot/ (October $5,2006)$.

Gene Ontology (GO), http://www.godatabase.org/cgi-bin/amigo/ go.cgi (October 23, 2006). 
PAUP* 4.0b10 Software, http://paup.csit.fsu.edu/.

Protein Families (Pfam), http://www.sanger.ac.uk/Software/ Pfam/ (October 15, 2006).

PSIGNFIT Software, http://www.bootstrap-software.org/.

The Institute for Genomic Research (TIGR) Arabidopsis thaliana v.13.0 Gene Ontology Assignments, http://compbio.dfci. harvard.edu/tgi/cgi-bin/tgi/GO_browser.pl?species = Arabi dopsis\&gi_dir $=$ agi $($ October 23,2006$)$.

Tree View v.1.6 Software, http://rana.lbl.gov/EisenSoftware.htm.

\section{Supplementary Material} ticle:

The following online material is available for this ar-

Table S1

Table S2

Table S3

Table S4
Table S5

Table S6

Table S7

Table S8

Table S9

Table S10

Table S11

Table S12

Table S13

Table S14

Table S15

Supplemental References

Figure S1

Figure S2

This material is available as part of the online article from http://www.scielo.br/gmb.

Associate Editor: Marco Aurélio Takita 
Table S1-Citrus ESTs homologous to Arabidopsis and Oryza sativa functionally-characterized ABA biosynthesis and signaling pathway genes.

\begin{tabular}{|c|c|c|c|c|c|c|}
\hline \multicolumn{2}{|c|}{ Arabidopsis/Oryza sativa } & \multicolumn{3}{|l|}{ CitEST } & \multirow{2}{*}{$\begin{array}{l}\text { Protein motifs and } \\
\text { biological process }\end{array}$} & \multirow[b]{2}{*}{ References } \\
\hline Name $^{a}$ & Gene & $\mathbf{E S T}^{\mathrm{b}}$ & $\%^{c}$ & e value & & \\
\hline$A A O$ & AT5G20960 & C1-CS (2) & 70.0 & $5 e-86$ & $\begin{array}{c}\text { aldehyde oxidase; } \\
\text { molybdopterin-binding } \\
\text { domain; FAD-binding } \\
\text { domain, ABA } \\
\text { biosynthesis }\end{array}$ & Seo et al., 2000 \\
\hline ABA1/LOS6/ & AT5G67030 & C1-CS (4) & 70.0 & $1 \mathrm{e}-146$ & zeaxanthin epoxidase, & Peeters et al., 2002 \\
\hline$Z E P$ & & C2-PT (3) & 55.0 & $1 \mathrm{e}-137$ & ABA biosynthesis & \\
\hline$A B A 3$ & AT1G16540 & $\begin{array}{c}\text { C1-CS/PT (2) } \\
\text { PT11-C1-900-046-C09-CT }\end{array}$ & $\begin{array}{l}65.0 \\
65.0\end{array}$ & $\begin{array}{l}3 e-35 \\
3 e-35\end{array}$ & $\begin{array}{l}\text { selenocysteine lyase, } \\
\text { ABA biosynthesis }\end{array}$ & Xiong et al., 2001 \\
\hline$A B F 2 / A R E B 1$ & AT1G45249 & CS00-C3-705-096-D09-CT & 50.0 & $3 e-26$ & bZIP domain & $\begin{array}{l}\text { Kobayashi et al., } \\
2005\end{array}$ \\
\hline$G C R 1$ & AT1G48270 & C1-CS/CR (3) & 84.0 & $1 \mathrm{e}-129$ & cAMP receptor & $\begin{array}{c}\text { Pandey and } \\
\text { Assmann, } 2004\end{array}$ \\
\hline
\end{tabular}




\begin{tabular}{|c|c|c|c|c|c|c|}
\hline \multirow[t]{2}{*}{ GPAl } & \multirow[t]{2}{*}{ AT2G26300 } & C1-CS/CR/PT/LT (8) & 86.0 & 0 & G protein $\alpha$ domain; ARF- & Pandey and \\
\hline & & CS00-C3-704-024-D11-CT & 86.0 & 0 & like domain & Assmann, 2004 \\
\hline \multirow[t]{2}{*}{ NCED } & \multirow[t]{2}{*}{ AT3G63520 } & PT11-C1-900-054-G12-CT & 70.0 & $1 e-111$ & 9-cis-epoxicarotenoid & Iuchi et al., 2001 \\
\hline & & & & & dioxigenase, biosynthesis & \\
\hline \multirow[t]{2}{*}{ OST1 } & \multirow[t]{2}{*}{ AT4G33950 } & PT11-C1-900-002-B02-CT & 81.0 & $6 e-125$ & serine/threonine protein & Mustilli et al., \\
\hline & & & & & kinase, signal transduction & 2002 \\
\hline \multirow[t]{6}{*}{$R C N 1$} & \multirow[t]{6}{*}{ AT3G25800 } & $\mathrm{C} 2-\mathrm{CS} / \mathrm{CR} / \mathrm{CA}(10)$ & 87.0 & 0 & armadillo/beta-catenin- & \multirow[t]{6}{*}{ Kwak et al., 2002} \\
\hline & & C1- CS/CR (2) & 84.0 & $7 e-101$ & like repeats; HEAT & \\
\hline & & C3-CS/CG (2) & 80.0 & 0 & repeats, serine/threonine & \\
\hline & & PT11-C1-900-014-E10-CT & 30.5 & 1e-99 & phosphatase type $2 \mathrm{~A}$ & \\
\hline & & CA26-C1-002-092-H05-CT & 15.2 & $2 \mathrm{e}-62$ & regulatory subunit, signal & \\
\hline & & & & & transduction & \\
\hline \multirow[t]{4}{*}{$R O P 6 / R A C l$} & \multirow[t]{4}{*}{ AT3G51300 } & C2-CS/CR/CG (11) & 91.0 & $2 e-96$ & Ras-like small GTPase, & Lemichez et al., \\
\hline & & C5-CS (3) & 90.0 & $6 e-96$ & signal transduction & 2001 \\
\hline & & C1-CS/CR/CA (6) & 86.0 & 1e-95 & & \\
\hline & & C4-CS/CR/PT (6) & 82.0 & $1 \mathrm{e}-87$ & & \\
\hline
\end{tabular}




\begin{tabular}{|c|c|c|c|c|c|c|}
\hline & & C3-CR (2) & 78.0 & $8 \mathrm{e}-74$ & & \\
\hline & & CS00-C1-101-048-A07-CT & 90.9 & $2 \mathrm{e}-94$ & & \\
\hline & & CG32-C1-003-037-B10-CT & 56.95 & $3 e-48$ & & \\
\hline & & PT11-C1-901-020-E06-CT & 0.3 & $2 \mathrm{e}-84$ & & \\
\hline ROP10 & AT3G48040 & C1-CS/CA (3) & 84.0 & $4 \mathrm{e}-90$ & ROP family & Xin et al., 2005 \\
\hline & & $\mathrm{C} 2-\mathrm{CS}(2)$ & 71.0 & $2 \mathrm{e}-83$ & & \\
\hline OsTRAB1 & $\mathrm{CAB} 85632^{\mathrm{c}}$ & CS00-C3-705-096-D09-CT & 48.0 & $1 e-39$ & Zinc finger transcription & Hobo et al., 1999 \\
\hline & & & & & factor, signal transduction & \\
\hline$Z E P 1$ & AT5G67030 & CS00-C3-702-073-E06-CT & 70.0 & $1 \mathrm{e}-146$ & mono-oxygenase domain & Xiong et al., 2002 \\
\hline & & PT11-C2-300-033-E11-CT & 55.0 & $1 e-137$ & & \\
\hline
\end{tabular}

\footnotetext{
${ }^{\mathrm{a}}$ Gene name abbreviations: $A A O$ : ABA-aldehyde oxidase, $A B A$ : ABA deficient, $A B F$ : ABRE-binding bZIP factor, $A B R E$ : ABA responsive element, $G C R$ : G protein-coupled receptor, GPA: G protein a subunit, LOS: low expression of osmotic stress-responsive genes, NCED: 9-cis-epoxy-carotenoid dioxygenase, Os: Oryza sativa, OST: open stomata; RCN1: roots curl in NPA, ROP: RHO of plants, TRAB: transcription factor responsible for ABA regulation, ZEP: zeaxanthin epoxidase.

${ }^{\mathrm{b}} \mathrm{C}$ : contig, CA: Citrus aurantium, CG: Citrus aurantifolia, CR: Citrus reticulata, CS: Citrus sinensis, LT: Citrus latifolia, PT: Poncirus trifoliata, (number of reads).

${ }^{c}$ Identity percentage at the amino acid level.

${ }^{\mathrm{d}}$ GenBank accession number.
} 
Table S2 - Citrus ESTs homologous to Arabidopsis and Oryza sativa functionally-characterized auxin metabolism genes.

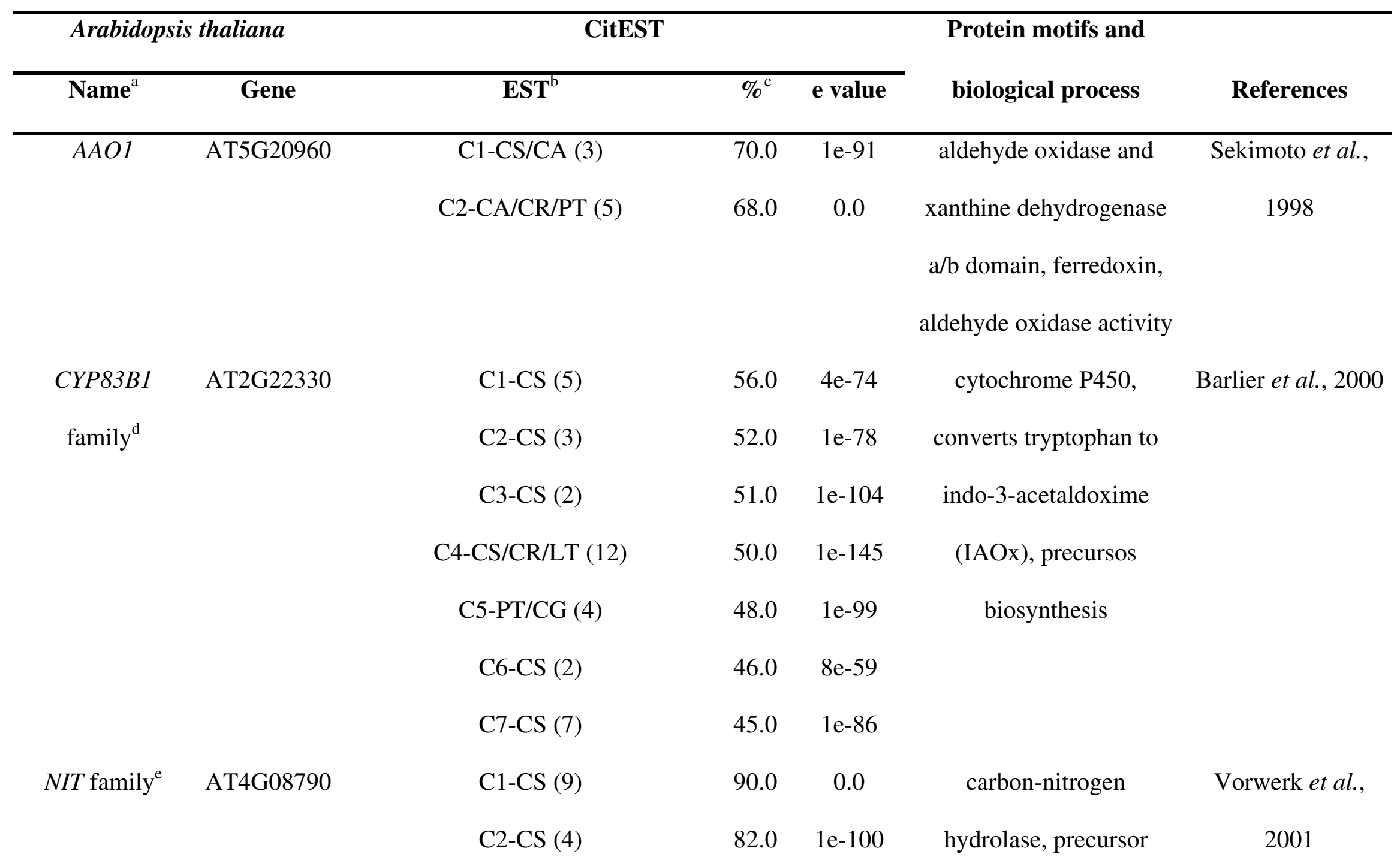


C3-CS (12) $\quad 67.0 \quad 8 \mathrm{e}-20 \quad$ biosynthesis

YUCCA family ${ }^{\mathrm{f}}$ AT4G32540

\section{C1-CR/CG/CS (9)}

C2-LT/CR/CG/CS (12)

C3-CS/LT/CR (21)

C4-CG (3)

C5-CR/CS/PT/CA/LT (30)
$50.0 \quad 1 \mathrm{e}-108$

flavin-containing

Zhao et al., 2001

50.0 1e-100 monooxygenase family,

$50.0 \quad 1 \mathrm{e}-88$ disulfide, monooxygenase

$49.0 \quad 5 e-92$

and oxidoreductase

$46.0 \quad 1 \mathrm{e}-103$

activity

${ }^{\mathrm{a}}$ Gene name abbreviations: $A A O$ : aldehyde oxidase, $C Y P$ : cytochrome P450, NIT: nitrilase, $Y U C C A$ : yucca tree.

${ }^{\mathrm{b}} \mathrm{C}$ : contig, CA: Citrus aurantium, CG: Citrus aurantifolia, CR: Citrus reticulata, CS: Citrus sinensis, LT: Citrus latifolia, PT: Poncirus trifoliata, (number of reads).

${ }^{\mathrm{c}}$ Identity percentage at the amino acid level.

${ }^{\mathrm{d}}$ CYP79B2 family in A. thaliana: AT4G31500, AT4G39950.

${ }^{\mathrm{e}}$ NIT family in A. thaliana: AT3G44310, AT3G44300.

${ }^{\mathrm{f}}$ YUCCA family in A. thaliana: AT1G04180, AT1G04610, AT1G21430, AT2G33230, AT4G13260, AT4G28720, AT5G11320, AT5G25620, AT5G43890. 
Table S3 - Citrus ESTs homologous to Arabidopsis functionally-characterized auxin signaling pathway genes.

\begin{tabular}{|c|c|c|c|c|c|c|}
\hline \multicolumn{2}{|c|}{ Arabidopsis thaliana } & \multicolumn{3}{|l|}{ CitEST } & \multicolumn{2}{|l|}{ Protein motifs ${ }^{\mathrm{d}}$ and } \\
\hline Name $^{a}$ & Gene & $\mathbf{E S T}^{\mathrm{b}}$ & $\%^{\mathrm{c}}$ & e value & biological process & References \\
\hline \multirow[t]{2}{*}{$A B P 1$} & AT4G02980 & CS00-C1-100-010-B05-CT & 79.0 & $3 e-78$ & unidimensional cell & Jones et al., 1998; \\
\hline & & & & & growth, auxin binding & Shimomura, 2006 \\
\hline \multirow[t]{9}{*}{$A R F$ family $^{\mathrm{e}}$} & AT1G59750 & C1-CG/CS/PT (7) ARF1 & 69.0 & $3 e-75$ & transcriptional factor B3 & Ulmasov et al., \\
\hline & & C2- PT/LT (3) ARF7 & 65.0 & 1e-151 & domain, auxin-mediated & 1997b; Okushima \\
\hline & & C3-CR (4) ARF7 & 55.0 & 1e-99 & transcriptional regulation & et al., 2005 \\
\hline & & C4-CS/CR (5) ARF7 & 54.0 & $1 \mathrm{e}-127$ & & \\
\hline & & C5- CS/CR/CL (5) ARF2 & 53.0 & $4 e-61$ & & \\
\hline & & C6-CS (2) & 49.0 & $3 e-91$ & & \\
\hline & & C7-CS/CR (4) & 42.0 & $1 e-85$ & & \\
\hline & & C8-CS/CR (2) & 41.0 & $3 e-62$ & & \\
\hline & & CS00-C3-705-071-D01-CT & 48.0 & $5 e-93$ & & \\
\hline$A U X / I A A$ & AT2G38120 & C1-CS/CR (4) AXR1 & 75.0 & 0.0 & transcription regulator & Overvoorde et al., \\
\hline family ${ }^{\mathrm{f}}$ & & C2-PT (3) & 73.0 & $9 e-73$ & acting as repressor of & 2006; Ulmasov et \\
\hline
\end{tabular}




\begin{tabular}{|c|c|c|c|c|c|c|}
\hline & & C3-CG (3) & 68.0 & $1 \mathrm{e}-71$ & auxin-inducible gene & al., 1997a \\
\hline & & C4- CS/CR/CA (12) & 68.0 & $2 \mathrm{e}-87$ & expression & \\
\hline & & C5-CS/PT (7) & 67.0 & $4 e-87$ & & \\
\hline & & C6-CS/CR (7) & 64.0 & $6 e-86$ & & \\
\hline & & C7- CS/CA/LT (4) & 64.0 & $6 e-86$ & & \\
\hline & & C8-CS/CG (12) & 59.0 & $3 e-89$ & & \\
\hline & & C9-CS/PT (5) & 51.0 & 1e-79 & & \\
\hline$B I G$ & AT3G02260 & C1-CS/CR/CA/CG (47) & 80.0 & 0.0 & $\begin{array}{l}\text { Zinc finger ZZ type, } \\
\text { polar auxin transport }\end{array}$ & Gil et al., 2001 \\
\hline CUL family ${ }^{\mathrm{g}}$ & AT4G02570 & C1-CS (9) & 89.0 & 0.0 & cullin domain, component & Gray et al., 1999; \\
\hline & & C2-CS/CR (12) AtCUL3 & 88.0 & $1 e-101$ & of SCF ubiquitin ligase & Quint et al., 2005 \\
\hline & & C3- CS/CR/CL/PT/CA (5) AtCUL1 & 83.0 & 0.0 & complexes, protein & \\
\hline & & C4- CS/CR/PT (4) AtCUL1 & & & degradation & \\
\hline & & & 83.0 & $1 e-113$ & & \\
\hline EIRI & AT5G57090 & $\mathrm{C} 2-\mathrm{CS} / \mathrm{CA}(2)$ & 49.0 & $1 e-158$ & auxin transport protein, & Luschnig et al., \\
\hline & & C1-CS/CR/CG (8) & 32.0 & $3 e-109$ & auxin:hydrogen symporter & 1998 \\
\hline
\end{tabular}




\begin{tabular}{|c|c|c|c|c|c|c|}
\hline & & CS00-C3-700-106-C03-CT & 35.0 & $3 e-93$ & activity & \\
\hline$P I N / P I D$ & AT1G73590 & C2-CA/CS (2) PIN3 & 25.0 & $3 e-89$ & auxin efflux carrier, & Petrasek et al., \\
\hline \multirow[t]{2}{*}{ family $^{\mathrm{h}}$} & & C1- CG/CS (7) PIN1 & 24.0 & $2 \mathrm{e}-75$ & auxin:hydrogen symporter & 2006; Vernoux et \\
\hline & & CS00-C3-700-106-C03-CT - PIN3 & 39.0 & $4 e-97$ & activity & al., 2000 \\
\hline \multirow[t]{5}{*}{ TIR1 } & AT3G62980 & C1-CS/CR (3) & 63.0 & 0.0 & leucine-rich repeat, & Ruegger et al., \\
\hline & & C2-CR/CS/CA/PT/CL (13) & 63.0 & 0.0 & cysteine-containing, & 1998; Dharmasiri \\
\hline & & C3-PT (2) & 59.0 & $1 \mathrm{e}-93$ & cyclin-like F-box, E3 & et al., 2005 \\
\hline & & C4-CS/LT (4) & 52.0 & $4 e-73$ & ubiquitin ligase $\mathrm{SCF}$ & \\
\hline & & PT11-C1-901-035-F11-CT & 57.0 & $3 e-84$ & complex, auxin receptor & \\
\hline
\end{tabular}

${ }^{\mathrm{a}}$ Gene name abbreviations: $A B P$ : auxin-binding protein, $A R F$ : auxin-responsive factor, $A U X / I A A$ : auxin-responsive protein /indoleacetic acid-induced protein, $A X R$ : auxin resistant, CUL: cullin, EIR: ethylene insensitive root, PID: pinoid, PIN: pin-formed, TIR: transport inhibitor response.

${ }^{\mathrm{b}} \mathrm{C}$ : contig, CA: Citrus aurantium, CG: Citrus aurantifolia, CR: Citrus reticulata, CS: Citrus sinensis, LT: Citrus latifolia, PT: Poncirus trifoliata, (number of reads).

${ }^{\mathrm{c}}$ Identity percentage at the amino acid level.

${ }^{\mathrm{d}}$ Protein motif: SCF: SKP1/Cullin/F-box protein.

eARF family in A. thaliana: AT1G19220, AT1G19850, AT1G30330, AT1G34170, AT1G34310, AT1G34390, AT1G34410, AT1G35240, AT1G35520, AT1G35540, AT1G43950, AT1G77850, AT2G24765, AT2G28350, AT2G33860, AT2G46530, AT2G47170, AT3G61830, AT4G23980, AT4G30080, AT5G20730, AT5G37020, AT5G60450, AT5G62000. 
${ }^{\mathrm{f}}$ AUX/IAA family in A. thaliana: AT5G65670, AT5G57420 , AT5G43700 , AT4G32280, AT4G29080 , AT4G28640 , AT4G14550, AT3G62100 , AT1G04100 , AT1G04240 , AT1G04250 , AT1G04550 , AT1G15050 , AT1G15580 , AT1G51950 , AT1G52830 , AT1G80390, AT2G01200 , AT2G22670 , AT2G33310 , AT2G46990 , AT3G04730 , AT3G15540 , AT3G16500 , AT3G17600 , AT3G23030 , AT3G23050。

${ }^{\mathrm{g}}$ CULIIN family in A. thaliana: AT1G02980, AT1G26830, AT1G69670.

hPIN/PID family in A. thaliana: AT1G23080 , AT1G70940 , AT1G77110 , AT2G01420 , AT2G34650 , AT5G15100 , AT5G54490. 
Table S4 - Citrus ESTs with homology to genes involved in brassinosteroid metabolism in Arabidopsis thaliana.

\begin{tabular}{|c|c|c|c|c|c|c|}
\hline \multicolumn{2}{|c|}{ Arabidopsis thaliana } & \multicolumn{3}{|l|}{ CitEST } & \multicolumn{2}{|l|}{ Protein motifs ${ }^{\mathrm{d}}$ and } \\
\hline Name $^{a}$ & Gene & $\mathbf{E S T}^{b}$ & $\%^{\mathrm{c}}$ & e value & biological process & References \\
\hline \multirow[t]{3}{*}{ BR6OX } & AT5G38970 & C3-CS/CR (3) & 68.2 & $2 \mathrm{e}-83$ & cytochrome P450, & Shimada $e t$ \\
\hline & & C1-CS (2) & 42.0 & $4 e-56$ & brassinosteroids C-6 oxidation, & al., 2001 \\
\hline & & & & & BR biosynthesis & \\
\hline \multirow[t]{4}{*}{$C P D$} & AT5G05690 & C3-CS/PT (6) & 80.7 & $1 \mathrm{e}-138$ & cytochrome P450, member of & Wang et al., \\
\hline & & C4-CS/CR (7) & 64.9 & $5 e-99$ & CP90A family, BR biosynthesis & 2002 \\
\hline & & C1-CS (2) & 43.4 & $2 \mathrm{e}-95$ & & \\
\hline & & C2-CS/CR (2) & 29.7 & $1 \mathrm{e}-88$ & & \\
\hline \multirow[t]{5}{*}{$C Y P 72 C 1$} & AT1G17060 & $\mathrm{C} 1-\mathrm{CS}(4)$ & 36.4 & $1 \mathrm{e}-51$ & cytochrome P450, BR & Bancos et \\
\hline & & C9-PT (2) & 28.6 & $1 e-54$ & biosynthesis & al., 2002 \\
\hline & & C4- CG/CS (4) & 23.5 & $1 \mathrm{e}-44$ & & \\
\hline & & CS00-C3-701-100-A11-UV & 33.9 & $1 \mathrm{e}-72$ & & \\
\hline & & CR05-C1-103-084-D10-CT & 32.9 & $7 e-45$ & & \\
\hline CYP90D1 & AT3G13730 & C4-CR (2) & 32.0 & $1 e-85$ & cytochrome P450 E-class, & Bancos et \\
\hline
\end{tabular}


C3-CS/CR (2)

$31.8 \quad 6 e-61$

member of CYP90D family,

al., 2002;

BR biosynthesis

Kim et al.,

2005

\begin{tabular}{|c|c|c|c|c|c|c|}
\hline \multirow[t]{3}{*}{ DET2 } & AT2G38050 & C1-CS (2) & 28.8 & $1 e-136$ & 3-oxo-5-alpha-steroid 4- & Fujioka $e t$ \\
\hline & & C2-CS (2) & 26.8 & 1e-131 & dehydrogenase, BR & al., 1997 \\
\hline & & & \multicolumn{4}{|c|}{ biosynthesis } \\
\hline \multirow[t]{2}{*}{$D W F 1$} & AT3G19820 & C1-CS/CR (25) & 56.3 & 1e-110 & $\mathrm{Ca}^{2+}$-dependent calmodulin & Choe et al., \\
\hline & & & & & binding, BR biosynthesis & $1999 a$ \\
\hline \multirow[t]{7}{*}{ DWF4 } & AT3G50660 & C4-CS/PT (7) & 38.0 & 1e-104 & C-22 hydroxylation of a variety & Choe et al., \\
\hline & & C3-CS/CR (3) & 32.7 & $3 e-98$ & of C27-, C28- and C29-sterols, & 2001 \\
\hline & & C2-CS (2) & 31.4 & $2 \mathrm{e}-95$ & BR biosynthesis & \\
\hline & & C8-CR/PT (2) & 26.2 & $7 e-28$ & & \\
\hline & & C5-CS/CR (7) & 22.0 & $1 e-34$ & & \\
\hline & & CR05-C3-700-062-F07-CT & 51.7 & $1 e-75$ & & \\
\hline & & CR05-C3-700-006-D11-EU & 24.8 & $1 e-26$ & & \\
\hline DWF5 & AT1G50430 & C2-CG (3) & 74.3 & 1e-121 & 7-DHC reductase / sterol delta- & Choe et al., \\
\hline
\end{tabular}


$\begin{array}{lll}\text { C1-CR (1) } \quad 23.0 \quad 2 \mathrm{e}-25 & 7 \text {-reductase (ST7R), BR } 2000\end{array}$

ROT3 AT4G36380

\begin{tabular}{|c|c|c|c|c|c|c|}
\hline \multirow[t]{7}{*}{ ROT3 } & AT4G36380 & C4-CS/PT (6) & 38.2 & $7 e-83$ & cytochrome $\mathrm{P} 450$ class $90 \mathrm{C} 1$, & Kim et al., \\
\hline & & C3-CS/CR (3) & 29.8 & $2 \mathrm{e}-50$ & BR biosynthesis & 1998 \\
\hline & & C5-CSCR (7) & 25.1 & $3 e-45$ & & \\
\hline & & C7-CR/PT (2) & 23.6 & $2 \mathrm{e}-41$ & & \\
\hline & & CG32-C1-003-089-B04-CT & 23.7 & $5 e-43$ & & \\
\hline & & CR05-C3-700-006-D11-EU & 25.2 & $2 \mathrm{e}-41$ & & \\
\hline & & CR05-C3-700-062-F07-CT & 19.9 & $5 e-31$ & & \\
\hline \multirow[t]{2}{*}{ STE1 } & AT3G02580 & C1-CS (3) & 68.1 & $1 \mathrm{e}-123$ & delta 7-sterol-C5-desaturase, & Choe et al., \\
\hline & & & & & BR biosynthesis & $1999 b$ \\
\hline
\end{tabular}

biosynthesis

${ }^{\mathrm{a} G e n e ~ n a m e ~ a b b r e v i a t i o n s: ~ B R 6 O X: ~ b r a s s i n o s t e r o i d ~ 6-o x i d a s e, ~} C P D$ : carboxypeptidase D precursor, $C Y P$ : cytochrome $\mathrm{P} 450$ precursor, $D E T$ : de-etiolated, $D W F$ :dwaf , ROT: rotundifolia, STE: sterol desaturase.

${ }^{\mathrm{b}} \mathrm{C}$ : contig, CG: Citrus aurantifolia, CR: Citrus reticulata, CS: Citrus sinensis, PT: Poncirus trifoliata, (number of reads).

${ }^{c}$ Identity percentage at the amino acid level.

${ }^{\mathrm{c}}$ Functional domain abbreviations: BR: brassinosteroid, DHC: delta-hydroxy-reductase. 
Table S5 - Citrus ESTs with homology to genes involved in brassinosteroid-initiated signal transduction in Arabidopsis thaliana.

\begin{tabular}{|c|c|c|c|c|c|c|}
\hline \multicolumn{2}{|c|}{ Arabidopsis thaliana } & \multicolumn{3}{|l|}{ CitEST } & \multicolumn{2}{|l|}{ Protein motifs $^{\mathrm{d}}$ and } \\
\hline Name $^{a}$ & Gene & EST $^{\mathrm{b}}$ & $\%^{\mathrm{c}}$ & e value & biological process & References \\
\hline \multicolumn{7}{|c|}{ receptors and putative receptors } \\
\hline \multirow[t]{6}{*}{ BRII } & AT4G39400 & CS00-C3-702-092-G08-CT & 80.8 & $1 \mathrm{e}-133$ & PK, ATP-binding region & Clouse et al., \\
\hline & & CS00-C1-650-008-E09-CT & 70.9 & $1 \mathrm{e}-115$ & signature, LRR receptor kinase, & 1996 \\
\hline & & PT11-C1-900-089-E02-CT & 63.9 & 1e-99 & brassinosteroid receptor, & \\
\hline & & CR05-C3-702-027-G11-CT & 63.1 & $5 e-90$ & systemin receptor & \\
\hline & & CS00-C3-700-068-G06-CT & 57.1 & $3 e-88$ & & \\
\hline & & CR05-C1-103-056-H03-CT & 42.5 & $1 e-73$ & & \\
\hline \multirow[t]{6}{*}{$B R L 1$} & AT1G55610 & C12-CS (7) & 58.9 & $1 \mathrm{e}-112$ & PK, ATP-binding region & Cano-Delgad \\
\hline & & C8-CR (3) & 47.1 & $2 \mathrm{e}-88$ & signature, LRR receptor kinase, & o et al., 2004 \\
\hline & & C5-CS/CR (3) & 41.0 & $4 e-76$ & brassinosteroid receptor & \\
\hline & & C2-CS/PT (2) & 35.4 & $2 e-64$ & & \\
\hline & & CR05-C3-702-017-C08-CT & 38.4 & $7 e-60$ & & \\
\hline & & CSO0-C3-702-076-D04-CT & 38.2 & $8 e-55$ & & \\
\hline
\end{tabular}




\begin{tabular}{|c|c|c|c|c|c|c|}
\hline & & CG32-C1-003-035-B06-CT & 35.3 & $4 e-65$ & & \\
\hline & & CR05-C3-701-030-G08-CT & 31.9 & $2 \mathrm{e}-50$ & & \\
\hline & & CR05-C1-100-070-E05-CT & 31.7 & $7 e-49$ & & \\
\hline & & CR05-C3-702-017-B06-CT & 31.6 & $3 e-49$ & & \\
\hline & & CS00-C3-703-071-D07-CT & 30.5 & $2 e-69$ & & \\
\hline$B R L 2$ & AT2G01950 & C2-CS/PT (2) & 35.4 & $5 e-63$ & $B R L$ family & Cano-Delgad \\
\hline & & CR05-C1-103-056-H03-CT & 57.5 & $2 \mathrm{e}-103$ & & o et al., 2004 \\
\hline & & CS00-C1-101-097-B06-EU & 35.7 & $3 e-71$ & & \\
\hline & & PT11-C1-901-087-D01-CT & 34.9 & $5 e-63$ & & \\
\hline$B R L 3$ & AT3G13380 & C3-CS/PT (2) & 45.7 & $4 e-77$ & $B R L$ family & Cano-Delgad \\
\hline & & C4-CS/CR (3) & 43.2 & $9 e-65$ & & o et al., 2004 \\
\hline & & C7-CS (2) & 37.0 & $6 e-55$ & & \\
\hline & & CS00-C1-100-123-E06-CT & 36.1 & $3 e-61$ & & \\
\hline & & CS00-C3-704-049-B04-CT & 35.0 & $2 e-67$ & & \\
\hline & & CS00-C1-102-052-F12-CT & 33.2 & $2 \mathrm{e}-58$ & & \\
\hline & & CSO0-C3-702-037-F05-CT & 32.6 & $4 e-65$ & & \\
\hline
\end{tabular}


CR05-C3-701-030-G08-CT $31.9 \quad$ 1e-49

CR05-C1-100-070-E05-CT $31.7 \quad 4 \mathrm{e}-47$

signaling intermediates

\begin{tabular}{|c|c|c|c|c|c|c|}
\hline \multirow[t]{9}{*}{$B A K 1$} & AT4G33430 & C9-CS/CR/LT (3) & 64.6 & $1 \mathrm{e}-155$ & LRR, PK domain, identical to & Li et al., \\
\hline & & C5-CS (4) & 55.0 & $1 e-123$ & somatic embryogenesis & 2002a; Nam \\
\hline & & C3-CS (5) & 48.5 & $1 \mathrm{e}-105$ & receptor-like kinase 3 (SERK3), & and $\mathrm{Li}, 2002$ \\
\hline & & CS00-C3-705-007-D04-CT & 46.6 & $2 \mathrm{e}-76$ & interacts with BRI1 in vitro and & \\
\hline & & CS00-C3-702-076-D04-CT & 37.5 & $1 \mathrm{e}-92$ & in vivo to form a heterodimer & \\
\hline & & CR05-C3-702-017-C08-CT & 37.1 & $1 \mathrm{e}-102$ & & \\
\hline & & CS00-C1-100-123-E06-CT & 36.4 & $6 e-98$ & & \\
\hline & & CG32-C1-003-071-D10-CT & 29.1 & $2 \mathrm{e}-83$ & & \\
\hline & & CS00-C1-100-104-H02-UV & 35.8 & $9 e-73$ & & \\
\hline \multirow[t]{4}{*}{$B A S 1$} & AT2G26710 & $\mathrm{C} 1-\mathrm{CS}(4)$ & 34.6 & $2 \mathrm{e}-99$ & cytochrome p450, control point & Neff et al., \\
\hline & & C8-PT (2) & 30.1 & $1 \mathrm{e}-47$ & between multiple photoreceptor & 1999 \\
\hline & & CR05-C1-103-084-D10-CT & 33.6 & $1 \mathrm{e}-54$ & systems and BR signal & \\
\hline & & CSO0-C3-701-100-A11-UV & 32.2 & $1 \mathrm{e}-72$ & transduction & \\
\hline
\end{tabular}




\begin{tabular}{|c|c|c|c|c|c|c|}
\hline & & CR05-C3-701-103-D05-CT & 26.2 & $7 e-69$ & pathways & \\
\hline & & CS00-C1-650-030-H10-CT & 22.8 & $4 e-52$ & & \\
\hline \multirow[t]{3}{*}{ BIN2 } & AT4G18710 & C8-CS (5) & 75.5 & $1 e-102$ & SHAGGY-related PK eta / & Li et al., \\
\hline & & $\mathrm{C} 1-\mathrm{CS} / \mathrm{PT}(2)$ & 28.4 & $1 e-61$ & ASK7, cross-talk between & $2001 b$ \\
\hline & & CR05-C1-100-026-F08-CT & 58.1 & $1 e-108$ & auxin and BR pathways & \\
\hline \multirow[t]{3}{*}{ BRS1 } & AT4G30610 & C4-CS (4) & 56.6 & & serine carboxypeptidase II, & Li et al., \\
\hline & & C1-CS (6) & 49.2 & & involved in BRI1-mediated & 2001a \\
\hline & & & & & signaling & \\
\hline \multirow[t]{5}{*}{$B S U 1$} & AT1G03445 & CS00-C3-701-035-G06-CT & 39.8 & $1 e-74$ & Kelch repeat, serine/threonine & Mora-Garcia \\
\hline & & CS00-C1-100-119-F05-CT & 34.3 & $2 \mathrm{e}-80$ & phosphoesterase, & et al., 2004 \\
\hline & & PT11-C9-005-041-C05-CT & 30.0 & $1 e-112$ & metallo-phosphoesterase, BR & \\
\hline & & PT11-C1-900-087-G08-CT & 27.6 & $3 e-84$ & signaling intermediate & \\
\hline & & CS13-C1-001-008-C12-CT & 23.2 & $9 e-86$ & & \\
\hline
\end{tabular}

transcription factors

BES1 AT1G19350 C3-CS (2) $40.9 \quad 1 \mathrm{e}-95 \quad$ plant DUF822, phosphorylated $\quad$ Yin et al.,


CR05-C1-103-054-F02-CT

BIM1

AT5G08130

C1-CS (3)

C2-CR/LT (2)

CR05-C1-102-035-G07-CT

BZR2

AT1G78700

CR05-C1-103-054-F02-CT

C3-CS/CR (3)
$58.4 \quad 8 \mathrm{e}-89$

by BIN2 GSK3 kinase, binds

E- box sequences (CANNTG)

$58.9 \quad$ le-112 bHLH, binds E -box sequences

(CANNTG)

$42.4 \quad 7 e-97$

$23.09 \mathrm{e}-60$

$52.3 \quad 1 \mathrm{e}-148$

plant DUF822, positive

regulator BR signaling

$B Z R$ family
2002; Yin et

al., 2005

Yin et al.,

2005

Wang et al.,

2002, He $e t$

al., 2005

He et al.,

${ }^{\mathrm{a} G e n e ~ n a m e ~ a b b r e v i a t i o n s: ~} B A K$ : BRI1-associated receptor kinase, BAS: PHYB-activation tagged supressor, BES: BRI1-EMS suppressor, BIM: BES1-interacting MYC-like protein , BIN: brassinosteroid insensitive, BRI: brassinosteroid insensitive, BRL: BRI1-like protein, BRS: BRI1 suppressor, BSU: BRI1 suppressor protein, BZR: brassinazole-resistant.

${ }^{\mathrm{b}}$ C: contig, CG: Citrus aurantifolia, CR: Citrus reticulata, CS: Citrus sinensis, LT: Citrus latifolia, PT: Poncirus trifoliata, (number of reads).

cIdentity percentage at the amino acid level.

${ }^{\mathrm{d}}$ Functional domain abbreviations: ASK:, Arabidopsis SHAGGY-related protein kinase, ATP: adenosine triphosphate, BR: brassinosteroid, DUF: domain of function unknown, LRR: leucine rich repeat, PK: protein kinase. 
Table S6 - Citrus ESTs with homology to genes involved in cytokinin metabolism and transport in Arabidopsis thaliana.

\begin{tabular}{|c|c|c|c|c|c|c|}
\hline \multicolumn{2}{|c|}{ Arabidopsis thaliana } & \multicolumn{3}{|l|}{ CitEST } & \multicolumn{2}{|l|}{ Protein motifs and } \\
\hline Name $^{a}$ & Gene & $\mathbf{E S T}^{\mathrm{b}}$ & $\%^{c}$ & e value & biological process & References \\
\hline \multicolumn{7}{|c|}{ biosynthesis } \\
\hline$\overline{A P T 3}$ & AT1G80050 & CL06-C4-501-001-G02-CT & 75.0 & $1 \mathrm{e}-81$ & $\begin{array}{c}\text { purine/pyrimidine } \\
\text { phosphoribosyl transferase, } \\
\text { purine salvage pathway }\end{array}$ & $\begin{array}{c}\text { Allen } \text { et al., } \\
2002\end{array}$ \\
\hline AtIPT1 & AT1G68460 & CS00-C3-704-028-G04-CT & 39.2 & $6 e-71$ & $\begin{array}{l}\text { tRNA isopentenyltransferase } \\
\text { activity, cytokinin biosynthesis }\end{array}$ & $\begin{array}{l}\text { Kakimoto, } \\
\text { 2001; Takei } \\
\text { et al., } 2001\end{array}$ \\
\hline AtIPT3 & AT3G63110 & CR05-C1-102-068-C11-CT & 36.2 & $4 e-60$ & $I P T$ family & $\begin{array}{l}\text { Kakimoto, } \\
2001\end{array}$ \\
\hline AtIPT4 & AT4G24650 & CR05-C1-102-068-C11-CT & 28.8 & $2 e-32$ & $I P T$ family & $\begin{array}{l}\text { Kakimoto, } \\
2001\end{array}$ \\
\hline AtIPT5 & AT5G19040 & CS00-C3-704-018-B02-CT & 41.2 & $9 e-55$ & $I P T$ family & $\begin{array}{l}\text { Kakimoto, } \\
2001\end{array}$ \\
\hline
\end{tabular}




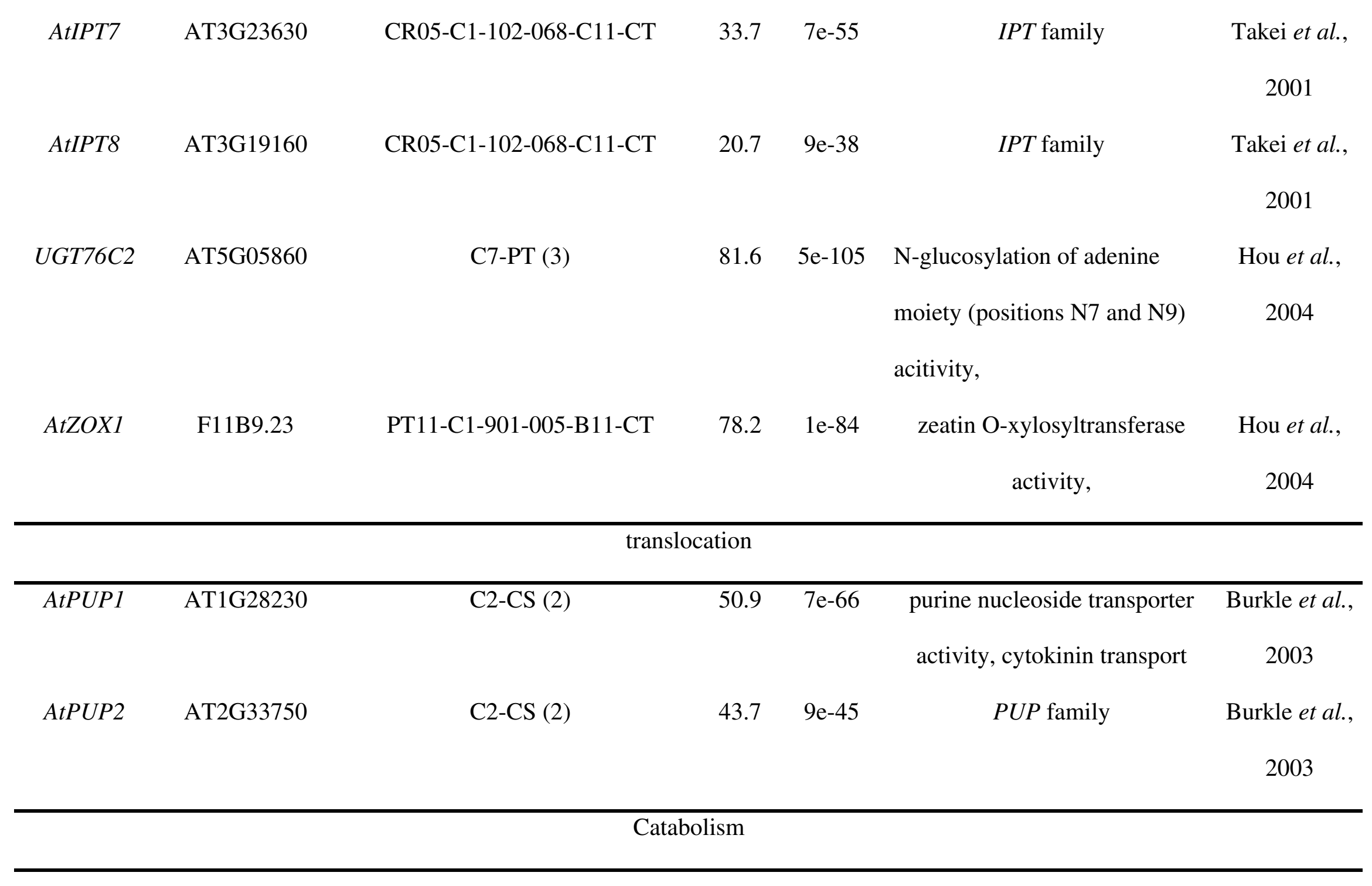


CKX2 AT2G19500

CS00-C1-102-073-H07-CT AT1G75450

CKX5 C1-CS (2)
27.7

$1 \mathrm{e}-55$

cytokinin catabolism, root cap,

al., 2003

stomatal complex, stipule, shoot

apex
$51.7 \quad 2 \mathrm{e}-86$
CKX family

Schmüllig et

${ }^{\mathrm{a} G e n e}$ name abbreviations: APT: adenine phosphoribosyltransferase, AtIP: Arabidopsis thaliana isopentenyl transferase, AtPUP: Arabidopsis thaliana purine permease, AtZOX: Arabidopsis thaliana zeatin O-xylosyltransferase, CKX: cytokinin oxidase/dehydrogenase, UGT76C2: UDP-glucose pyrophosphorylase.

${ }^{\mathrm{b}} \mathrm{C}$ : contig, CL: Citrus limonia, CR: Citrus reticulata, CS: Citrus sinensis, PT: Poncirus trifoliata, (number of reads).

${ }^{\mathrm{c}}$ Identity percentage at the amino acid level. 
Table S7 - Citrus ESTs with homology to genes involved in cytokinin signal transduction in Arabidopsis thaliana.

\begin{tabular}{|c|c|c|c|c|c|c|}
\hline \multicolumn{2}{|c|}{ Arabidopsis thaliana } & \multicolumn{2}{|c|}{ CitEST } & \multicolumn{3}{|c|}{ Protein motifs and } \\
\hline Name $^{a}$ & Gene & $\mathbf{E S T}^{\mathrm{b}}$ & $\%^{c}$ & e value & biological process & References \\
\hline \multicolumn{7}{|c|}{ receptors and putative receptors } \\
\hline AHK1/ & AT2G47430 & C2-CS (3) & 30.3 & $5 e-67$ & protein histidine kinase, & Inoue et al., \\
\hline CKII & & & & & cytokinin receptor & 2001 \\
\hline$A H K 2$ & AT5G35750 & C7-CS (2) & 62.2 & $4 e-75$ & $A H K$ family & Higuchi et \\
\hline & & & & & & al., 2004 \\
\hline \multirow[t]{2}{*}{$A H K 3$} & AT1G27320 & C1-CR (2) & 68.8 & $5 e-92$ & $A H K$ family & Nishimura et \\
\hline & & C3-PT (3) & 22.9 & $6 e-75$ & & al., 2004 \\
\hline$A H K 4 /$ & AT2G01830 & C2-CS (16) & 51.6 & $4 \mathrm{e}-81$ & $A H K$ family & Higuchi et \\
\hline \multicolumn{2}{|c|}{ CRE1/WOL } & & & & & al., 2004 \\
\hline \multicolumn{7}{|c|}{ histidine-phosphotransfer proteins } \\
\hline \multirow[t]{2}{*}{$A H P 1$} & AT3G21510 & C2-CS (4) & 23.3 & $2 \mathrm{e}-47$ & histidine kinase activity & Suzuki et al., \\
\hline & & & & & & 2000 \\
\hline$A H P 2$ & AT3G29350 & C2-CS (4) & 25.3 & $2 \mathrm{e}-48$ & $A H P$ family & Suzuki et al., \\
\hline
\end{tabular}




\begin{tabular}{|c|c|c|c|c|c|c|}
\hline AHP3 & AT5G39340 & C2-CS (4) & 24.2 & $3 e-49$ & $A H P$ family & $\begin{array}{c}\text { Suzuki et al., } \\
2000\end{array}$ \\
\hline AHP4 & AT3G16360 & CS00-C1-102-072-B03-CT & 21.7 & $3 e-40$ & $A H P$ family & $\begin{array}{c}\text { Suzuki et al., } \\
2000\end{array}$ \\
\hline AHP5 & AT1G03430 & CS00-C3-704-018-B02-CT & 34.6 & $9 e-55$ & $A H P$ family & $\begin{array}{c}\text { Suzuki et al., } \\
2000\end{array}$ \\
\hline
\end{tabular}

response regulators

\begin{tabular}{|c|c|c|c|c|c|c|}
\hline$A R R 1$ & AT3G16857 & CR05-C3-701-021-A12-CT & 49.3 & $1 e-57$ & $\begin{array}{l}\text { two-component response } \\
\text { regulator }\end{array}$ & $\begin{array}{l}\text { Mason et al., } \\
2005\end{array}$ \\
\hline$A R R 2$ & AT4G16110 & CS00-C1-102-045-A08-CT & 23.6 & $5 e-54$ & $A R R$ family & $\begin{array}{c}\text { Hwang et al., } \\
2002\end{array}$ \\
\hline$A R R 3$ & AT1G59940 & PT11-C1-901-071-A09-CT & 20.9 & $1 e-59$ & $A R R$ family & $\begin{array}{l}\text { To et al., } \\
2004\end{array}$ \\
\hline$A R R 4$ & AT1G10470 & PT11-C1-901-071-A09-CT & 21.9 & $6 e-59$ & $A R R$ family & $\begin{array}{l}\text { Sweere et } \\
\text { al., } 2001\end{array}$ \\
\hline
\end{tabular}




\begin{tabular}{|c|c|c|c|c|c|c|}
\hline ARR5 & AT3G48100 & PT11-C1-901-071-A09-СТ & 16.9 & $3 e-50$ & $A R R$ family & $\begin{array}{l}\text { Hwang et al., } \\
2002\end{array}$ \\
\hline ARR6 & AT5G62920 & PT11-C1-901-071-A09-CT & 12.9 & $6 e-49$ & $A R R$ family & $\begin{array}{l}\text { Hwang et al., } \\
2002\end{array}$ \\
\hline$A R R 7$ & AT1G19050 & PT11-C1-901-071-A09-CT & 11.7 & $5 e-48$ & $A R R$ family & $\begin{array}{l}\text { Hwang and } \\
\text { Sheen, } 2001\end{array}$ \\
\hline ARR9 & AT3G57040 & CSO0-C3-700-065-A09-CT & 58.2 & $3 e-60$ & $A R R$ family & $\begin{array}{l}\text { Hwang et al., } \\
2002\end{array}$ \\
\hline ARR10 & AT4G31920 & CSO0-C1-102-006-D06-CT & 26.3 & $4 \mathrm{e}-48$ & $A R R$ family & $\begin{array}{l}\text { Hwang and } \\
\text { Sheen, } 2001\end{array}$ \\
\hline ARRII & AT1G67710 & $\begin{array}{l}\text { CS00-C1-102-045-A08-CT } \\
\text { CR05-C1-100-016-F10-CT }\end{array}$ & $\begin{array}{l}53.2 \\
14.0\end{array}$ & $\begin{array}{l}7 e-47 \\
7 e-68\end{array}$ & $A R R$ family & $\begin{array}{c}\text { Imamura et } \\
\text { al., } 2003\end{array}$ \\
\hline ARR14 & AT2G01760 & CR05-C3-701-021-A12-CT & 40.0 & $2 \mathrm{e}-49$ & $A R R$ family & $\begin{array}{l}\text { Tajima et al., } \\
2004\end{array}$ \\
\hline ARR15 & AT1G74890 & PT11-C1-901-071-A09-CT & 20.4 & $3 e-44$ & $A R R$ family & $\begin{array}{l}\text { Hwang et al., } \\
2002\end{array}$ \\
\hline
\end{tabular}




\begin{tabular}{|c|c|c|c|c|c|c|}
\hline \multirow[t]{2}{*}{ ARR16 } & AT2G40670 & PT11-C1-900-041-F09-CT & 18.2 & $5 e-39$ & $A R R$ family & Hwang et al., \\
\hline & & CS00-C3-700-065-A09-CT & 16.7 & $1 \mathrm{e}-38$ & & 2002 \\
\hline \multirow[t]{2}{*}{ ARR17 } & AT3G56380 & C5-PT (5) & 19.5 & $1 \mathrm{e}-41$ & $A R R$ family & Tajima et al., \\
\hline & & & & & & 2004 \\
\hline \multirow[t]{2}{*}{ ARR18 } & AT5G58080 & CR05-C3-701-021-A12-CT & 34.1 & $4 \mathrm{e}-32$ & $A R R$ family & Hwang and \\
\hline & & CS00-C1-102-045-A08-CT & 23.6 & $4 e-27$ & & Sheen, 2001 \\
\hline \multirow[t]{2}{*}{ ARR19 } & AT1G49190 & CR05-C3-701-021-A12-CT & 24.8 & $5 e-23$ & $A R R$ family & Hwang and \\
\hline & & & & & & Sheen 2001 \\
\hline \multirow[t]{2}{*}{$A R R 20$} & AT3G62670 & CR05-C3-701-021-A12-CT & 27.4 & $2 \mathrm{e}-21$ & $A R R$ family & Hwang et al., \\
\hline & & & & & & 2002 \\
\hline \multirow[t]{3}{*}{$A R R 21$} & AT5G07210 & CR05-C3-701-021-A12-CT & 25.2 & $5 e-18$ & $A R R$ family & Hwang et al., \\
\hline & & & & & & 2002 \\
\hline & & other signaling compon & and tra & scription & & \\
\hline \multirow[t]{2}{*}{ KNAT2 } & AT1G70510 & C3-CR (2) & 32.4 & $1 \mathrm{e}-31$ & homeodomain protein, & Hamant $e t$ \\
\hline & & PT11-C2-301-095-B03-CT & 40.1 & $5 e-29$ & meristem development & al., 2002; \\
\hline
\end{tabular}


al., 2005

$S P Y$

AT3G11540
CR05-C1-103-015-E09-CT

CS00-C1-102-059-G10-CT

C4-CR (3)

C1-CS (4)
$27.4 \quad 2 \mathrm{e}-65$

$25.0 \quad 4 \mathrm{e}-43$

$15.5 \quad 3 e-28$

$20.2 \quad 3 e-43$

$13.7 \quad 7 \mathrm{e}-32$

PT11-C2-301-019-G09-CT $13.8 \quad 3 \mathrm{e}-44$

${ }^{\mathrm{a}}$ Gene name abbreviations: AHK: Arabidopsis thaliana histidine kinase protein, AHP: Arabidopsis thaliana histidine phosphotransfer protein, ARR: Arabidopsis thaliana response regulator, CKI: cytokinin insensitive , CRE: cytokinin receptor, KNAT: class I KNOTTED1-like TALE homeodomain, SPY: spindly, STM: shoot meristemless, WOL: wooden leg.

${ }^{c}$ Identity percentage at the amino acid level.

${ }^{\mathrm{b}} \mathrm{C}$ : contig, CR: Citrus reticulata, CS: Citrus sinensis, PT: Poncirus trifoliata, (number of reads). 
Table S8 - Citrus ESTs with homology to genes involved in ethylene biosynthesis in Arabidopsis thaliana.

\begin{tabular}{|c|c|c|c|c|c|c|}
\hline \multicolumn{2}{|c|}{ Arabidopsis thaliana } & \multicolumn{3}{|l|}{ CitEST } & \multicolumn{2}{|l|}{ Protein motifs $^{\mathrm{d}}$ and } \\
\hline Name $^{a}$ & Gene & $\mathbf{E S T}^{\mathrm{b}}$ & $\%^{\mathrm{c}}$ & e value & biological process & References \\
\hline$A C O$ & AT1G62380 & C21-CA/CS/CR/PT (7) & 74.3 & $1 \mathrm{e}-142$ & 1-aminocyclopropane-1- & Tang et al., \\
\hline \multirow[t]{4}{*}{ family $^{\mathrm{u}}$} & & C18-PT (15) & 63.8 & $1 e-126$ & carboxylate oxidase, synthesis & 1993 \\
\hline & & C20-PT (2) & 48.0 & $1 \mathrm{e}-121$ & of ethylene from ACC & \\
\hline & & C17-PT (2) & 30.7 & 1e-111 & & \\
\hline & & C4-CS (2) & 30.0 & $1 \mathrm{e}-92$ & & \\
\hline \multirow[t]{4}{*}{$A C S$ family $^{\mathrm{v}}$} & AT3G61510 & C1-CS (3) ACS3 & 53.7 & $3 e-97$ & 1-aminocyclopropane-1- & Woeste $e t$ \\
\hline & & C2-CS/CR (5) ACS12 & 47.6 & $1 \mathrm{e}-93$ & carboxylate (ACC) synthase, & al., 1999; \\
\hline & & C3-PT (3) ACS12 & 46.9 & $5 e-90$ & conversion of AdoMet to ACC & Babula et al., \\
\hline & & C4-CS/CG (9) ACS10 & 36.6 & $2 e-82$ & & 2006 \\
\hline \multirow[t]{2}{*}{$E F E$} & AT1G05010 & C22-CA/CG/CS/CR (34) & 75.5 & $1 \mathrm{e}-158$ & $A C O$ family & Gomez-Lim \\
\hline & & & & & & et al., 1993 \\
\hline \multirow[t]{2}{*}{ ETO1 } & AT3G51770 & C3-CS/CR (4) & 71.1 & 0.0 & TRP repeat, BTB/POZ domain, & Guzman and \\
\hline & & $\mathrm{C} 2-\mathrm{CS} / \mathrm{CR} / \mathrm{PT}(11)$ & 57.9 & 0.0 & ACS degradation via $26 \mathrm{~S}$ & Ecker, 1990, \\
\hline
\end{tabular}


C1-CS (3)

\section{CS00-C3-703-024-E09-CT}

C1-CS/CR (89)

C4-LT/PT (4)

C2-CS/CR (11)

C3-CS/CR (3)
$47.8 \quad 8 \mathrm{e}-66$

$50.9 \quad 6 e-73$

$93.6 \quad 0.0$

$81.2 \quad 0.0$

80.4

0.0

$80.4 \quad 1 \mathrm{e}-111$

a Gene name abbreviations:ACO: aminocyclopropane carboxylate oxidase, ACS: aminocyclopropane carboxylate synthase, EFE: ethylene forming enzyme, ETO: ethylene overproduction $S A M$ : S-adenosylmethionine synthetase.

${ }^{\mathrm{b}}$ C: contig, CA: Citrus aurantium, CG: Citrus aurantifolia, CR: Citrus reticulata, CS: Citrus sinensis, LT: Citrus latifolia, PT: Poncirus trifoliata, (number of reads).

${ }^{c}$ Identity percentage at the amino acid level.

${ }_{\mathrm{d}}^{\mathrm{d}}$ rotein motif abbreviations: ACC: aminocyclopropane-1-carboxylate, BTB: broad complex-tramtrack-bric-à-brac, TRP: tetratrico peptide repeat.

eACO family: AT2G19590, AT3G47190.

fACS family: AT1G01480, AT1G62960, AT2G22810, AT3G49700 (ETO3), AT4G08040, AT4G11280, AT4G26200, AT4G37770, AT5G51690, AT5G65800, AT3G47190. 
Table S9 - Citrus ESTs with homology to genes involved in ethylene signal transduction in Arabidopsis thaliana.

\begin{tabular}{|c|c|c|c|c|c|c|}
\hline \multicolumn{2}{|c|}{ Arabidopsis thaliana } & \multicolumn{3}{|l|}{ CitEST } & \multicolumn{2}{|l|}{ Protein motifs $^{\mathrm{d}}$ and } \\
\hline Name $^{a}$ & Gene & $\mathbf{E S T}^{\mathrm{b}}$ & $\%^{\mathrm{c}}$ & e value & biological process & References \\
\hline \multicolumn{7}{|c|}{ receptors } \\
\hline \multirow[t]{4}{*}{ ETRI } & AT1G66340 & C2-CS/CR (18) & 80.8 & 0.0 & GAF domain, histidine kinase & Chang et al., \\
\hline & & C12-CS/CR/PT (6) & 59.5 & $1 \mathrm{e}-158$ & A, response regulator receiver, & 1993; \\
\hline & & C7-CS/CR/PT (15) & 58.8 & 0.0 & ethylene perception & Chiwocha et \\
\hline & & C15-PT (2) & 45.9 & $1 \mathrm{e}-142$ & & al., 2005 \\
\hline \multirow[t]{2}{*}{ ETR2 } & AT3G23150 & CR05-C1-102-100-D04-CT & 45.1 & $9 e-47$ & ETR family & Sakai et al., \\
\hline & & & & & & 1998 \\
\hline \multirow[t]{5}{*}{ ERS1 } & AT2G40940 & C3-CS/CR (4) & 72.5 & 0.0 & GAF domain, histidine kinase & Hua et al., \\
\hline & & C4-CR/PT (3) & 44.9 & $1 e-151$ & A, response regulator receiver, & 1998, Sakai \\
\hline & & PT11-C1-901-090-C03-CT & 51.8 & 1e-96 & ethylene perception & et al., 1998; \\
\hline & & CSO0-C1-101-103-E11-EU & 50.5 & $1 \mathrm{e}-103$ & & Qu and \\
\hline & & & & & & Schaeller, \\
\hline
\end{tabular}




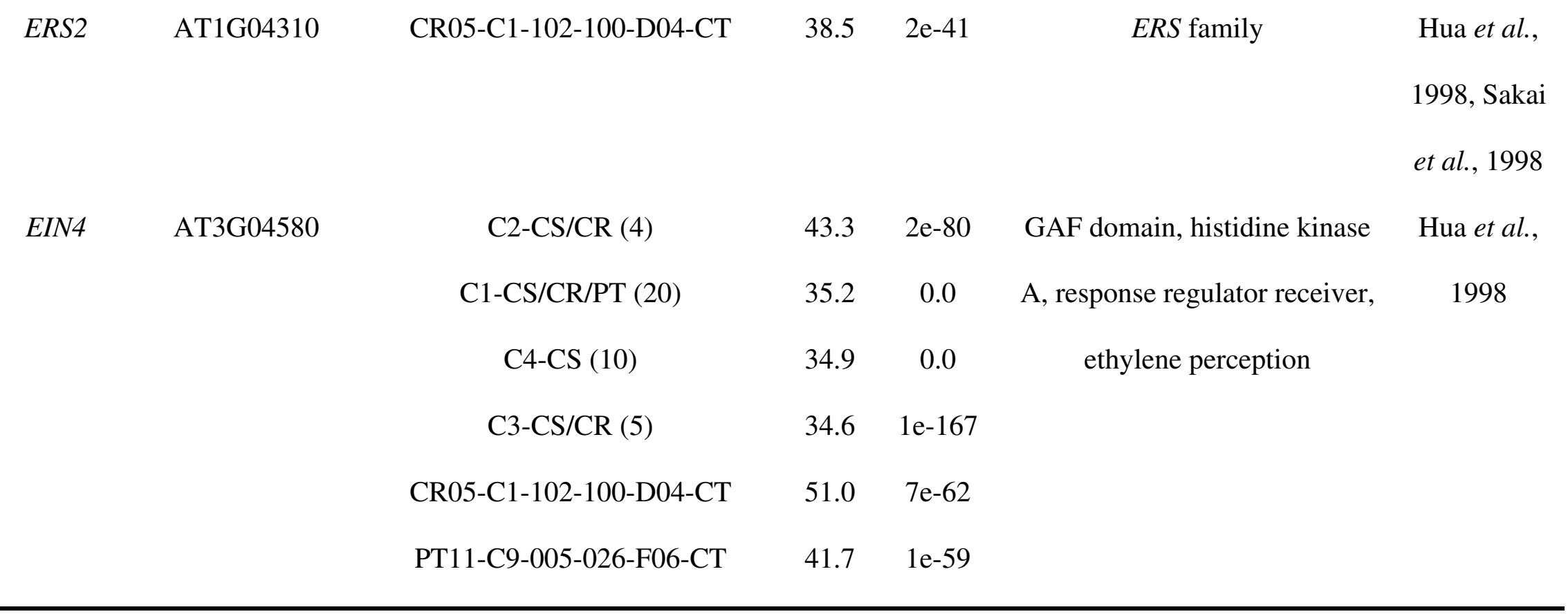

early events

\begin{tabular}{ccccccc}
\hline CTR1 & AT5G03730 & C3-CS (4) & 81.4 & $1 \mathrm{e}-137$ & serine/threonine protein kinase, & Kieber $e t$ \\
& C30-CG (2) & 50.4 & $3 \mathrm{e}-75$ & MAP kinase, signaling partner, al., 1993 \\
& C2-CS (6) & 40.6 & $1 \mathrm{e}-141$ & forms a complex with ethylene \\
& CR05-C3-700-099-B10-CT & 60.5 & $6 \mathrm{e}-61$ & receptor \\
& CS00-C3-702-066-C07-CT & 45.6 & $1 \mathrm{e}-142$ & \\
& C3-PT (3) & 60.1 & $1 \mathrm{e}-100$ & NRAMP, metal transporter Guzman and
\end{tabular}


C1-CA/CS (9) $\quad 43.7 \quad$ 1e-137 family, signaling partner $\quad$ Ecker, 1990;

Alonso et

al., 1999

RAN1

AT5G44790

CR05-C1-100-099-E06-CT

$57.3 \quad 9 \mathrm{e}-85$

E1, E2 copper-exporting

Hirayama et

ATPase, signaling partner

al., 1999

\begin{tabular}{|c|c|c|c|c|c|c|}
\hline \multicolumn{7}{|c|}{ primary transcription factors } \\
\hline$\overline{E I N 3}$ & AT3G20770 & C1-CS/PT (6) & 63.7 & $1 \mathrm{e}-65$ & EIN3 domain, transcriptional & Guo and \\
\hline & & $\mathrm{C} 2-\mathrm{CS} / \mathrm{PT}(2)$ & 35.9 & $1 e-127$ & activator & Ecker, 2003 \\
\hline & & C4-CS (4) & 33.3 & $4 \mathrm{e}-47$ & & \\
\hline \multirow[t]{4}{*}{$E I L$ family $^{\mathrm{e}}$} & AT2G27050 & C6-CS/PT (13) EIL1 & 57.4 & 0.0 & similar to EIN3, transcriptional & Alonso et al., \\
\hline & & C5-CS/CR (14) EIL1 & 53.1 & $1 \mathrm{e}-178$ & activator & 2003 \\
\hline & & C3-CS (2) EIL1 & 45.4 & $3 e-67$ & & \\
\hline & & CS00-C3-700-066-A07-CT & 33.3 & $3 e-34$ & & \\
\hline
\end{tabular}

secondary transcription factors

C2-CR/CS (32)

$64.0 \quad 4 \mathrm{e}-95$

LRR cysteine-containing

Guo and 
C3-CR/PT (5)

$41.8 \quad 3 e-51$ subtype, cyclin-like F box,

EREBP, transcriptional

regulator

HLS1 AT4G37580
$51.37 e-69$

45.9

$3 e-59$

\section{C1-CS (3)}

\section{regulator}

N-acetyltransferase, putative, Lehman et

histone deacetylation

al., 1996; Li

${ }^{\mathrm{a} G e n e}$ name abbreviations: CTR: constitutive triple response; EBF: ethylene binding factor; EIL: EIN3-like; EIN: ethylene insensitive; ERS: ethylene response sensor; ETR:ethylene receptor; HLS: hookless; RAN: responsive to antagonist.

${ }^{\mathrm{b}} \mathrm{C}$ : contig, CG: Citrus aurantifolia, CR: Citrus reticulata, CS: Citrus sinensis, PT: Poncirus trifoliata, (number of reads).

${ }^{\mathrm{c}}$ Identity percentage at the amino acid level.

${ }^{\mathrm{d}}$ Protein motif abbreviations: ATP: adenosine triphosphate; GAF: cGMP-specific and -stimulated phosphodiesterases, Anabaena adenyMte cydases and Escherichia coli FhlA; GMP: EREBP: ethylene response element binding protein, LRR: leucine-rich repeat; MAP: mitogen-activated protein kinase; NRAMP: natural resistance-associated macrophage protein.

${ }^{\text {e} E I N 3 / E I L ~ f a m i l y: ~ A T 5 G 21120, ~ A T 1 G 73730 . ~}$ 
Table S10 - Citrus ESTs with homology to genes involved in gibberellic acid biosynthesis, metabolism and signal transduction in Arabidopsis thaliana.

\begin{tabular}{|c|c|c|c|c|c|c|}
\hline \multicolumn{2}{|c|}{ Arabidopsis thaliana } & \multicolumn{3}{|c|}{ CitEST } & \multicolumn{2}{|l|}{ Protein motifs and } \\
\hline Name $^{a}$ & Gene & $\mathbf{E S T}^{b}$ & $\%^{\mathrm{c}}$ & e value & biological process & References \\
\hline \multicolumn{7}{|c|}{ biosynthesis and metabolism } \\
\hline$K A O-1$ & AT5G25900 & C1-CS (6) & 35.3 & $2 e-65$ & ent-kaurene acid oxidase, & Hedden and \\
\hline \multirow[t]{2}{*}{$G A 3$} & & & & & oxides ent -kaurene to ent- & Phillips, \\
\hline & & & & & kaurenoic acid & 2000 \\
\hline GA3 & AF537321.1 & C2-CS (16) & 28.2 & $3 e-55$ & ent -kaurene acid oxidase & Hedden and \\
\hline \multirow[t]{2}{*}{$K A O-1$} & & & & & family & Phillips, \\
\hline & & & & & & 2000 \\
\hline GA3 & AT5G25900 & $\mathrm{C} 3-\mathrm{CS}(2)$ & 31.2 & $3 e-62$ & ent -kaurene acid oxidase & Hedden and \\
\hline \multirow[t]{2}{*}{$K A O-1$} & & & & & family & Phillips, \\
\hline & & & & & & 2000 \\
\hline$G A 3$ & AT5G25900 & C4-CS (3) & 51.6 & $7 e-81$ & ent -kaurene acid oxidase & Hedden and \\
\hline$K A O-1$ & & & & & family & Phillips, \\
\hline
\end{tabular}




\begin{tabular}{|c|c|c|c|c|c|c|}
\hline \multirow[t]{2}{*}{$K A O 2$} & AF537321.1 & C5-CS (3) & 56.1 & $1 \mathrm{e}-76$ & ent -kaurene acid oxidase & Hedden and \\
\hline & & CSO0-C3-700-003-C06-CT & 42.0 & $2 \mathrm{e}-47$ & family & Phillips, \\
\hline & & & & & & 2000 \\
\hline \multirow[t]{3}{*}{ KAO2 } & AT2G32440 & C6-CS/CR (6) & 17.5 & $6 e-24$ & ent -kaurene acid oxidase & Hedden and \\
\hline & & CSO0-C2-003-029-C06-CT & 10.6 & $1 \mathrm{e}-15$ & family & Phillips, \\
\hline & & & & & & 2000 \\
\hline \multirow[t]{3}{*}{ KAO2 } & AT2G32440 & C7-PT (2) & 21.1 & $6 e-45$ & ent -kaurene acid oxidase & Hedden and \\
\hline & & & & & family & Phillips, \\
\hline & & & & & & 2000 \\
\hline \multirow[t]{3}{*}{$G A 4$} & AT5G24530 & C8-CS/CR (2) & 15.8 & $2 \mathrm{e}-21$ & GA3b hydroxilase, converts & Yamaguchi \\
\hline & & CS00-C1-102-018-C03-CT & 56.8 & $5 e-40$ & $\mathrm{GA}_{9}$ to $\mathrm{GA}_{4}$ e $\mathrm{GA}_{20}$ to $\mathrm{GA}_{1}$ & and Kamiya, \\
\hline & & & & & & 2000 \\
\hline GA5 & AT4G10490 & C9-CS (3) & 18.2 & 0.0 & GA20 oxidase 1 biosynthesis, & Yamaguchi \\
\hline \multirow[t]{2}{*}{ GA20OXI } & & & & & converts $\mathrm{GA}_{12}$ to $\mathrm{GA}_{9}$ and $\mathrm{GA}_{53}$ & and Kamiya, \\
\hline & & & & & to $\mathrm{GA}_{20}$ Converts $\mathrm{GA}_{12}$ to $\mathrm{GA}_{25}$ & 2000 \\
\hline
\end{tabular}




\begin{tabular}{|c|c|c|c|c|c|c|}
\hline GA5 & AT5G51810 & C10-CS (2) & 43.0 & $2 \mathrm{e}-61$ & Gibberellin GA20 oxidase, & Yamaguchi \\
\hline \multirow[t]{2}{*}{ GA20OXI } & & CS00-C3-704-020-H12-CT & 34.0 & $5 e-35$ & converts $\mathrm{GA}_{12}$ to $\mathrm{GA}_{9}$ and $\mathrm{GA}_{53}$ & and Kamiya, \\
\hline & & & & & to $\mathrm{GA}_{20}$ & 2000 \\
\hline \multirow[t]{4}{*}{ GA $20 X 1$} & AT1G50960 & C1-CS/CR (21) & 21.9 & $2 \mathrm{e}-32$ & Gibberellin 2-oxidase1, & Yamaguchi \\
\hline & & PT11-C1-901-051-F06-CT & 17.8 & $8 \mathrm{e}-26$ & converts $\mathrm{C} 19-\mathrm{GA}$ to & and Kamiya, \\
\hline & & & & & biologically inactive GA. GA & 2000 \\
\hline & & & & & catabolism. & \\
\hline \multirow[t]{3}{*}{ GA2OX1 } & AT3G63010 & C2-CS (2) & 64.4 & $1 \mathrm{e}-112$ & Gibberellin 2-oxidase1 family & Yamaguchi \\
\hline & & & & & & and Kamiya, \\
\hline & & & & & & 2000 \\
\hline \multirow[t]{2}{*}{$C P S / G A 1$} & & CS00-C1-100-036-B10-CT & 12.2 & $2 e-54$ & converts geranyl-geranyl & Yamaguchi \\
\hline & & & & & diphosphate to ent-Copalyl & et al., 1998 \\
\hline
\end{tabular}

signal transduction

DELLA- AT5G27320 C1-CS/CL (3) $18.2 \quad$ 2e-43 cytochrome P450, GAI-RGA Bolle et al.,


modulator

\begin{tabular}{|c|c|c|c|c|c|c|}
\hline DELLA- & AT1G50420 & C2-CS (5) & 33.1 & $7 e-69$ & GAI-RGA family & Bolle et al., \\
\hline$G A I / R G A$ & & & & & & 2004 \\
\hline$D E L L A-$ & AT2G14920 & C3-CS/CR (2) & 74.0 & 0.0 & GAI-RGA family & Bolle et al., \\
\hline$G A I / R G A$ & & & & & & 2004 \\
\hline DELLA- & AT2G01570 & C4-CS/CR/PT (6) & 17.4 & $2 \mathrm{e}-42$ & GAI-RGA family & Bolle et al., \\
\hline GAI/RGA & & & & & & 2004 \\
\hline DELLA- & AT1G14920 & C5-CG (2) & 35.0 & $4 e-71$ & GAI-RGA family & Bolle et al., \\
\hline$G A I / R G A$ & & & & & & 2004 \\
\hline DELLA- & AT2G01570 & C6-CS/PT (2) & 32.3 & $1 e-69$ & GAI-RGA family & Bolle et al., \\
\hline$G A I / R G A$ & & & & & & 2004 \\
\hline GAI & AT1G14920 & LT33-C1-003-051-C11-CT & 6.8 & $8 e-26$ & GAI-RGA family & Pysh et al., \\
\hline & & & & & & 1999 \\
\hline$G A M Y B$ & AT1G77180 & CR05-C1-103-051-C01-CT & 13.6 & $6 e-23$ & & Gocal et al., \\
\hline
\end{tabular}




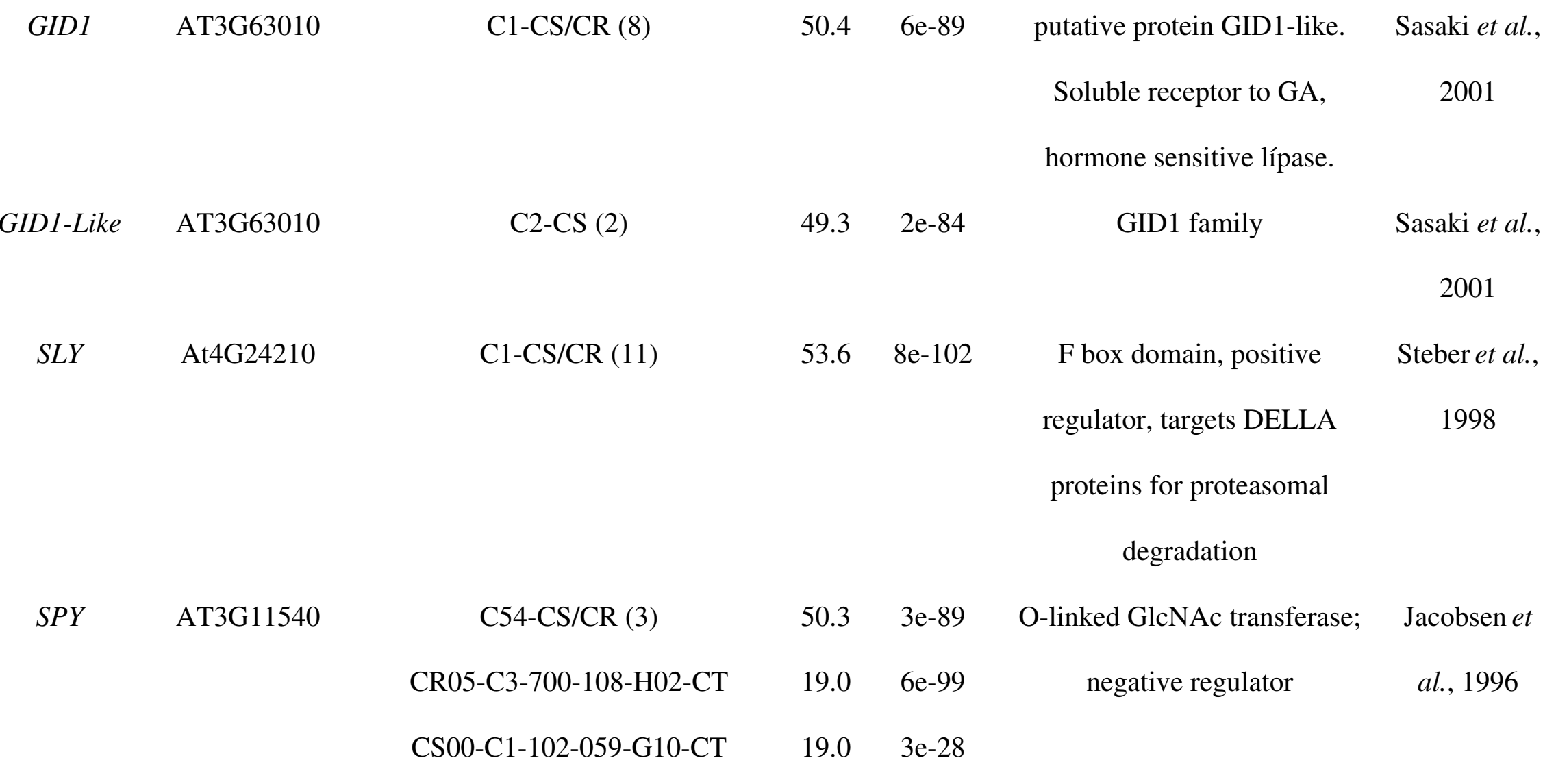

\footnotetext{
${ }^{\mathrm{a}}$ Gene name abbreviations: $C P S$ : ent-copalyl diphosphate synthase, GAI: gibberellic acid insensitive, GAMYB: gibberellic acid-induced MYB transcription factor, GAOX: gibberellic acid oxidase; GID: gibberellin insensitive dwarf-1, KAO: kaurene acid oxidase, RGA: repressor of gal-3, SLY: sleepy, SPY: spindly.

${ }^{\mathrm{b}} \mathrm{C}$ : contig, CL: Citrus limonia, CR: Citrus reticulata, CS: Citrus sinensis, LT: Citrus latifolia, PT: Poncirus trifoliata, (number of reads).

${ }^{\mathrm{c}}$ Identity percentage at the amino acid level.
} 
Table S11 - Citrus ESTs with homology to genes involved in jasmonic acid biosynthesis in Arabidopsis thaliana.

\begin{tabular}{|c|c|c|c|c|c|c|}
\hline \multicolumn{2}{|c|}{ Arabidopsis thaliana } & \multicolumn{3}{|l|}{ CitEST } & \multicolumn{2}{|l|}{ Protein motifs ${ }^{\mathrm{c}}$ and } \\
\hline Name $^{a}$ & Gene & $\mathbf{E S T}^{\mathrm{b}}$ & $\%^{c}$ & e value & biological process & References \\
\hline$A O C /$ & AT3G25760 & C1-CS (5) AOC4 & 55.1 & $8 \mathrm{e}-70$ & oxide cyclase, formation of & He et al., \\
\hline ERD12 & & $\mathrm{C} 3-\mathrm{CS} / \mathrm{CR}$ (3) AOC2 & 48.4 & $5 e-58$ & cyclic allene oxide, & 2002 \\
\hline family & & PT11-C9-005-019-B11-CT - AOC2 & 58.9 & $4 \mathrm{e}-74$ & 13-hydroxyperoxyde & \\
\hline \multirow{3}{*}{ AOS1 } & \multirow{3}{*}{ AT5G42650 } & & \multicolumn{4}{|c|}{ metabolism } \\
\hline & & C4-CS/PT (2) & 44.5 & $1 \mathrm{e}-165$ & cytochrome p450 CYP74, & von Malek et \\
\hline & & C3-CR/PT (4) & 41.1 & 1e-101 & allene oxide synthesis, & al., 2002 \\
\hline \multirow{7}{*}{ AtSS family } & \multirow{7}{*}{ AT1G74020 } & C1-CS/CR (20) & 39.2 & $1 \mathrm{e}-122$ & \multirow[t]{3}{*}{ 9-hydroxyperoxyde metabolism } & \\
\hline & & C2- CS (8) & 36.0 & $2 \mathrm{e}-76$ & & \\
\hline & & PT11-C1-900-026-D07-CT & 32.3 & $1 e-66$ & & \\
\hline & & C6-CS/PT (2) & 34.9 & $1 \mathrm{e}-78$ & \multirow{4}{*}{$\begin{array}{l}\text { strictosidine synthase, alkaloid } \\
\text { and terpenoid biosynthesis }\end{array}$} & Devoto et \\
\hline & & C5-CS/PT (4) & 34.6 & $1 \mathrm{e}-74$ & & al., 2005 \\
\hline & & C4-CS/CR/LT/PT (7) & 31.9 & $6 e-78$ & & \\
\hline & & C3-CS (4) & 27.5 & $1 e-47$ & & \\
\hline
\end{tabular}




\begin{tabular}{|c|c|c|c|c|c|c|}
\hline & & CR05-C1-103-066-G10-CT & 21.4 & $5 e-56$ & & \\
\hline & & CS00-C3-704-013-C11-CT & 20.8 & $5 e-35$ & & \\
\hline \multirow[t]{5}{*}{$D A D 1$} & AT2G44810 & C1-CS/CG (2) & 33.7 & $2 \mathrm{e}-87$ & esterase/lipase/thioesterase, & Matsui et al., \\
\hline & & C2-CS (5) & 25.7 & $2 \mathrm{e}-81$ & chloroplast phospholipase A1, & 2004 \\
\hline & & C3-CR (7) & 25.0 & $2 \mathrm{e}-80$ & oxylipin biosynthesis & \\
\hline & & CR05-C1-102-055-E10-CT & 24.4 & 1e-79 & & \\
\hline & & CR05-C3-701-019-C07-CT & 23.5 & $1 e-37$ & & \\
\hline \multirow[t]{9}{*}{$F A S$} & AT4G05160 & C13-CG (2) & 54.0 & $3 e-148$ & AMP-dependent synthetase and & Liechti et al., \\
\hline & & C5-CS/CR/CL (3) & 40.8 & $1 \mathrm{e}-150$ & ligase, fatty acid esterification & 2006 \\
\hline & & $\mathrm{C} 3-\mathrm{CS} / \mathrm{CR} / \mathrm{CA}(12)$ & 33.6 & 1e-91 & & \\
\hline & & C7-CS-CG (6) & 31.7 & $1 e-115$ & & \\
\hline & & C2-CS/PT (7) & 30.7 & $1 e-102$ & & \\
\hline & & C9-CS/CR/PT (9) & 23.5 & $1 e-96$ & & \\
\hline & & C4-CR/CS (3) & 21.4 & $5 e-72$ & & \\
\hline & & C11-CS/CR/PT (15) & 21.0 & $1 e-71$ & & \\
\hline & & CG32-C1-003-036-C11-CT & 40.5 & $1 e-136$ & & \\
\hline
\end{tabular}




\begin{tabular}{|c|c|c|c|c|c|c|}
\hline & & PT11-C1-900-014-E04-CT & 40.5 & $1 e-63$ & & \\
\hline & & CR05-C3-701-007-F02-CT & 37.4 & $6 e-42$ & & \\
\hline & & PT11-C1-901-019-D03-CT & 31.4 & $1 e-46$ & & \\
\hline & & LT33-C1-003-020-D08-CT & 26.5 & $1 e-36$ & & \\
\hline & & CS00-C3-704-092-H02-CT & 25.8 & $3 e-37$ & & \\
\hline & & CS00-C3-700-089-H08-CT & 24.6 & $1 e-93$ & & \\
\hline & & CSO0-C3-700-016-E08-CT & 23.2 & $4 e-75$ & & \\
\hline & & CR05-C1-102-040-B05-CT & 22.2 & $2 e-31$ & & \\
\hline$J M T$ & AT1G19640 & C7-CS/CR (53) & 45.5 & $9 e-89$ & s-adenyl-methione- dependent & Seo et al., \\
\hline & & C5-CS (2) & 35.4 & $2 e-46$ & carboxyl methyltransferase, & 2001 \\
\hline & & C4-CS (4) & 33.2 & $8 e-30$ & formation of methyljasmonate & Zubieta $e t$ \\
\hline & & C6-CR (2) & 30.8 & $1 e-32$ & from jasmonic acid & al., 2003 \\
\hline & & C1-CS/CR (2) & 30.1 & $6 e-40$ & & \\
\hline & & $\mathrm{C} 2-\mathrm{CS} / \mathrm{CR}(11)$ & 30.1 & $2 e-33$ & & \\
\hline & & C3-CS (2) & 20.7 & $1 \mathrm{e}-28$ & & \\
\hline & & CR05-C1-102-008-E06-CT & 37.8 & $1 e-47$ & & \\
\hline
\end{tabular}




\begin{tabular}{|c|c|c|c|c|c|c|}
\hline & & CR05-C1-102-065-B11-CT & 33.2 & $1 \mathrm{e}-41$ & & \\
\hline & & CSO0-C5-003-042-D10-CT & 29.0 & $2 \mathrm{e}-48$ & & \\
\hline & & CS00-C3-705-072-E08-CT & 27.2 & $8 \mathrm{e}-34$ & & \\
\hline & & CSO0-C3-703-095-H07-CT & 27.2 & $6 e-32$ & & \\
\hline & & CS00-C1-100-036-G09-CT & 25.1 & $4 e-53$ & & \\
\hline & & CL06-C4-500-008-D11-CT & 24.3 & $5 e-27$ & & \\
\hline LOX family & AT1G55020 & C3-CS/CR/LT/PT (7) AtLOX3 & 71.9 & 0.0 & lipoxygenase, LH2 domain, & Bell and \\
\hline & & C5-CR (2) AtLOX3 & & & hydroperoxidation of lipids & Mullet, \\
\hline & & C1-CS/CR (12) AtLOX2 & 62.8 & $1 \mathrm{e}-121$ & & 1993; \\
\hline & & C8-CL (2) AtLOX2 & 61.5 & $1 e-168$ & & Montillet et \\
\hline & & $\mathrm{C} 2-\mathrm{CS}(2) \operatorname{AtLOX} 1$ & 58.4 & $2 \mathrm{e}-90$ & & al., 2004 \\
\hline & & C4-CS/CR/PT (89) AtLOX2 & 58.2 & $9 e-93$ & & \\
\hline & & C6-CS (5) AtLOX3 & 57.0 & 0.0 & & \\
\hline & & C7-CS/PT (3) AtLOX1 & 53.6 & 0.0 & & \\
\hline & & CS00-C3-701-113-F10-CT- & 38.8 & 0.0 & & \\
\hline & & $A t \mathrm{LOX} 2$ & 65.2 & $3 e-90$ & & \\
\hline
\end{tabular}




\begin{tabular}{|c|c|c|c|c|c|c|}
\hline & & CR05-C1-102-100-D10-CT & & & & \\
\hline & & $-\operatorname{At} \mathrm{LOX} 2$ & 59.4 & $1 \mathrm{e}-105$ & & \\
\hline & & CG32-C1-003-091-C03-CT - & & & & \\
\hline & & $A t \mathrm{LOX} 1$ & 53.1 & 1e-92 & & \\
\hline & & PT11-C2-301-049-G03-CT- & & & & \\
\hline & & AtLOX2 & 51.4 & $4 e-97$ & & \\
\hline & & CR05-C3-701-084-G10-CT- & & & & \\
\hline & & AtLOX2 & 50.5 & $4 e-84$ & & \\
\hline & & CR05-C1-103-013-A07-CT- & & & & \\
\hline & & $A t \mathrm{LOX} 1$ & 47.7 & $2 e-64$ & & \\
\hline & & CS00-C3-701-073-E12-CT - & & & & \\
\hline & & $A t \mathrm{LOX} 2$ & 29.6 & $1 e-84$ & & \\
\hline$O P R / D D E$ & AT1G76680 & C1-CS (2) OPR2 & 74.6 & $1 \mathrm{e}-168$ & NADH:flavin & Biesgen and \\
\hline family & & C4-CS (7) OPRL2 & 71.4 & $1 \mathrm{e}-141$ & oxidoreductase/NADH oxidase, & Weiler, \\
\hline & & C5-CA/CR (2) OPR1 & 66.5 & $8 \mathrm{e}-88$ & oxylipin metabolism & 1999; Costa \\
\hline & & C2-CS/CR (7) OPR3/DDE1 & 57.4 & $1 \mathrm{e}-108$ & & et al., 2000 \\
\hline
\end{tabular}




\begin{tabular}{|c|c|c|c|c|}
\hline C7-PT (2) OPR3/DDE1 & 48.9 & $6 e-77$ & & \\
\hline C3-CS/CR (2) OPR1 & 30.6 & $3 e-57$ & & \\
\hline C6-CS/CR (11) OPR2 & 28.1 & $2 e-26$ & & \\
\hline CR05-C3-702-015-A10-CT- OPR2 & 66.9 & 1e-104 & & \\
\hline PT11-C1-901-020-B03-CT- OPR1 & & & & \\
\hline & 60.7 & 1e-108 & & \\
\hline C4-CS/CR/PT (14) & 88.7 & 0.0 & thiolase, fatty acid $\beta$-oxidation & Pinfiel-Wells \\
\hline C3-CS/LT (12) & 77.7 & 0.0 & & et al., 2005; \\
\hline C5-CG (4) & 38.2 & $8 \mathrm{e}-31$ & & Weber et al., \\
\hline C1-CS (3) & 33.5 & $1 \mathrm{e}-69$ & & 1997 \\
\hline C2-CS/CR/PT (8) & 31.7 & $1 \mathrm{e}-63$ & & \\
\hline PT11-C1-900-034-A08-CT & 55.7 & $3 e-76$ & & \\
\hline CS00-C1-101-061-E07-CT & 51.1 & $6 e-71$ & & \\
\hline C1-CA/CS/CR/PT (9) & 83.5 & 0.0 & fatty acid desaturase, type 2 , & Kachroo et \\
\hline C2-CS (4) & 47.0 & $7 e-74$ & fatty acid desaturation & al., 2001; \\
\hline PT11-C9-005-040-F11-CT & 45.8 & $2 \mathrm{e}-71$ & & Kachroo et \\
\hline
\end{tabular}




$\begin{array}{lll}\text { CS00-C3-701-010-D08-CT } & 35.9 & 8 \mathrm{e}-34 \\ \text { CA26-C1-002-053-D07-CT } & 33.9 & 2 \mathrm{e}-54 \\ & & \\ \text { CA26-C1-002-049-D02-CT } & 30.6 & 2 \mathrm{e}-38\end{array}$

\footnotetext{
${ }^{\mathrm{a}}$ Gene name abbreviations: $A O C$ : allene oxide cyclase, $A O S$ : allene oxide synthase, AtSS: strictosidine synthase, $D A D$ : defective in anther dehiscence, $D D E$ : deiscence dficient, ERD: early-responsive to dehydration stress protein, FAS:fatty acid esterification, JMT: jasmonic acid carboxyl methyltransferase, $L O X$ : lipoxygenase, $O P R$ : $12-$ oxophytodienoate reductase, $P E D$ : peroxisome defective, $S S$ : stearoyl-ACP desaturase.

${ }^{\mathrm{b}}$ Identity percentage at the amino acid level.

${ }^{\mathrm{b}} \mathrm{C}$ : contig, CA: Citrus aurantium, CG: Citrus aurantifolia, CL: Citrus limonia, CR: Citrus reticulata, CS: Citrus sinensis, LT: Citrus latifolia, PT: Poncirus trifoliata, (number of reads).

${ }^{c}$ Functional domain abbreviations: AMP: adenosine monophosphate; CYP: cytochrome protein; LH: leucine and histidine; NADH: reduced nicotinamide adenine dinucleotide.
} 
Table S12 - Citrus ESTs with homology to genes involved in jasmonic acid-mediated signal transduction in Arabidopsis thaliana.

\begin{tabular}{|c|c|c|c|c|c|c|}
\hline \multicolumn{2}{|c|}{ Arabidopsis thaliana } & \multicolumn{2}{|c|}{ CitEST } & \multicolumn{3}{|c|}{ Protein motifs ${ }^{\mathrm{d}}$ and } \\
\hline Name $^{\mathrm{a}}$ & Gene & $\mathbf{E S T}^{\mathrm{b}}$ & $\%^{\mathrm{c}}$ & e value & biological process & References \\
\hline \multirow[t]{3}{*}{$\overline{A S 1}$} & AT2G37630 & C25-CS/CR (4) & 67.3 & $1 \mathrm{e}-138$ & MYB-type DNA binding factor, & He and Gan, \\
\hline & & C31-PT (2) & 20.7 & $1 e-68$ & transcriptional regulation, & 2001 \\
\hline & & C19-CS (8) & 20.4 & $2 e-67$ & development & \\
\hline \multirow[t]{10}{*}{ ATAF2 } & AT5G08790 & C12-PT (2) & 54.3 & $6 e-80$ & NAM family, NAC domain, & Delessert et \\
\hline & & C14-CS/CA (8) & 50.7 & $4 e-80$ & putative transcriptional & al., 2005 \\
\hline & & C13-PT (2) & 41.7 & $1 e-77$ & activator & \\
\hline & & C7-CS/PT (8) & 39.6 & $2 e-87$ & & \\
\hline & & C9-CS/CR/CG (3) & 33.1 & $3 e-79$ & & \\
\hline & & C5-CS/CR (6) & 32.5 & $2 \mathrm{e}-83$ & & \\
\hline & & C1-CS (2) & 32.2 & $6 e-81$ & & \\
\hline & & $\mathrm{C} 2-\mathrm{CS}(2)$ & 30.4 & $2 e-77$ & & \\
\hline & & C4-CS (7) & 30.0 & $7 e-68$ & & \\
\hline & & C10-CS (8) & 29.7 & $1 \mathrm{e}-49$ & & \\
\hline
\end{tabular}




\begin{tabular}{|c|c|c|c|c|c|c|}
\hline & & C8-CR (4) & 29.0 & $4 e-69$ & & \\
\hline & & $\mathrm{C} 11-\mathrm{CS} / \mathrm{PT}(2)$ & 27.0 & $1 e-57$ & & \\
\hline & & C3-CS (5) & 26.1 & $6 e-56$ & & \\
\hline & & PT11-C1-901-017-B05-CT & 25.8 & $3 e-47$ & & \\
\hline & & LT33-C1-003-033-C02-CT & 24.7 & $2 e-49$ & & \\
\hline & & CR05-C3-700-031-C10-UV & 20.3 & $1 \mathrm{e}-28$ & & \\
\hline AtCHL2 & AT5G43860 & C1-CS/CR (32) & 38.4 & $4 e-67$ & esterase/lipase/thioesterase, & Tsuchiya et \\
\hline & & C2-PT (3) & 30.6 & $5 e-34$ & chlorophyll degradation & al., 1999 \\
\hline & & CR05-C3-702-087-F05-CT & 37.6 & $5 e-53$ & & \\
\hline$A t H C H 1 B$ & AT3G12500 & C3-CS/CR/PT (4) & 56.2 & 1e-102 & basic endochitinase, signaling & Ellis and \\
\hline & & C4-CR (4) & 56.2 & 1e-105 & pathway during systemic & Turner, 2001 \\
\hline & & C7-PT (2) & 52.6 & $2 \mathrm{e}-99$ & acquired resistance & \\
\hline & & C8-PT (2) & 52.5 & $4 e-91$ & & \\
\hline & & $\mathrm{C} 1-\mathrm{CS} / \mathrm{CR}(10)$ & 51.6 & $3 e-93$ & & \\
\hline & & C6-CS/CR (40) & 50.3 & $2 \mathrm{e}-91$ & & \\
\hline & & C5-CR (8) & 48.1 & $4 e-89$ & & \\
\hline
\end{tabular}




\begin{tabular}{|c|c|c|c|c|c|c|}
\hline & & C2-CS (4) & 46.7 & $3 e-71$ & & \\
\hline & & PT11-C2-301-044-E11-CT & 43.1 & $5 e-84$ & & \\
\hline \multirow[t]{13}{*}{ AtMPK4 } & AT4G01370 & C7-CS (3) & 76.9 & $1 e-159$ & MAP kinase, mediates & Grant et al., \\
\hline & & C8-CS/PT (9) & 73.7 & $1 e-163$ & pathogen-induced responses & 2000 \\
\hline & & C2-CS (9) & 68.6 & $1 \mathrm{e}-150$ & & \\
\hline & & C9-CS/PT (6) & 65.7 & $1 e-143$ & & \\
\hline & & C1-CS/CR (9) & 52.9 & $1 \mathrm{e}-117$ & & \\
\hline & & C4-CS/CR (4) & 44.4 & $1 e-104$ & & \\
\hline & & C6-CR (7) & 43.4 & $1 e-106$ & & \\
\hline & & C5-CR (3) & 42.8 & 2e-99 & & \\
\hline & & C11-CS/CG (2) & 39.0 & $3 e-94$ & & \\
\hline & & C10-CR/PT (2) & 35.4 & $1 \mathrm{e}-71$ & & \\
\hline & & C3-CS/CR (4) & 28.4 & $3 e-72$ & & \\
\hline & & PT11-C2-300-090-C08-CT & 54.0 & $6 e-95$ & & \\
\hline & & CR05-C1-100-043-E08-CT & 31.9 & $3 e-81$ & & \\
\hline$A t P R B 1$ & AT2G14580 & C1-CS/CL (2) & 44.1 & $7 e-38$ & allergen $\mathrm{V} 5 / \mathrm{Tpx}-1$ related & Santamaria \\
\hline
\end{tabular}


CS00-C2-003-083-H02-CT

$C A D 1$

AT5G44070

COII

AT2G39940

CORI3

AT4G23600

CPC AT2G46410

CA26-C1-002-066-G04-CT

$43.5 \quad 4 \mathrm{e}-40$

domain, pathogenesis related

et al., 2001;

protein

Mur et al.,

2006

80.5 3e-90 phytochelatin synthase domain, Xiang and

$30.4 \quad 1 \mathrm{e}-36$

cadmium tolerance

Oliver, 1998

$72.9 \quad 1 \mathrm{e}-115$

E3 ubiquitin ligase SCF

Devoto et

$46.3 \quad 4 \mathrm{e}-55$

complex F-box subunit, LRR-

al., 2002;

C1-CS/LT (4)

C7-CR/CL/CA (3)

C1-CS/CR (2)

CR05-C1-102-097-D08-CT

CS00-C1-102-059-A03-CT

C3-CS/LT (2)

C10-CR/LT (3)

C9-CR/CG (2)
$29.7 \quad 5 e-37$

$29.5 \quad 1 e-27$

$32.0 \quad 1 \mathrm{e}-58$

$38.6 \quad 3 e-60$

$30.8 \quad 6 e-48$

$24.1 \quad 1 \mathrm{e}-45$

$39.53 e-46$

$39.5 \quad 2 \mathrm{e}-46$

$28.9 \quad 5 e-33$ containing, transcriptional

$$
\text { regulation }
$$

Ren et al.,

2005

aminotransferase domain class I Jones et al.,

and II, cystine lyase function,

2003

responsive to wounding

MYB-type DNA binding factor, Koshino-

transcriptional regulation, root

Kimura $e t$

differentiation

al., 2005; 
CS00-C2-003-009-A06-CT

40.0

$3 e-35$

$\begin{array}{ccc}\text { CPR5 / } & \text { AT5G64930 } & \text { CS00-C3-700-005-C07-CT } \\ \text { HYS1 } & \text { LT33-C1-003-078-H06-CT } \\ \text { CYT1 } & \text { AT2G39770 } & \text { C4-CS/LT (19) } \\ & \text { C3-CS (2) } \\ & \text { C1-CS (4) }\end{array}$

ESP

AT1G54040

$H D 1$

AT4G38130

$J R 1$

AT3G16470
CL06-C4-501-031-D06-CT

C2-CS (7)

C1-CS (4)

PT11-C2-300-054-C06-CT

C1-CS (2)

C2-LT (3)

CS00-C2-003-054-C10-CT

C2-CS/CR (3)

C1-CS (2)
$25.3 \quad 1 \mathrm{e}-24 \quad$ no functionally characterized

$21.3 \quad 5 \mathrm{e}-18$

89.5

$78.9 \quad 1 \mathrm{e}-160$

$41.0 \quad 1 \mathrm{e}-63$

$51.4 \quad 1 \mathrm{e}-86$

$42.9 \quad \mathrm{e}-104$

$20.5 \quad 7 \mathrm{e}-60$

$24.1 \quad 1 \mathrm{e}-85$

$85.2 \quad 0.0$

$31.1 \quad 1 \mathrm{e}-88$

$55.2 \quad 1 \mathrm{e}-107$

$27.3 \quad 5 e-29$

$22.2 \quad 2 \mathrm{e}-35$

domain, senescence

mannose-1-pyrophosphatase,

cell wall carbohydrate

biosynthesis and protein

glycosylation

$$
\text { motif (4 repeats) }
$$

Kwak et al.,

\section{5}

Yoshida et

al., 2002

al., 2001

epithiospecifier protein, Kelch

Zabala et al.,

2005

\begin{tabular}{|c|c|}
\hline histone deacetylase, jasmonic & Devoto et \\
\hline acid-induced pathogen & al., 2002 \\
\hline \multicolumn{2}{|l|}{ resistance } \\
\hline jacalin lectin family, lectin & León et al., \\
\hline
\end{tabular}




\begin{tabular}{|c|c|c|c|c|c|c|}
\hline & & CR05-C1-100-093-F10-CT & 19.9 & $1 e-35$ & binding protein, response to & al., 2006 \\
\hline & & CG32-C1-003-076-F02-CT & 19.3 & $2 \mathrm{e}-35$ & wounding & \\
\hline \multirow[t]{11}{*}{$L D O X$} & AT4G22880 & C3-CS (9) & 40.2 & $5 e-77$ & 2OG-Fe(II) oxygenase & Devoto et \\
\hline & & C6-CS/CR (22) & 39.9 & $5 e-76$ & superfamily, anthocyanin & al., 2005 \\
\hline & & C4-CS (2) & 33.2 & $1 \mathrm{e}-45$ & biosynthesis, vacuole formation & \\
\hline & & C2-CS/CR (2) & 32.1 & $4 e-48$ & & \\
\hline & & C1-CS/CR (3) & 31.6 & $2 \mathrm{e}-51$ & & \\
\hline & & C5-CS/CR (6) & 27.0 & $4 e-45$ & & \\
\hline & & PT11-C1-900-048-G06-CT & 35.5 & $6 e-65$ & & \\
\hline & & CR05-C1-102-021-H06-CT & 34.1 & $2 \mathrm{e}-57$ & & \\
\hline & & CS12-G8-000-003-B09-CT & 32.2 & $1 \mathrm{e}-59$ & & \\
\hline & & CS00-C3-700-004-D07-CT & 29.3 & $6 e-54$ & & \\
\hline & & CG32-C1-003-071-C04-CT & 28.9 & $5 e-52$ & & \\
\hline$M Y C 2 /$ & AT1G32640 & C2-CS/CR (2) & 39.1 & $4 e-59$ & basic helix-loop-helix DNA & Boter et al., \\
\hline JIN1 & & CR05-C3-701-055-H07-CT & 39.6 & $2 e-54$ & binding domain, transcriptional & 2004 \\
\hline
\end{tabular}




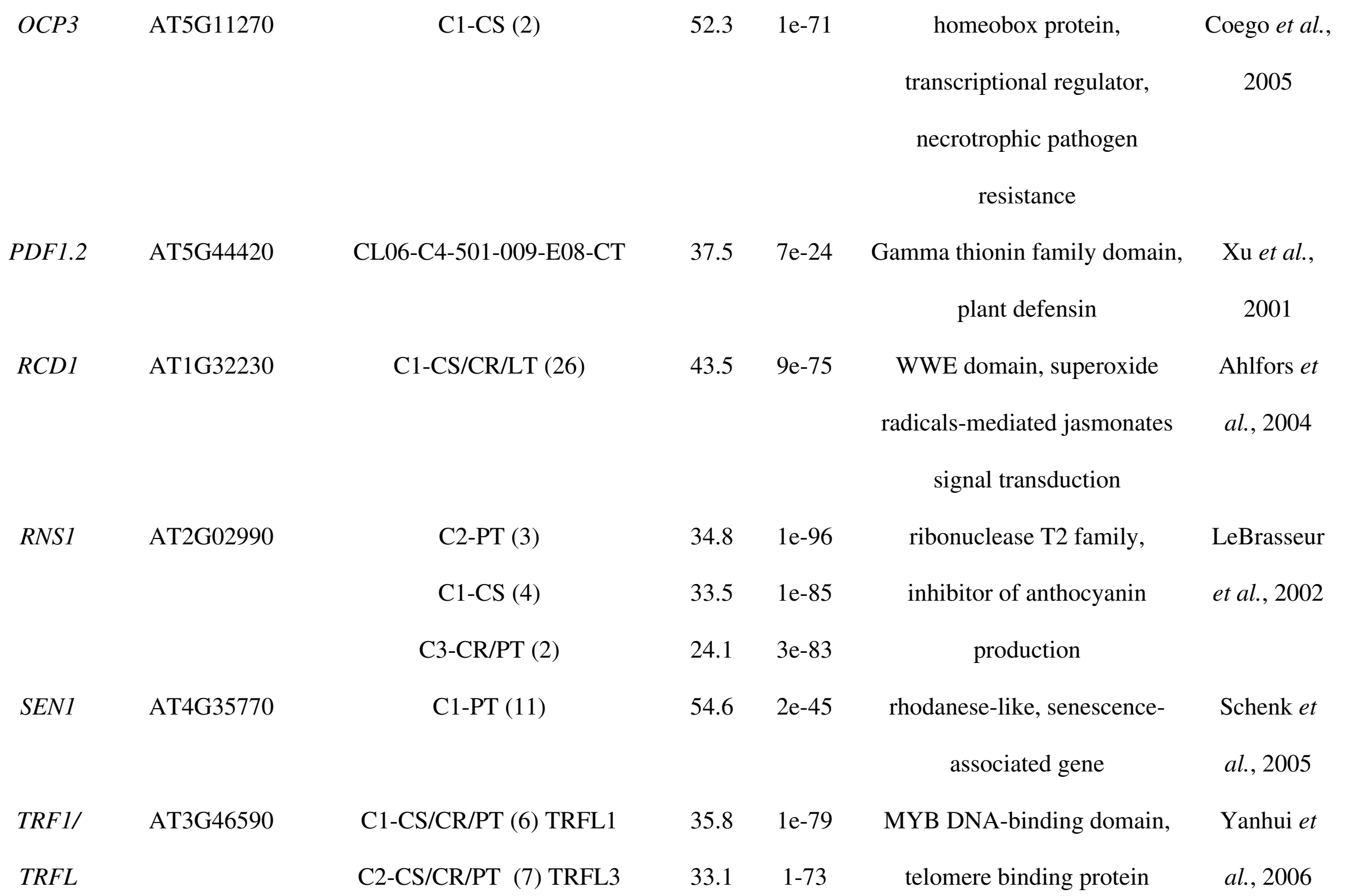




\begin{tabular}{|c|c|c|c|c|c|c|}
\hline \multirow{8}{*}{$V S P$ family } & \multirow[t]{8}{*}{ AT5G24780 } & C1-CS (2) VSP2 & 39.3 & $6 e-63$ & HAD superfamily (subfamily & Berger et al., \\
\hline & & C2-CR (12) VSP2 & 38.1 & $1 \mathrm{e}-62$ & IIIB) phosphatase, pathogen & 1995; Berger \\
\hline & & C3-CS/CR (5) VSP1 & 37.4 & $2 \mathrm{e}-55$ & and herbivore protection & et al., 2002 \\
\hline & & C4-CS (2) VSP2 & 28.0 & $5 e-56$ & & \\
\hline & & C5-CS/PT (6) VSP1, VSP2 & 22.6 & $1 e-56$ & & \\
\hline & & CSO0-C3-705-032-G02-CT VSP2 & 20.0 & $2 \mathrm{e}-44$ & & \\
\hline & & CA26-C1-002-050-E09-CT & & & & \\
\hline & & VSP2 & 18.5 & $1 \mathrm{e}-48$ & & \\
\hline \multirow[t]{3}{*}{ VTC2 } & \multirow[t]{3}{*}{ AT4G26850 } & C3-CS/CR (82) & 72.9 & $1 \mathrm{e}-176$ & novel protein, ascorbate & Pavet et al., \\
\hline & & C2-PT (2) & 51.0 & $1 \mathrm{e}-72$ & biosynthesis & 2005 \\
\hline & & C1-CS/CR (4) & 50.0 & $2 \mathrm{e}-78$ & & \\
\hline \multirow[t]{4}{*}{ WRKY70 } & \multirow[t]{4}{*}{ AT3G56400 } & C1-CS (2) & 35.0 & $7 e-34$ & WRKY transcription factor; & Li et al., \\
\hline & & C3-CS (2) & 29.3 & $4 e-33$ & Group III & 2004 \\
\hline & & C2-CS/PT (7) & 28.6 & $3 e-34$ & & \\
\hline & & C4-CR (3) & 23.5 & $9 e-45$ & & \\
\hline
\end{tabular}


${ }^{a}$ Gene name abbreviations: AS: asymmetric leaves, At: Arabidopsis thaliana, ATAF: Arabidopsis thaliana activation factor, CAD: cadmium sensitive, CHL: chlorophyllase, COI: coronatine insensitive, CORI: coronatine induced CPC: caprice , CPR: constitutive expressor of pathogenesis-related genes , CYT: cytokinesis defective , ESP: epithiospecifier modifier, $H C H$ : basic endochitinase, HD: histone deacetylase, HYS: hypersenescence , JIN: jasmonate insensitive, JR: jasmonic acid responsive , LDOX: leucoanthocyanidin dioxygenase , $M P K$ : mitogen-activated protein kinase, $O C P$ : overexpressor of cationic peroxidase, $P D F$ : plant defensin, $P R B$ : pathogenesis-related barley protein , RCD: radical-induced cell death, $R N S$ : ribonuclease, $S E N$ : senescence, $T R F$ : telomere repeat-binding factor, TRFL: TRF-like, $V T C$ : vitamin C defective, $V S P$ : vegetative storage protein.

${ }^{\mathrm{b}} \mathrm{C}$ : contig, CA: Citrus aurantium, CG: Citrus aurantifolia, CL: Citrus limonia, CR: Citrus reticulata, CS: Citrus sinensis, LT: Citrus latifolia, PT: Poncirus trifoliata, (number of reads).

${ }^{c}$ Identity percentage at the amino acid level.

${ }^{\mathrm{d}}$ Functional domain abbreviations: CUC: cup-shaped cotyledons, HAD: haloacid dehalogenase, LRR: leucine-rich repeat,, MAP: mitogen-activated protein, MYB: retroviral oncogene v-myb, NAC: Petunia NAM and Arabidopsis ATAF1, ATAF2, and CUC2 , NAM: no apical meristem, SCF: Skp1, Cdc53, an F-box complex, WWE: domain is named after three of its conserved residues (tryptophan, tryptophan and glutamate), WRKY: a 60 amino acid region that is defined by the conserved amino acid sequence WRKYGQK at its N-terminal end, together with a novel zinc-finger- like motif . 
Table S13 - Citrus ESTs homologous to functionally-characterized plant peptide hormones ${ }^{\mathrm{a}}$.

\begin{tabular}{|c|c|c|c|c|c|c|}
\hline \multicolumn{2}{|c|}{ Arabidopsis thaliana } & \multicolumn{3}{|l|}{ CitEST } & \multicolumn{2}{|l|}{ Protein motifs and } \\
\hline Name $^{b}$ & Gene & $\mathbf{E S T}^{\mathrm{c}}$ & $\%^{d}$ & e value & biological process & References \\
\hline \multirow[t]{4}{*}{$P S K 1$} & AT3G44735 & CS00-C3-703-089-C10-CT & 50.0 & $2 \mathrm{e}-11$ & conserved C-terminal & Matsubayash \\
\hline & & & & & sYIsYTQ, sulfated tyrosine & $i$ and \\
\hline & & & & & residues & Sakagami, \\
\hline & & & & & & 2006 \\
\hline \multirow[t]{6}{*}{$R A L F L$} & AT1G02900 & CS12-C1-001-016-E04-CT & 55.0 & $1 e-25$ & conserved C-Terminal domain, & Olsen et al., \\
\hline & & CA26-C1-002-074-E06-CT & 54.2 & $7 e-26$ & funcion unknown, secretory & 2002 \\
\hline & & CR05-C3-702-097-F10-CT & 54.2 & $7 e-26$ & system, less than 200 amino & \\
\hline & & CS00-C1-101-094-H04-UV & 54.2 & $9 e-26$ & acids in length & \\
\hline & & LT33-C1-003-017-H11-CT & 44.2 & $4 \mathrm{e}-24$ & & \\
\hline & & LT33-C1-003-022-B03-CT & 38.3 & $7 e-20$ & & \\
\hline \multirow[t]{2}{*}{ BRII } & AT4G39400 & CS00-C3-702-092-G08-CT & 80.8 & $1 \mathrm{e}-133$ & leucine-rich repeat receptor & Scheer et al., \\
\hline & & CS00-C1-650-008-E09-CT & 70.9 & $1 \mathrm{e}-115$ & kinase, plasma membrane & 2003 \\
\hline
\end{tabular}




\begin{tabular}{|c|c|c|c|c|c|c|}
\hline & & PT11-C1-900-089-E02-CT & 63.9 & $1 e-99$ & localization, BR signal & \\
\hline & & CR05-C3-702-027-G11-CT & 63.1 & $5 e-90$ & transduction, systemin recepto & \\
\hline & & CS00-C3-700-068-G06-CT & 57.1 & $3 e-88$ & & \\
\hline & & CR05-C1-103-056-H03-CT & 42.5 & $1 e-73$ & & \\
\hline$R O T 4 / D V L$ & AT2G36985 & CS00-C3-703-011-C08-CT & 25.6 & $3 e-12$ & RTF (ROTUNDIFOLIA) & Narita et al., \\
\hline & & LT33-C1-003-050-C02-CT & 22.2 & $2 \mathrm{e}-05$ & domain - 29-amino acid & 2004; Wen et \\
\hline & & & & & domain, whole protein 54 & al., 2004 \\
\hline
\end{tabular}

\footnotetext{
${ }^{a}$ Database searches of CitEST have been unable to recover homologs of the following peptide hormones: Solanum lycopersicum systemins (TomSys), S. lycopersicum small, secreted, cysteine rich proteins (SCR/SP11), Arabidopsis thaliana small, secreted, cysteine rich proteins-like (SCRL), A. thaliana inflorescence deficient in abscission (IDA, AT1G68765), A. thaliana inflorescence deficient in abscission-like IDL (AT3G25655), A. thaliana POLARIS (PLS) (AT4G39403), A. thaliana CLAVATA3 (CLV3, AT2G27250), A. thaliana CLV3-like (CLE, AT1G73165 and approximately other 100 similar sequences).

${ }^{\mathrm{b}}$ Gene name abbreviations: PSK1: phytosulfokine; RALFL: rapid alkalinization factor-like; BRI1: brassinosteroid insensitive1; ROT4/DVL: rotundifolia4/devil.

${ }^{\mathrm{C} C A}$ : Citrus aurantium, CR: Citrus reticulata, CS: Citrus sinensis, LT: Citrus latifolia, PT: Poncirus trifoliata.

${ }^{\mathrm{d}}$ Identity percentage at the amino acid level.
} 
Table S14 - Citrus ESTs with homology to genes involved in salicylic acid metabolism in plants.

\begin{tabular}{|c|c|c|c|c|c|c|}
\hline \multicolumn{2}{|c|}{ Arabidopsis thaliana } & \multicolumn{3}{|l|}{ CitEST $^{b}$} & \multicolumn{2}{|l|}{ Protein motifs and } \\
\hline Name $^{\mathrm{a}}$ & Gene & EST & $\%^{\mathrm{c}}$ & e value & biological process & References \\
\hline \multicolumn{7}{|c|}{ biosynthesis } \\
\hline ATCM2 & AT5G10870 & CS00-C1-102-092-A04-CT & 60.8 & $9 \mathrm{e}-71$ & $\begin{array}{c}\text { chorismate mutase activity, } \\
\text { aromatic amino acid family } \\
\text { biosynthesis, shikimate } \\
\text { pathway, located in cytosol }\end{array}$ & $\begin{array}{c}\text { Eberhard et } \\
\text { al., } 1996\end{array}$ \\
\hline ICS1 & AT1G74710 & C1-CR/CS (4) & 69.1 & $5 e-72$ & $\begin{array}{l}\text { isochorismate synthase activity, } \\
\text { salicylic acid biosynthesis, } \\
\text { systemic acquired resistance }\end{array}$ & $\begin{array}{l}\text { Wildermuth } \\
\text { et al., } 2001\end{array}$ \\
\hline$P A L 1$ & AT2G37040 & C3-CA (2) & 88.4 & e-148 & phenylpropanoid biosynthesis, & Rohde et al., \\
\hline & & $\mathrm{C} 1-\mathrm{CG}(3)$ & 77.9 & $4 e-75$ & phenylalanine ammonia-lyase & 2004 \\
\hline & & C1-CR (6) & 74.9 & $1 e-78$ & activity & \\
\hline & & C3-CR (4) & 71.5 & e-100 & & \\
\hline & & C1-CS (42) & 82.5 & 0 & & \\
\hline
\end{tabular}




\begin{tabular}{|c|c|c|c|c|c|c|}
\hline & & C2-CS (5) & 82.8 & e-130 & & \\
\hline & & CR05-C3-700-042-D03-CT & 66.7 & $3 e-42$ & & \\
\hline & & CS00-C1-100-081-H07-CT & 74.1 & e-113 & & \\
\hline & & CL06-C4-500-043-E07-CT & 95.9 & e-130 & & \\
\hline \multirow[t]{7}{*}{$P A L 2$} & AT3G53260 & C5-LT/CS (2) & 78.5 & $6 e-46$ & phenylpropanoid biosynthesis, & Rohde et al., \\
\hline & & C4-CA (2) & 77.7 & $3 e-61$ & phenylalanine ammonia-lyase & 2004 \\
\hline & & C2-CR (2) & 79.3 & $3 e-86$ & activity & \\
\hline & & C1-LT (5) & 79.2 & e-162 & & \\
\hline & & C2-LT (2) & 77.8 & $3 e-78$ & & \\
\hline & & CS00-C3-702-093-C03-CT & 76.6 & $4 \mathrm{e}-86$ & & \\
\hline & & CS13-C1-001-005-A02-CT & 48.5 & $5 e-42$ & & \\
\hline prephenate & AT1G11790 & C1-CS (3) & 58.2 & $2 \mathrm{e}-55$ & amino acid binding, prephenate & \\
\hline dehydratase & & C2-CA/CS (2) & 72.3 & $\mathrm{e}-114$ & dehydratase activity, & \\
\hline family & & C3-CS/CR (4) & 65.4 & $2 \mathrm{e}-61$ & metabolism, L-phenylalanine & \\
\hline protein & & & & & biosynthesis, located in & \\
\hline
\end{tabular}




\begin{tabular}{|c|c|c|c|c|c|c|}
\hline putative & AT3G10340 & C3-CA/PT/CS (4) & 85.3 & 0 & biosynthesis, L-phenylalanine & Appert et al., \\
\hline phenylalani & & C4-PT (2) & 92.3 & e-108 & catabolism, located in & 1994 \\
\hline ne & & CL06-C4-500-043-E07-CT & 95.9 & e-130 & cytoplasm, has ammonia-lyase & \\
\hline ammonia- & & CR05-C3-700-098-F08-CT & 61.4 & $1 e-34$ & activity & \\
\hline lyase & & C1-CA (2) & 87.4 & 0 & & \\
\hline \multicolumn{7}{|c|}{ catabolism } \\
\hline \multirow[t]{6}{*}{ AmSAMT } & AAN40745 & $\mathrm{C} 1-\mathrm{CR} / \mathrm{CS}(2)$ & 34.9 & $1 \mathrm{e}-40$ & S-adenosyl-L-methionine- & Ross et al., \\
\hline & & C3-CS (2) & 45.6 & $1 \mathrm{e}-29$ & dependent carboxyl & 1999; Negre \\
\hline & & C6-CR/CS (3) & 38.9 & $5 e-29$ & methyltransferase, formation of & et al., 2003 \\
\hline & & CS00-C5-003-030-G01-CT & 41.4 & $5 e-27$ & methylsalicylate / & \\
\hline & & & & & methylbenzoate respectively & \\
\hline & & & & & from salicylic and benzoic acid & \\
\hline \multirow[t]{3}{*}{ NtSAGTase } & AAF61647 & C1-CS (5) & 51.4 & $1 e-82$ & transferase and UDP-glucosyl & Lee and \\
\hline & & C2-CR/CS (2) & 57.1 & e-131 & transferase activity, transferring & Raskin, \\
\hline & & CS13-C1-001-006-B05-CT & 42.3 & $4 e-62$ & hexosyl groups & 1999; \\
\hline
\end{tabular}


Blanco et al.

${ }^{\mathrm{a} G e n e}$ name abbreviations: CM: chorismate mutase, ICS: isochorismate synthase, PAL: phenylalanine ammonia-lyase, AmSAMT: Antirrhinum majus S-adenosyl-Lmethionine:salicylic acid methyltransferase; NtSAGTase: Nicotiana tabacum salicylic acid glucosyltransferase.

${ }^{\mathrm{b}} \mathrm{C}$ : contig, CA: Citrus aurantium, CG: Citrus aurantifolia, CL: Citrus limonia, CR: Citrus reticulata, CS: Citrus sinensis, LT: Citrus latifolia, PT: Poncirus trifoliata, (number of reads).

${ }^{\mathrm{c}}$ Identity percentage at the amino acid level. 
Table S15 - Citrus ESTs with homology to genes involved in salicylic acid signal transduction in plants ${ }^{\mathrm{a}}$.

\begin{tabular}{|c|c|c|c|c|c|c|}
\hline \multicolumn{2}{|c|}{ Arabidopsis thaliana } & \multicolumn{3}{|l|}{ CitEST } & \multicolumn{2}{|l|}{ Protein motifs and } \\
\hline Name $^{b}$ & Gene & $\mathbf{E S T}^{\mathrm{c}}$ & $\%^{d}$ & e value & biological process & References \\
\hline AtWhyl & AT1G14410 & C1-CR/CS/LT/PT (10) & 69.7 & $1 \mathrm{e}-94$ & $\begin{array}{l}\text { functions in DNA binding, } \\
\text { located in chloroplast and in } \\
\text { plastid chromosome }\end{array}$ & $\begin{array}{c}\text { Desveaux et } \\
\text { al., } 2004\end{array}$ \\
\hline$C D R 1$ & AT5G33340 & $\mathrm{C} 1-\mathrm{CR} / \mathrm{CS} / \mathrm{PT}(4)$ & 52.4 & e-118 & defense response to pathogenic & Xia et al., \\
\hline & & C4-CR/CS (19) & 55.6 & e-119 & bacteria; proteolysis; located in & 2004 \\
\hline & & C10-CS/PT (7) & 55.8 & e-122 & apoplast; aspartic-type & \\
\hline & & C11-CG (2) & 43.6 & $6 e-47$ & endopeptidase activity; pepsin & \\
\hline & & CR05-C1-100-021-A01-CT & 49.5 & $1 e-51$ & A activity & \\
\hline EDS1 & AT3G48090 & C1-CR/CS (8) & 43.6 & e-129 & lipase activity, signal transducer & Wiermer $e t$ \\
\hline & & & & & activity, triacylglycerol & al., 2005 \\
\hline EDS5 & AT4G39030 & C2-CS/PT (3) & 67.3 & $7 e-84$ & defense response, salicylic acid & Nawrath et \\
\hline & & C3-CR (3) & 69.3 & $1 \mathrm{e}-71$ & biosynthesis, multidrug efflux & al., 2002 \\
\hline & & C4-CS (7) & 66.8 & e-146 & pump activity & \\
\hline
\end{tabular}




\begin{tabular}{|c|c|c|c|c|c|c|}
\hline & & CA26-C1-002-088-C11-CT & 51.1 & $2 \mathrm{e}-45$ & & \\
\hline & & CG32-C1-003-085-F02-CT & 54.7 & $1 e-43$ & & \\
\hline & & LT33-C1-003-064-B03-CT & 74.3 & $1 e-96$ & & \\
\hline ICS1 & AT1G74710 & C1-CR/CS (4) & 69.1 & $5 e-72$ & $\begin{array}{l}\text { isochorismate synthase activity, } \\
\text { salicylic acid biosynthesis, } \\
\text { systemic acquired resistance }\end{array}$ & $\begin{array}{l}\text { Wildermuth } \\
\text { et al., } 2001\end{array}$ \\
\hline$N D R 1$ & AT3G20600 & $\begin{array}{c}\text { C1-CS (3) } \\
\text { CR05-C3-701-043-E04-CT }\end{array}$ & $\begin{array}{l}50.9 \\
43.2\end{array}$ & $\begin{array}{l}8 e-52 \\
4 e-21\end{array}$ & $\begin{array}{l}\text { defense response to pathogenic } \\
\text { bacteria and fungi, } \\
\text { incompatible interaction, } \\
\text { located in membrane }\end{array}$ & $\begin{array}{l}\text { Coppinger et } \\
\text { al., } 2004\end{array}$ \\
\hline$N P R 1$ & AT1G64280 & $\begin{array}{l}\text { C9-CG/CS/CA (5) } \\
\text { C10-CR (2) }\end{array}$ & $\begin{array}{l}58.9 \\
54.1\end{array}$ & $\begin{array}{l}2 \mathrm{e}-82 \\
4 \mathrm{e}-91\end{array}$ & $\begin{array}{l}\text { cell death, response to heat, } \\
\text { response to bacteria and insect, } \\
\text { systemic acquired resistance, } \\
\text { salicylic acid mediated } \\
\text { signaling pathway }\end{array}$ & $\begin{array}{c}\text { Cao et al., } \\
1997\end{array}$ \\
\hline$N P R 4$ & AT4G19660 & C11-CS/CR/LT (5) & 46.8 & $5 e-95$ & response to pathogenic bacteria, & Liu et al., \\
\hline
\end{tabular}




\begin{tabular}{|c|c|c|c|c|}
\hline $\mathrm{C} 12-\mathrm{CS} / \mathrm{CA} / \mathrm{CR}$ (4) & 46.2 & $1 e-95$ & response to pathogenic fungi; & 2005 \\
\hline C13-CR (3) & 46.6 & $7 e-48$ & located in nucleus; functions in & \\
\hline CR05-C1-102-062-E01-CT & 43.6 & $9 \mathrm{e}-42$ & protein binding; required for & \\
\hline CR05-C3-702-071-B07-CT & 49.2 & $2 \mathrm{e}-60$ & basal defense against & \\
\hline CS00-C3-704-097-E10-CT & 52.5 & $3 e-53$ & pathogens, and may be & \\
\hline PT11-C2-300-016-C11-CT & 42.5 & $5 e-39$ & $\begin{array}{l}\text { implicated in the cross-talk } \\
\text { between the SA- and JA- } \\
\text { dependent signaling pathways }\end{array}$ & \\
\hline C1-CA (3) & 75.1 & e-163 & catalase activity; serves to & Chen et al., \\
\hline C2-CA (3) & 92.4 & 0.0 & protect cells from the toxic & 1993 \\
\hline $\mathrm{C} 1-\mathrm{CG}(8)$ & 89.5 & 0.0 & effects of hydrogen peroxide; & \\
\hline C1-CR (33) & 78.7 & e-179 & inhibited by salicylic acid & \\
\hline C2-CR (57) & 89.2 & 0.0 & & \\
\hline C1-CS (28) & 78.9 & 0.0 & & \\
\hline $\mathrm{C} 2-\mathrm{CS}(52)$ & 89.4 & 0.0 & & \\
\hline C1-LT (4) & 73.4 & e-173 & & \\
\hline
\end{tabular}




\begin{tabular}{|c|c|c|c|c|c|c|}
\hline & & C1-PT (31) & 89.4 & 0.0 & & \\
\hline & & C2-PT (2) & 82.3 & $4 e-84$ & & \\
\hline \multirow[t]{5}{*}{$N t S A B P 2$} & AAR87711 & C1-CG/CR/CS (7) & 56.0 & $3 e-81$ & lipase, alpha/beta hydrolase & Kumar and \\
\hline & & C2-CA/CG/CR/CS (2) & 42.0 & $4 e-59$ & fold, may generate a lipid- & Klessig, \\
\hline & & C4-CA/CG/CR/CS (7) & 55.0 & $6 e-82$ & derived signal, responsible for & 2003 \\
\hline & & C5-CR/CS/PT (6) & 57.0 & $1 \mathrm{e}-82$ & the conversion of MeSA into & Forouhar $e t$ \\
\hline & & & & & SA & al., 2005 \\
\hline \multirow[t]{8}{*}{ PAD4 } & AT3G52430 & C16-CS (2) & 43.6 & $2 e-59$ & response to insect, systemic & Jirage et al., \\
\hline & & & & & acquired resistance, salicylic & 1999 \\
\hline & & & & & acid mediated signaling & \\
\hline & & & & & pathway, defense response to & \\
\hline & & & & & pathogenic bacteria, & \\
\hline & & & & & incompatible interaction, leaf & \\
\hline & & & & & senescence; protein binding; & \\
\hline & & & & & has lipase activity & \\
\hline SAG101 & AT5G14930 & C17-CS (2) & 34.8 & $2 \mathrm{e}-29$ & carboxylic ester hydrolase & Feys et al., \\
\hline
\end{tabular}


activity

C2-CG/CR/CS (10)

C3-CR/CS/PT (5)

CR05-C1-100-077-F10-CT.

C1-CR/CS/PT (3)

$58.0 \quad \mathrm{e}-114$

$T G A$ family

Johnson et

$V A D 1$

AT1G02120

76.0

e-138

$75.0 \quad \mathrm{e}-140$

$59.0 \quad 6 e-69$

region leucin zipper, DNA

al., 2003

binding

family
(TGA3)

AT1G22070

20
C1-CR/CS (2)

CR05-C1-103-019-B12-CT

C1-CR/CS (2)
CR05-C1-103-019-B12-CT

49

0

$1 \mathrm{e}-18$

$\begin{array}{cc} & \text { al., } 2003 \\ \text { putative membrane-associated } & \text { Lorrain } \text { et } \\ \text { protein containing a GRAM } & a l ., 2004 \\ \text { domain, a lipid or protein } & \\ \text { binding signaling domain } & \end{array}$

\footnotetext{
${ }^{a}$ Database searches of CitEST have been unable to recover homologs of the ACD6, a novel ankyrin repeat and transmembrane-domain containing protein.

${ }^{\mathrm{b}}$ Gene name abbreviations: AtWhy1: A. thaliana Whirly 1, CDR: constitutive disease resistance, EDS: enhanced disease susceptibility, ICS: isochorismate synthase, NDR: nonrace specific disease resistance, NPR: nonexpresser of PR genes, NtCAT: Nicotiana tabacum catalase, NtSABP2: Nicotiana tabacum salicylic acid-binding protein, PAD: phytoalexin-deficient, $S A G$ : senescence-associated gene, TGA: transcription factors that interacts with sequence elements containing 'TGACG' motifs, VAD: vascular associated death.

${ }^{\mathrm{c} C}$ : contig, CA: Citrus aurantium, CG: Citrus aurantifolia, CL: Citrus limonia, CR: Citrus reticulata, CS: Citrus sinensis, LT: Citrus latifolia, PT: Poncirus trifoliata, (number of reads).

${ }^{\mathrm{d}}$ Identity percentage at the amino acid level.
} 